\title{
Validation of the assessment of food intake in humans
}

Citation for published version (APA):

Goris, A. H. C. (2001). Validation of the assessment of food intake in humans. [Doctoral Thesis, Maastricht University]. Universiteit Maastricht. https://doi.org/10.26481/dis.20010406ag

Document status and date:

Published: 01/01/2001

DOI:

10.26481/dis.20010406ag

Document Version:

Publisher's PDF, also known as Version of record

\section{Please check the document version of this publication:}

- A submitted manuscript is the version of the article upon submission and before peer-review. There can be important differences between the submitted version and the official published version of record.

People interested in the research are advised to contact the author for the final version of the publication, or visit the DOI to the publisher's website.

- The final author version and the galley proof are versions of the publication after peer review.

- The final published version features the final layout of the paper including the volume, issue and page numbers.

Link to publication

\footnotetext{
General rights rights.

- You may freely distribute the URL identifying the publication in the public portal. please follow below link for the End User Agreement:

www.umlib.nl/taverne-license

Take down policy

If you believe that this document breaches copyright please contact us at:

repository@maastrichtuniversity.nl

providing details and we will investigate your claim.
}

Copyright and moral rights for the publications made accessible in the public portal are retained by the authors and/or other copyright owners and it is a condition of accessing publications that users recognise and abide by the legal requirements associated with these

- Users may download and print one copy of any publication from the public portal for the purpose of private study or research.

- You may not further distribute the material or use it for any profit-making activity or commercial gain

If the publication is distributed under the terms of Article $25 \mathrm{fa}$ of the Dutch Copyright Act, indicated by the "Taverne" license above, 


\section{Validation of the assessment of food intake in humans}




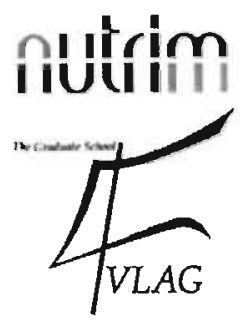

(C) Annelies Goris, Maastricht 2001

[SBN: 90-9014581-8

Productie: Datawyse, Maastricht

Tekening omslag: Pita Vreugdenhil

Printing of this thesis was financially supported by the Nederlandse Associatie voor de Studie naar Obesitas, Nutricia Nederland B.V. and Philips Research. 


\section{Validation of the assessment of food intake in humans}

\section{PROEFSCHRIFT}

ter verkrijging van de graad van doctor aan de Universiteit van Maastricht, op gezag van de Rector Magnificus, Prof. Dr. A.C. Nieuwenhuijzen Kruseman, volgens het besluit van het College van Decanen, in het openbaar te verdedigen op vrijdag 6 april 2001 om 14.00 uur

door

Annelies Heleen Carolien Goris

geboren te Brummen op 25 januari 1972. 
Promotor:

Prof. Dr. K.R. Westerterp

Beoordelingscommissie:

Prof. dr. ir. P.A. van den Brandt (voorzitter)

Prof. dr. A.V. Astrup (University Denmark)

Prof. dr. ir. W.H.M. Saris

Prof. dr. ir. J.C. Seidell (Vrije Universiteit Amsterdam)

Prof. dr. E.F.M. Wouters 
Aan mijn ouders, voor Ronald 



\section{Contents}

Chapter 1 Introduction.

Chapter 2 Underreporting of habitual food intake is explained by 23 undereating in highly motivated lean women.

Chapter 3 Improved reporting of habitual food intake after confrontation 35 with earlier results on food reporting.

Chapter 4 Undereating and underrecording of habitual food intake in obese men: selective underreporting of fat intake.

Chapter 5 Postabsorptive respiratory quotient and food quotient - an 57 analysis in lean and obese men and women.

Chapter 6 Use of a triaxial accelerometer to validate reported food 67 intakes.

Chapter 7 Repeated measurement of habitual food intake increases 77 underreporting and induces selective underreporting.

Chapter 8 Energy balance in depleted ambulatory patients with chronic obstructive pulmonary disease; the effect of physical activity and oral nutritional supplementation.

Chapter 9 General discussion.

Summary

Samenvatting

Dankwoord

Curriculum Vitae

Publications 

Chapter 1

Introduction 
Nutrition is an easy topic of discussion for most people, but when asked to record habitual food intake one is often not able to do this accurately. Food intake in humans in their own environment is one of the hardest parameters to measure. Still, the measured food intake is often related to health or disease parameters in epidemiological studies and it is used as a measure of actual food intake in intervention studies. Obviously this has consequences.

For example, obese subjects often believe that their food intake is equal to or even lower than the food intake of lean subjects and that their obesity is due to metabolic defects causing low energy expenditure. This is confirmed by the self reported food intakes of obese and lean subjects. However, in a study with obese and lean women the obese women had a higher energy expenditure than the lean women while the self reported energy intake of the obese women was significantly lower than their energy expenditure, in contrast with the lean women. The obese women underreported their food intake with $33 \%$ (41). This first observation in 1986 has been confirmed by many more studies and one may conclude that mostly self-reported food intake is not valid. Errors in the assessment of food intake may be both quantitative and qualitative.

The main question of this thesis is how to validate assessment of habitual food intake in humans. In this introduction, first an overview of frequently used dietary assessment methods is given, followed by a description of available validation methods. Thereafter, the problem of errors, both quantitative and qualitative, in reported food intake are discussed. Finally the outline of the thesis is presented.

\section{Dietary assessment}

Food intake can be measured on national, household or individual level. Standard methods of determining food intake are:

I Indirect from food balance sheets (import/export of food, changes in food stocks etc.), information on group consumption $(5,12,42)$

2 Estimation by recall of food consumed over the last day, week, or longer

3 Measurement and recording of food intake as it is eaten in daily life $(5,12)$.

Methods 2 and 3 measure the food intake of individuals to get information on mean food consumption of a group of individuals, inter-individual variation of food consumption in groups, or intra-individual variation over time. Examples are food frequency questionnaires. 24-hour dietary recall, dietary history, weighed or estimated dietary record and the double portion technique with nutrient and/or energy analysis. The mcasured tood intake can be converted into intake of energy, macronutrients and micronutrients using food composition tables (or nutrient and/or energy analysis of the food sample in case of the double portion technique).

The choice of a dietary assessment method depends on the type of information needed. An overview of frequently used dietary assessment methods is presented in table 1.1.

Both the food frequency questionnaire and the 24-hour recall are not suitable to measure habitual food intake of individual subjects. The food frequency questionnaire measures a limited number of dietary components instead of the total diet. The 24-hour recall is only suitable for the determination of the food consumption at a group level. 
Table 1.1: Overview of dietary assessment methods (5, 12).

\begin{tabular}{|c|c|c|c|}
\hline Method & Description & $\begin{array}{l}\text { Observation } \\
\text { period }\end{array}$ & Type of information \\
\hline $\begin{array}{l}\text { Food frequency } \\
\text { questionnaire }\end{array}$ & Questionnaire & $\begin{array}{l}\text { Week, month, } \\
\text { year }\end{array}$ & $\begin{array}{l}\text { Qualitative (sometimes } \\
\text { also quantitative) }\end{array}$ \\
\hline 24 hour dietary recall & Interview & Past 24 hour & $\begin{array}{l}\text { Qualitative and } \\
\text { quantitative (estimated) }\end{array}$ \\
\hline Dietary history & $\begin{array}{l}\text { Interview, with eventually } \\
3 \text { day dietary record as a } \\
\text { cross-check }\end{array}$ & $\begin{array}{l}\text { Week, month, } \\
\text { year }\end{array}$ & $\begin{array}{l}\text { Qualitative and } \\
\text { quantitative (estimated) }\end{array}$ \\
\hline Dietary record & $\begin{array}{l}\text { Food intake is recorded as } \\
\text { eaten in a food diary }\end{array}$ & $\begin{array}{l}1,3,7 \text { or more } \\
\text { days }\end{array}$ & $\begin{array}{l}\text { Qualitative and } \\
\text { quantitative (estimated or } \\
\text { weighed) }\end{array}$ \\
\hline $\begin{array}{l}\text { Double portion } \\
\text { technique }\end{array}$ & $\begin{array}{l}\text { Equivalent amount of food } \\
\text { items consumed have to be } \\
\text { collected for later analysis }\end{array}$ & $\begin{array}{l}1,3,7 \text { or more } \\
\text { days }\end{array}$ & $\begin{array}{l}\text { Qualitative and } \\
\text { quantitative } \\
\text { (weighed) }\end{array}$ \\
\hline
\end{tabular}

The length of the observation period depends on the level of accuracy required and the level of day-to-day variability in the intake of the foods or nutrients studied. Edholm et al. measured energy expenditure and energy intake in individual men for 2 weeks and showed that mean energy expenditure was close to intake on weekly and fortnightly basis. Individual intakes were highly variable from day to day and were often not in daily or weekly balance with energy expenditure (15). This study of Edholm et al. was conducted in a military situation, but comparable results were also found in a study of Sjödin et al. with cross-country skiers (50). Basiotis et al. calculated that the minimum time interval to measure habitual energy intake was 31 days for the individual level and 3 days for a group level. For accurate estimation of separate nutrients such as fat the number of days required is 6 for a measurement at group level and about 65 for a measurement at an individual level (4).

The assessment of food intake is subject to different types of error, depending on the method used. Errors in food tables and coding errors are for all methods the same, and are relatively small. Larger errors in the assessment of food intake might be due to the phenomenon that subjects tell the interviewer their perception of what they eat instead of their real consumption. Subjects can give wrong quantitative and/or qualitative information to the researcher. The use of a weighed dietary record can solve the problem of inaccurate weights of foods. However, the disadvantage of this is that weighing all the food might interfere more with the habitual consumption than other methods do. Memory failure might cause errors in the food frequency questionnaire, 24-hour recall or dietary history method. Overall, the precision of the assessment of food intake will probably be not better than $10 \%$ (19). Small errors may have large consequences, but anyhow, errors higher than $10 \%$ lead at least to erroneous conclusions in quantitative nutrition research. Therefore, it is obvious that the measurement of food intake requires an external validation.

\section{Validation methods}

Validation methods must be independent of the dietary assessment method used (25). Thus, e.g. validation of a food frequency questionnaire with a dietary record is useless. 
Physiological measures should be used as a reference. Table 1.2 gives an overview of existing and new methods (still to be validated) for the validation of energy and macronutrient intake, which are further described in the text below. The use of biomarkers for the validation of the intake of micronutrients is beyond the scope of this thesis and will not be discussed here.

Table 1.2: Overview of physiological references and thcir assessment methods, for energy and macronutrient intake.

\begin{tabular}{lll}
\hline Physiological measure & Method & Reference for \\
\hline Energy expenditure & $\begin{array}{l}\text { Doubly labelled water } \\
\text { Basal metabolic rate and physical } \\
\text { activity* } \\
\text { Basal metabolic rate } \\
\text { Repeated body mass measurements } \\
\text { Deuterium elimination* }\end{array}$ & $\begin{array}{l}\text { Energy (food) intake } \\
\text { Energy balance }\end{array}$ \\
$\begin{array}{ll}\text { Water loss } \\
\text { Nitrogen loss }\end{array}$ & $\begin{array}{l}\text { Change in diet } \\
\text { Water intake, food } \\
\text { recording }\end{array}$ \\
\hline
\end{tabular}

* Methods still to be validated.

Reported food (energy) intake can be validated against measured energy expenditure, a measure for total energy expenditure like basal metabolic rate and physical activity, or just basal metabolic rate. Subjects should be in energy balance as reflected by a stable body weight or corrections for energy imbalance should be made.

\section{Foud infake; tolal energy expenditure}

Total energy expenditure of subjects in their habitual environment can be measured with the doubly labelled water $\left({ }^{2} \mathrm{H}_{2}{ }^{18} \mathrm{O}\right)$ method. Subjects are given a weighed dose of doubly labelled water, where ${ }^{2} \mathrm{H}$ is eliminated as water while ${ }^{18} \mathrm{O}$ is eliminated as both water and carbon-dioxide. The difference between the two elimination rates (measured from collected body fluids samples, like urine) is a measure for carbon-dioxide production. The $\mathrm{CO}_{2}$ production is converted to energy expenditure with the use of the food quotient (ratio of the calculated carbon-dioxide production and oxygen consumption when the consumed food is fully oxidised) of the diet $(48,59)$. The coefficient of variation for energy expenditure measured with doubly labelled water in free living subjects is about $6 \%(48)$. The doubly labelled water method is the most accurate method for the validation of reported energy intake by subjects in free living situations. However, its expenses and availability of oxygen-18 water make it relatively less practical for studies with a large number of subjects.

\section{Food intake; basal metabolic rate and physical activity}

A combination of basal metabolic rate (BMR) and physical activity is another method to validate reported energy intake accurately. Total energy expenditure (EE) is the sum of BMR, physical activity and diet induced energy expenditure (a relatively constant fraction of about $10 \%$ of energy intake, and, when subjects are in energy balance, also about $10 \%$ of total EE). BMR is the main component of total EE and can be measured with a ventilated hood or calculated with formulas using age. sex, height and weight or formulas using body composition. Physical activity can range from zero in subjects lying in bed all day to about $60 \%$ of total $\mathrm{EE}$ in highly active subjects. Physical 
activity is the most variable part of total $\mathrm{EE}$ and can be measured with activity diaries, questionnaires, heart rate monitoring or accelerometers. A tri-axial accelerometer appeared to give the most reliable measure of individual physical activity in free living situations $(37,55)$. An example of a tri-axial accelerometer for movement registration is the Tracmor. The Tracmor has been validated against doubly labelled water $(9,57)$. The combination of BMR and physical activity assessed with a triaxial accelerometer might be a promising validation method for total energy intake.

\section{Food intake; basal metabolic rate}

The ratio energy expenditure / basal metabolic rate (EE/BMR) is known as the physical activity level and in case of no misreporting EE/BMR is equal to energy intake /BMR (EL/BMR). The ratio El/BMR is therefore often used in studies to identify underreporting, notably identification of overreporting with this ratio is rarely done. Goldberg et al. (1991) made cut-off limits to recognise underreporting at group level. They adopted a cut-off limit for EI/BMR of 1.35 as indicator for underreporting. A physical activity level below 1.35 is not very likely unless someone has a very inactive lifestyle (20). However the proposed cut-off limits for the ratio El/BMR have failed to identify underreporters of food intake at the individual level $(7,8)$.

\section{Change in diet; energy balance}

Energy balance over the recording period is an indication for a change in diet or expenditure while food recording. A positive or negative energy balance, i.e. a higher or lower energy intake compared to energy expenditure, can be estimated with measurements of body mass at the start and end of the recording period. In a study by Stockley (52) subjects weighed and recorded their food intake for 16 days. The body mass of the subjects was measured at the start and end of the recording period and showed a significant decrease of $0.8 \mathrm{~kg}$. The subjects ate less than usual during the 16 days of food recording (52).

Body mass might fluctuate from one week to another. Thus body mass changes over a recording period should be compared with body mass changes over a non-recording period to determine a change in diet in the recording period. The assessment of changes in body composition over the recording period give information about the energy content of the body mass change, but methods for the measurement of the body composition are not enough accurate yet as for this purpose (38). The energy content of the body mass has to be estimated (58)

Next to changing their diet, subjects might also misrecord their food intake and therefore an independent marker for misrecording is required.

\section{Water intake, food recording; water loss}

Deuterium used to measure water loss can serve as a biomarker for water intake in healthy subjects. Normally, one is in water balance and a water intake, corrected for metabolic water, below or above water loss indicates misrecording of water intake. We hypothesised that the recording of water intake is indicative for the food intake recording as well. The deuterium elimination method is used before in studies which measured the milk intake of infants with deuterium $(11,17,34)$. This method appeared to be very sensitive, since it showed a recovery rate of $98 \pm 3 \%$ of the milk intake (17). 
The use of water loss as a marker for total food intake recording by adults might be a promising method for the validation of food recording.

\section{Nitrogen (protein) intake; nitrogen loss}

The reported protein intake can be validated with measuring nitrogen loss. Healthy adults are in nitrogen balance and nitrogen loss in urine was found to be $81 \pm 5 \%$ of total nitrogen loss per 24 hour. The remaining $19 \%$ of total nitrogen loss is mainly found in the faeces (6). The completeness of 24-hour urine collections can be checked with para-amino benzoic acid (PABA) which subjects have to take at each meal. PABA recoveries of more than $90 \%$ indicates complete 24 -hour urine collection. Eight 24-hour urine collections appeared to be sufficient to estimate dietary nitrogen intake (not necessarily measured at the same time as the urine collections) up to within $81 \pm 5 \%$ (SD) (6). In the European Prospective Investigation into Cancer and Nutrition a food frequency questionnaire in combination with twelve 24-hour recalls was compared with four 24 hour urine samples in 134 subjects. The reported protein intake correlated with estimated protein excretion $(r=0.46)$; it was on average $23 \%$ lower than the estimated protein excretion assessed from urinary nitrogen measurements indicating a $23 \%$ underreporting of protein intake (29).

Carbohydrate / fat intake: carbohydrate, fat oxidation

There are no validated biomarkers for carbohydrate and fat intake yet. A possible indicator for the carbohydrate and fat intake might be postabsorptive respiratory quotient (RQ) as it is thought to be a function of the macronutrient ratio of the food intake, i.e. the food quotient (FQ) (36). Normally, subjects who are in energy balance are also in substrate balance and the RQ measured over a 24 hour period is equal to $\mathrm{FQ}$ (18). The RQ is 0.7 for fat oxidation, 1.0 for carbohydrate oxidation and the RQ for a mixed diet will be between 0.7 and 1.0. Whether a postabsorptive RQ can distinguish e.g. high fat consumers from low fat consumers is not clear yet.

\section{Misreporting of food intake}

The use of validation methods for reported food intake make the misreporting of habitual food intake visible. Quantitative misreporting of food intake can indicate both under- and overreporting. Since most studies have found a self-reported energy intake below energy expenditure as measured with doubly labelled water, misreporting of food intake mostly means underreporting of food intake. Figure 1.1 shows studies which validated reported energy intake with energy expenditure as assessed with doubly labelled water (total number of subjects $=473$ ). The issue of under- and overreporting, as well as selective misreporting, is described shortly. 


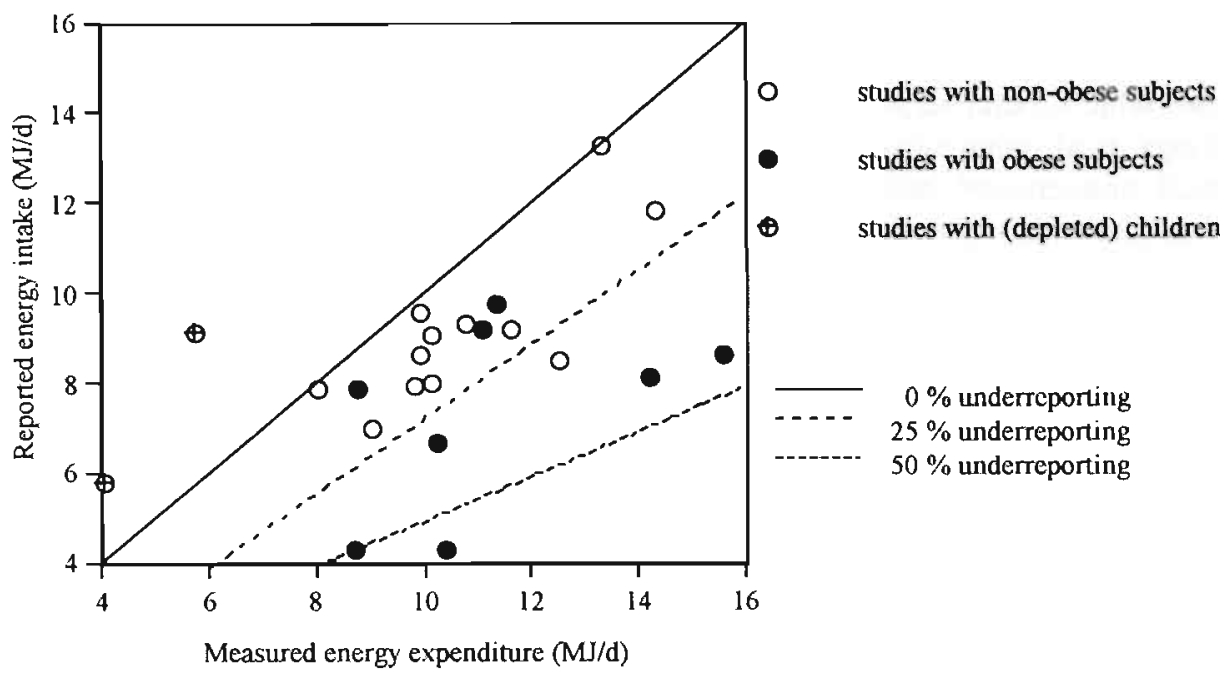

Figure 1.1 Reported energy intake (dietary record) plotted against energy expenditure as measured with doubly labelled water of studies with obese subjects $(n=161)$, lean subjects $(n=235)$, (depleted) children $(\mathrm{n}=77)(2,8,10,16,21,24,26,30,35,39,40,41,43,45,49,51,53,54)$.

\section{Underreporting of food intake}

Studies which used a dietary record to measure food intake and doubly labelled water as biomarker reported percentages underreporting ranging from 20 to $50 \%$ in obese subjects $(2,10,28,30,41,46,54,56)$ and from 0 to $30 \%$ in lean subjects $(1,2,14,16$, $33,32,35,39,46,47,49,50,56)$.

The percentage underreporting appeared to be positively related to the body mass index of subjects $(53,56)$. However, the list of studies with lean subjects shows that underreporting not only occurs in obese subjects. Reported energy intake and measured energy expenditure in children below 9 years showed a good agreement ( 14 , 32). Studies with children above this age (10-18 years) found an underreporting of food intake ranging from 11 to $33 \%(1,13,32)$. Livingstone et al. measured energy intake and energy expenditure in children from 3 to 18 years old. In the younger children the reporting of food intake was shared with parents and other adults who surrounded the child, and there was a good agreement between energy intake and energy expenditure. In the older age groups the children had to report their food intake themselves. Many children appeared to forget to record everything, to find it too much a burden or, in case of adolescent girls, preoccupation with body weight appeared to result in errors in the reporting of food intake ranging from 11 to $33 \%$ (32).

The percentages underreporting measured in studies with elderly subjects were not different from those in studies with younger subjects (below $55 \mathrm{yr}$.) $(8,45,53)$. The degree of obesity seems to influence the reporting of food intake more than the age of subjects. Lissner et al. stated that obese and lean subjects both underreport their food intake. The magnitude of underreporting depended primarily on the energy requirements of the individual subjects and was not related to their \% body fat (31). Moreover, underreporting of food intake was not a function of type of dietary assessment method used $(3,45)$. 


\section{Overreporting of food intake}

Next to the many studies showing an underreporting of food intake there are also some studies which found an overreporting of food intake. A typical example is a study by Stallings et al. who measured the energy expenditure by the doubly labelled water method and energy intake by a 3 day weighed dietary record in children and adolescents with severe disabilities. The recorded energy intake was about $50 \%$ higher than the measured energy expenditure. The intake of the children was recorded by the caregivers who also fed the children (51), again reflecting their perception instead of the actual consumption. Studies of Kayser et al. and Johnson et al., with depleted nursing home patients, also reported an overestimation of the habitual food intake (23, 27). The increased awareness by the nurses during the food recording period resulted in a higher figure than real intake in the depleted nursing-home patients $(23,27)$. Additional information on overrecording of food intake and/or of a change in diet during food recording would be useful for the determination of the nutrition status of the (depleted) patients.

\section{Selective misreporting of food intake}

A selective misreporting of food intake can indicate a misreporting of type of food (e.g. sweets), type of eating moment (snacks vs. meals), type of meal (breakfast, lunch or dinner) or macronutrient (fat, carbohydrate, protein or alcohol) or combinations of these. In a study by Rothenberg et al. with elderly subjects ( 440 females, 369 males) the food intake, measured with a dietary history method, was compared with categories of the ratio EI/BMR. The EI/BMR categories for females were $<1.20,1.20-1.82,>1.82$ and for males $<1.20,1.20-2.10,>2.10$. The reported food choice differed with EI/BMR category, especially regarding sugar and sweet intake. Subjects with a lower EI/BMR reported a lower sugar and sweet intake, a lower spread and cooking fat intake and higher intakes of fish, meat, vegetables and fruits (44). However, the ratio EI/BMR failed to identify misreporters of food intake at the individual level and is probably not the most suitable method for the assessment of selective underreporting. Heitmann et al. used nitrogen loss as an independent biomarker and compared it with reported intakes in 323 men and women (lean and obese). The energy expenditure was estimated from physical activity as measured with a questionnaire and BMR estimated with equations. The underreporting of protein was disproportional to the underreporting of energy suggesting a selective underreporting of fat and carbohydrate rich foods. The degree of obesity also influenced the dietary reporting both quantitatively and qualitatively (22).

Data on an indication of selective misreporting by subjects in their own environment are not yet available. Studies on qualitative misreporting are necessary to get information on which foods, meals or macronutrients are vulnerable to misreporting.

\section{Change in reporting behowiour with repeated dietary assessment}

For the study of the effect of (nutrition) intervention on food intake, repeated measurements of food intake are necessary. The reporting accuracy of the food intake might change between successive measurements which would indicate that subjects cannot act as their own controls. A change in reporting accuracy was reported in a study by Westerterp et al. who measured food intake (7-day dietary record) and energy expenditure (with doubly labelled water) in 16 non-obese men and women before and 
after a 40 week exercise intervention. Before the start of the intervention the difference between energy intake and energy expenditure was $-5 \pm 2.8 \%$ (not significant) and after the 40 weeks the difference had increased to $-19 \pm 17 \%(\mathrm{P}<0.01)$. The subjects perceived the reporting of their food intake for the fourth time (subjects also reported food intake two times during the intervention) as a real burden (56). If an increased misreporting of food intake means a higher misrecording and / or a larger change in the diet is still unknown. Nutrition intervention studies might even stimulate selective over- or underrecording of specific food stuffs, i.e. subjects might report the foods they are supposed to eat for the study.

\section{Outline of the thesis}

For validation of quantitative and qualitative assessment of habitual daily food intake in adults, the validation of the 7-day weighed food intake record is chosen here. This method does not rely on the memory of a subject and measures recent habitual food intake of individuals and groups. Seven days is the minimum number of days to measure mean daily energy requirement and it is probably the maximum number of days to keep a weighed food record; accuracy will drop with more than 7 days because of a declined motivation of the subjects. The 7-day weighed food record is evaluated on accuracy of recording and on the burden for subjects in the first study.

The validation of the 7-day food record is executed with several biomarkers, i.e. 1) the combination of basal metabolic rate and physical activity (assessed with a triaxial accelerometer) as a marker for total energy intake, 2) water loss (deuterium) as a marker for food recording, 3) repeated body mass measurements as a marker for a change in the diet and 4) postabsorptive respiratory quotient as a marker for the carbohydrate / fat ratio of the diet. Both the combination basal metabolic rate and physical activity and the sum of a change in the diet and misrecording were validated against total misreporting assessed by the doubly labelled water method. The ratio ElBMR, being not very useful for the identification of misreporting, and the measurement of nitrogen loss as marker for reported protein intake, being already validated, are not used.

Since dieticians are familiar with accurately weighing and reporting food intake they were chosen as subjects in the first study to evaluate the 7-day weighed food record. In this study (chapter 2) the water balance method was used to identify possible misrecording of food intake. The measurement of body mass changes over the recording period was used to determine a possible change in the diet. The simultaneous measurement of possible misrecording and a possible change in the diet gives insight in the reporting behaviour of subjects.

Information on a change in the diet and misrecording was used as key information to inform subjects about their way of food intake reporting. This might stimulate motivated subjects to improve their food intake reporting the next time. Thus, the subjects of the first study were confronted with their reporting behaviour and they were asked to record their food intake a second time (chapter 3 ).

Some qualitative misreporting of food intake has been indicated (22), but independent measurements are necessary to determine possible selective misreporting of type of macronutrient or type of meal. Chapter 4 describes a study about qualitative and 
quantitative misreporting of food intake in obese men. The reported food intake was validated with assessment of energy expenditure by doubly labelled water.

A biomarker for protein intake is available in the form of nitrogen loss. but markers for the carbohydrate fat ratio of the diet have not been found yet. Chapter 5 shows the results of an analysis of postabsorptive respiratory quotient and food quotient in lean and obese men and women.

Since validation of energy intake cannot always be executed with the doubly labelled water method, a more practical method to validate total food intake is required in nutrition research. The combination of basal metabolic rate and physical activity as assessed with an accelerometer appeared to be a promising biomarker and was validated against doubly labelled water in a group of men and women (chapter 6).

Chapter 7 describes a study which measures the influence of repeated measurements of food intake on reporting behaviour in the elderly, including possible misrecording or a change in the diet.

A nutrition intervention might influence food intake reporting behaviour even more than other interventions do. Chapter 8 describes the results of a nutrition intervention study in depleted, ambulatory patients with chronic obstructive pulmonary disease. The effect of oral nutritional supplements on habitual food intake and food intake reporting behaviour was studied in these patients.

Finally, all results are discussed and conclusions are drawn in chapter 9 Recommendations for future research as well as options for the valid assessment of habitual food intake are given.

\section{References}

1. Bandini, LG, Cyr, H, Must, A, and Dietz, WH. Validity of reported energy intake in preadolescent girls. Am J Clin Nutr 65: 1138S-I 141S. 1997.

2. Bandini, LG, Schoeller, DA, Cyr, HN, and Dietz, WH. Validity of reported energy intake in obese and nonobese adolescents. Am J Clin Nutr 52: 42]-425. 1990.

3. Barett-Connor, E. Nutrition epidemiology: how do we know what they ate? Am J Clin Nutr 54 182S-187S, 1991

4. Basiotis, PP, Welsh, SO, Cronin, FJ, Kelsay, JL, and Mertz, W. Number of days of food intake records required to estimate individual and group nutrient intakes with defined confidence. $J$ Nutr 117: 1638-1641, 1987

5. Bingham, SA. The dietary assessment of individuals: methods, accuracy, new techniques and recommendations. Nutr Abst and Rev 57: 705-742, 1987

6. Bingham, SA, and Cummings, JH. Urine nitrogen as an independent validatory measure of dietary intake: a study of nitrogen balance in individuals consuming their normal diet. Am J Clin Nutr 42 . $1276-1289,1985$.

7. Black. A. The sensitivity and specificity of the Goldberg cut-off for EI:BMR for identifying diet reports of poor validity. Eur J Clin Nutr 54: 395-404, 2000.

8. Black, AE, Bingham, SA, Johansson, G, and Coward. WA. Validation of dietary intakes of protein and energy against. 24 hour urinary $N$ and DLW energy expenditure in middle-aged women, retired men and post-obese subjects: comparisons with validation against presumed energy requirements. Eur J Clin Nutr 51: 405-413, 1997

9. Bouten, C, Verboeket-van de Venne, W. Westerterp. K. Verduin. M. and Janssen. J. Daily: physical activity assessment: comparison betwcen movement registration and doubly labeled watcr. J Appl Physiol 81: 1019-1026, 1996. 
10. Buhl, KM, Gallagher, D, Hoy, K, Matthews, DE, and Heymsfield, SB. Unexplained disturbance in body weight regulation: diagnostic outcome assessed by doubly labeled water and body composition analyses in obese patients reporting low energy intakes. J Am Diet Assoc 95: 1393$1400,1995$.

11. Butte, NF, Garza, MD, Smith, EO, and Nichols, BL. Evaluation of the deuterium dilution technique against the test-weighing procedure for the determination of breast milk intake. Am J Clin Nutr 37: 996-1003, 1983.

12. Cameron, M, and Staveren, Wv. Manual of methodology for food consumption studies. Oxford: Oxford University Press, 1988.

13. Champagne, CM, Baker, NB, DeLany, JP, Harsha, DW, and Bray, GA. Assessment of energy intake underreporting by doubly labeled water and observations on reported nutrient intakes in children. J Am Diet Assoc 98: 426-430, 1998.

14. Davies, PSW, Coward, WA, Gregory, J, White, A, and Mills, A. Total energy expenditure and energy intake in the pre-school child: a comparison. Br J Nutr 72: 13-20, 1994.

15. Edholm, OG. Fletcher. JG, Widdowson, EM, and McCance, RA. The energy expenditure and food intake of individual men. Br J Nutr 9: 286-300, 1955.

16. Edwards, JE, Lindeman, AK. Mikesky. AE, and Stager, JM. Energy balance in highly trained female endurance runners. Med Sci Sports Exerc 25: 1398-1404. 1993.

17. Fjeld. CR Brown. KH. and Schoeller. DA. Validation of the deuterium oxide method for mcasuring average daily milk intake in infants. Am J Clin Nutr 48: 671-679, 1988.

18. Flatt, JP. Dietary fat, carbohydrate balance, and weight maintenance. Ann N Y Acad Sci 683: 122$140,1993$.

19. Garrow, J. Treat obesity seriously, a clinical manual. Edinburgh: Churchill Livingstone, 1981.

20. Goldberg, GR, Black. AE, Jebb, SA. Cole, TJ, Murgatroyd, PR, Coward, WA, and Prentice, AM. Critical evaluation of energy intake data using fundamental principles of energy physiology: 1. Derivation of cut-off limits to identify under-recording. Eur J Clin Nutr 45: 569-581, 1991.

21. Goran, MI. and Pochlman. ET. Total energy expenditure and energy requirements in healthy elderly persons. Metabolism 41: 744-753, 1992.

22. Heitmann, B. Lissner, L. and Osler, M. Do we eat less fat, or just report so? Int J Obes 24: 435442. 2000 .

23. Johnson, LE, Dooley, PA and Gleick, JB. Oral nutritional supplement use in elderly nursing home patients. J Am Geriatr Soc 41: 947-952. 1993.

24. Johnson, RK. Soultanakis. RP, and Matthew', DE. Literacy and body fatness are associated with underreporting of energy intake in US low-income women using the multiple-pass 24 -hour recall: a doubly labeled water study. J Am Diet Assoc 98: 1136-1140, 1998

25. Kaaks, RJ. Biochemical markers as additional measurements in studies of the accuracy of dietary questionnaire measurements: conceptual issues. Am J Clin Nutr 65: 1232S-1239S, 1997.

26. Kaskoun, MC, Johnson, RK, and Goran, MI. Comparison of energy intake by semiquantitative food-frequency questionnaire with total energy expenditure by the doubly labeled water method in young children. Am J Clin Nutr 60: 43-47, 1994.

27. Kayser-Jones, J, Schell, ES, Porter, C, Barbaccia, JC, Steinbach, C, Bird, WF, Redford, M, and Pengilly, K A prospective study of the use of liquid oral dietary supplements in nursing homes. J Am Geriatr Soc 46: 1378-1386, 1998

28. Kumpen, KP. Saris, WH, and Westerterp. KR. Energy balance during an 8-wk energy-restricted diet with and without exercise in obese women. Am J Clin Nutr 62: 722-729, 1995.

29. Kroke, A. Klipstein-Grobusch, K, Voss, A, Moseneder, J, Thielecke, F, Noack, R, and Boeing, H. Validation of a self-administered food-frequency questionnaire administered in the European Prospective Investigation into Cancer and Nutrition (EPIC) Study: comparison of energy, protein, and macronutrient intakes estimated with the doubly labeled water, urinary nitrogen, and repeated 24-h dietary recall methods. Am J Clin Nutr 70: 439-447, 1999.

30. Lichtman, SW, Pisarska. K, Raynes Berman, E, Pestone, M, Dowling, H, Offenbacher, E, Weisel, H. Heshka. S. Matthews. DE, and Heymsfield, SB. Discrepancy between self-reported and actual caloric intake and excrcise in obese subjects. N Engl J Med 327: 1893-1898, 1992. 
53. Tomoyasu, NJ, Toth, MJ, and Poehlman, ET. Misreporting of total energy intake in older men and women. J Am Geriatr Soc 47: 710-715, 1999.

54. Velthuis-te Wierik, EJ, Westerterp, KR, and van den Berg, H. Impact of a moderately energyrestricted diet on energy metabolism and body composition in non-obese men. Int J Obes Relat Metab Disord 19: 318-324, 1995.

55. Westerterp, K. Assessment of physical activity level in relation to obesity: current evidence and research issues. Med Sci Sports Exerc 31: S522-S525, 1999.

56. Westerterp, K, Verboeket-van de Venne, W, Meijer, G, and ten Hoor, F. Self-reported intake as a measure for energy intake. A validation against doubly labelled water. Obes Eur 91: 17-22, 1991.

57. Westerterp, KR, and Bouten, CVC. Physical activity assessment: comparison between movement registration and doubly labeled water method. Z Emahrungswiss 36: 263-267, 1997.

58. Westerterp, KR, Donkers, JH, Fredrix, EW, and Boekhoudt, P. Energy intake, physical activity and body weight: a simulation model. Br J Nutr 73: 337-347, 1995.

59. Westerterp, KR, Wouters, L, and van Marken Lichtenbelt, W. The Maastricht protocol for the measurement of body composition and energy expenditure with labeled water. Obes Res 3 suppl 1 $49-57,1995$ 

Chapter 2

Underreporting of habitual food intake is explained by undereating in highly motivated lean women

Annelies HC Goris, Klaas R Westerterp

Department of Human Biology, Maastricht University, The Netherlands

Published in: Journal of Nutrition 1999: 129: 878-882. 


\section{Abstract}

Underreporting of habitual food intake can be explained by underrecording and/or undereating. This study was designed to discriminate between the two errors mentioned, by measuring energy- and water balance. Twenty-four lean, female dieticians were recruited as subjects. Energy intake and water intake were measured for one week with a weighed dietary record. Energy expenditure was estimated from measurements of resting metabolic rate, and measured physical activity with a triaxial accelerometer for movement registration. Water loss was estimated with deuterium labelled water. Energy balance was determined by measuring the change in body mass over a nonrecording week (preceding the recording week) and over the recording week. Mean energy- and water intake were $8.5 \pm 1.0 \mathrm{MJ} / \mathrm{d}$ and $2.3 \pm 0.5 \mathrm{l} / \mathrm{d}$. The change in body mass in the nonrecording week was $0.1 \pm 0.6 \mathrm{~kg}$ and in the recording week $0.6 \pm 0.8 \mathrm{~kg}$ (paired t-test; $\mathrm{P}=0.02$ ), indicating $16 \%$ undereating. Recorded water intake plus calculated metabolic water closely matched measured water loss ( $r=0.93$; $\mathrm{P}=0.0001$ ), which indicated a high recording precision. In conclusion, in the studied group of highly motivated lean women, there was $16 \%$ underreporting of habitual food intake, which could be explained by undereating.

\section{Introduction}

Nutrition research requires a valid measurement of habitual food intake. Standard methods used for determining habitual food intake include interviewing subjects about their usual or past intake and food records kept by the subjects at the time of consumption. Yet, measurements of food intake have often been prone to errors, e.g., underrecording or undereating. Since the doubly labelled water method has come into use for the validation of energy intake (assuming energy balance), many studies have found a self reported energy intake below measured energy expenditure $(1,2,6,7,9$, $12,13,15,14,16,18,19,20,21,23,24,25,27)$. The doubly labelled water method is an accurate and precise method to measure energy expenditure in free-living subjects. Underreporting of habitual food intake (i.e., a discrepancy between energy intake and expenditure) can be divided into underrecording and undereating, but the distinction has seldom been made. By underrecording is meant a discrepancy between energy intake and measured energy expenditure with no change in body mass. and by undereating a discrepancy accompanied by a decline in body mass over the food recording interval (17). Milne et al. (1991) tried to distinguish underrecording and undereating in their study. Energy expenditure was assessed from predicted basal metabolic rate (calculated from subjects height, weight and age) and the physical activity level (obtained by activity diaries for each day). Body mass was measured at the start and end of the recording week at the same time of day, but not necessarily in subjects with an empty stomach. The size of underreporting, and thus of undereating and underrecording, could only be estimated in this study.

Studies that measured energy intake with a food record and energy expenditure with the doubly labelled water method found discrepancies ranging from 20 to $50 \%$ in obese subjects $(2,6,12,13,19,20,21,25,27)$ and from 0 to $30 \%$ in lean subjects $(1$, $2,7,9,15,14,16,18,20,21,23,24,27)$. One of the few studies that found a reported 
energy intake equal to measured energy expenditure was a study of Sjödin et al. (24). This study was done with eight cross country skiers (four men and four women) who reported their food intake for four consecutive days assisted by two dieticians who were present at all meals, likely an ideal situation. Other studies by Davies et al. (7) in children from 1.5 to 4.5 years, by Westerterp et al. (27) in adults before an exercise training and by Schulz et al. (23) in students found a reported energy intake nearly equal to energy expenditure. Most other studies found discrepancies $>5 \%$ between energy intake and expenditure; these were attributed to underreporting. Measurements of body mass were done in some of the above mentioned studies, but a determination of the fraction of underreporting attributed to undereating could not be made $(2,6,7$, $9,12,13,16,18,19,20,21,23,24.25 .27)$. Other studies did not measure body mass at the start and end of the recording interval and attributed the underreporting completely to underrecording of energy intake $(1,14,15)$. Repeated measurements of body mass on an accurate scale in the morning before any beverage or food consumption and after voiding are necessary to detect undereating. This might be a reason for not addressing the issue of undereating in most studies.

In addition, a distinction between underrecording and undereating is difficult to make because a decline in body mass does not necessarily have to exclude underrecording; both can occur at the same time. An independent measure for underrecording is therefore necessary.

This study was designed to discriminate between underrecording and undereating by comparing reported food intake with measured energy expenditure and water loss. Food and water intake were measured with a 7-day weighed food record, and energy expenditure was estimated by measurements of resting metabolic rate and physical activity. A triaxial accelerometer for movement registration measured physical activity (validated by Bouten et al. (5) with doubly labelled water), a less expensive alternative for the doubly labelled water method. Water loss was measured with deuterium elimination. Under normal conditions, water balance is preserved, and water intake matches water loss. Water loss might slightly deviate from water intake during the postovulatory phase of the menstrual cycle for premenopausal women, but this is very small (e.g., a water retention of $0.5 \mathrm{~V} / \mathrm{wk}$ gives, on a total water loss of $21 \mathrm{l} / \mathrm{wk}$, a $2 \%$ deviation of measured water loss). "Underdrinking" because of food recording is not realistic. Thus a water intake, corrected for metabolic water, lower than water loss indicates underrecording. Portion size errors have to be minimal to be able to distinguish underrecording from undereating. Therefore, dieticians were chosen as subjects because they are familiar with accurately weighing and reporting food intake. The objective of this study was to sort out the two errors that contribute to underreporting of habitual food intake, i.e., underrecording and undereating.

\section{Subjects and methods}

\section{Design}

Food intake was measured with a 7-day food record. Energy balance was monitored by measurement of body mass. Subjects were weighed one week before the start of the food-recording week, at the start and at the end of the recording week. Thus, possible weight fluctuations because of food recording could be compared with normal weight 
fluctuations. During week one, the nonrecording week, there were no further measurements. In week two, energy and water intake were measured with a weighed food record. Energy expenditure was estimated by two measurements of resting energy expenditure (at the start and end of the recording week) and by the assessment of physical activity during the whole recording week. Water loss was measured with deuterium elimination.

\section{Subjects}

Twenty-seven dieticians were recruited from the Maastricht University, university hospital, home nursing association and dietician practices in Maastricht and the surrounding area. Subjects were informed about the goal of the study to stimulate them to record their food intake accurately. All subjects were healthy women with a mean age of $34 \pm 9$ years (range 22-60) and a mean body mass index of $22.1 \pm 2.3 \mathrm{~kg} / \mathrm{m}^{2}$ (range 17.4-26.0). Two subjects were post-menopausal. Subjects who were pregnant, lactating or dieting were not included in the study. The protocol was approved by the university ethics committee.

\section{Body mass}

Body mass was measured three times at 7-day intervals. Because weight fluctuations can be influenced by phase of menstrual cycle, the phase of the cycle in the recording week was noted. Subjects were weighed (in underwear) in the morning before any beverage or food consumption and after voiding, on a digital balance accurate to 0.01 $\mathrm{kg}$ (Sauter, Ebingen, Germany).

\section{Food and wat'r intake}

A seven day weighed food record was chosen, because it does not rely on the memory of a subject and it is commonly used for measuring recent habitual food intake of individuals and groups. Subjects were instructed to weigh everything they ate and drank on an electronic scale (EKS; Sélestat, Sweden; max. 2000g; accurate to lg) and record it in a structured food diary. The food records were converted into intakes of total energy and water with a computer program based on food tables (Becel Nutrition Program, 1988).

The amount of metabolic water was estimated from protein, fat and carbohydrate intake derived from the 7-day food record and from the change in body mass. Oxidation water is $0.41 \mathrm{ml} / \mathrm{g}$ for protein, $1.07 \mathrm{ml} / \mathrm{g}$ for fat and $0.6 \mathrm{ml} / \mathrm{g}$ for carbohydrate (10). A change in body mass of $1 \mathrm{~kg}$ is assumed to be a change of 0.75 $\mathrm{kg}$ fat mass and $0.25 \mathrm{~kg}$ fat free mass. Fat mass is pure fat and fat free mass is $73 \%$ water and $27 \%$ protein (28).

\section{Energy expenditure}

Energy expenditure (EE) was estimated from measured resting metabolic rate (RMR) and physical activity (PA). Diet-induced energy expenditure was not measured in this study; it is a constant fraction of $10 \%$ of total energy expenditure in subjects consuming an average mixed diet (31).

Resting metabolic rate was measured by means of an open circuit ventilated hood system, in the morning in a fasting state while lying for $30 \mathrm{~min}$ in supine position. Gas analyses were performed by a paramagnetic oxygen analyzer (Servomex type 500A, 
Crowborough Sussex, United Kingdom) and an infrared carbon dioxide analyzer (Servomex type 500A, Crowborough Sussex, United Kingdom), similar to the analysis system described by Schoffelen et al. (22). Weir's formulas were used for calculating RMR (26).

Physical activity was registered with a triaxial accelerometer for movement registration (Tracmor, Philips Research, Eindhoven, The Netherlands). The Tracmor was an improved version (same principle, but smaller $7 \times 2 \times 0.8 \mathrm{~cm}$ ) of the Tracmor used in previous studies (5). In short, the Tracmor measures accelerations in the anteroposterior, mediolateral and vertical directions. The Tracmor has been validated against doubly labelled water (5). Subjects wore the Tracmor in a belt at the back of the waist during waking hours and recorded the times at which they got up, put on and off the Tracmor and when they went to bed. The registered accelerations in counts/minute were used as an objective measure for the physical activity level of each subject.

\section{Water loss}

Water loss over the recording week was measured with the deuterium elimination method (10). Subjects drank a deuterium $\left({ }^{2} \mathrm{H}_{2} \mathrm{O}\right)$ dilution $(70 \mathrm{~g}$ water with an enrichment of 5 atom percentage excess ${ }^{2} \mathrm{H}$ ) after voiding (baseline urine sample) the evening before the start of the recording week. Elimination was calculated from two urine samples directly after dosing (at day 1 in the morning and evening) and two at the end of the observation period (day 7 in the evening, day 8 in the morning). Deuterium content was measured in urine samples with an isotope ratio mass spectrometer (30). Water loss was calculated from ${ }^{2} \mathrm{H}$ elimination with the equation of Fjeld et al. (10), as described previously (29).

\section{Questionnaire}

At the end of the recording week subjects filled in a questionnaire about their experiences with food recording to determine if they always weighed and recorded their food intake and if they changed their habitual food intake.

\section{Siatistics}

Twenty-seven subjects were recruited; three subjects were excluded from statistical analysis because of missing physical activity registration by the Tracmor.

Mean values and standard deviations were calculated. A one factor ANOVA for repeated measures and a Scheffé test (post-hoc) were used to compare the three measurements of body mass. The changes in body mass were compared with a paired t-test. A factorial ANOVA test was used to measure the influence of the phase of the menstrual cycle on the body mass changes.

Measurements of RMR at the start and end of the recording week were compared with a paired $t$-test and means were calculated if the two measurements did not differ significantly.

RMR, PA and body mass changes are all independent measures for energy metabolism. Multiple and simple regression analyses were used to assess the contribution of these independent variables to reported energy intake.

The ratio between energy intake and resting metabolic rate (EI/RMR) is often used to identify underreporting. For subjects in energy balance EI/RMR ranges between a 
minimum of 1.1, in somebody with zero activity, and a higher value of about 2.5 in very active subjects. A low EL/RMR can be caused by underrecording or undereating. With simple regression analysis,s the contribution of physical activity and the change in body mass to EL/RMR were tested. Significance was reached when $P<0.05$. The StatView SE+ (1988, Abacus Concepts, Berkeley, CA) was used for statistical analysis.

\section{Results}

The results of the three body mass measurements (mean \pm SD) were, in sequence of time, $61.5 \pm 8.1,61.5 \pm 8.0$ and $61.0 \pm 7.9 \mathrm{~kg}$. The last mean body mass differed significantly from the first two measurements $(\mathrm{P}<0.01)$. Mean body mass changes over the nonrecording and recording week (table 2.1$)$ differed significantly $(P<0.02)$ and were independent of the phase of the menstrual cycle $(P>0.05)$.

Figure 2.1 presents the individual changes in body mass over the nonrecording week and the recording week. The change in body mass indicated that most subjects (18 out of the 24) were in negative energy balance. The mean body mass loss of $0.57 \mathrm{~kg}$ over the recording week represented $17.1 \mathrm{MJ}[1 \mathrm{~kg}$ body mass was assumed to be equivalent to $30 \mathrm{MJ}(28)$ ] or $2.4 \mathrm{MJ} /$ day. Energy expenditure calculated from energy intake and body mass loss was $10.8 \pm 2.8 \mathrm{MJ} / \mathrm{d}$. The discrepancy between reported energy intake and calculated energy expenditure was $16 \pm 29 \%$ of calculated energy expenditure.

The results of reported energy intake and estimated energy expenditure are summarised in table 2.1. Measurements of RMR did not differ significantly from each other and mean values of both measurements were calculated for each subject. The mean ratio of energy intake to resting metabolic rate (FI/RMR) was $1.4 \pm 0.2$ for this group and ranged from 1.1 to 1.7 .

Table 2.1: Reported intakes of energy and water and estimates of energy expenditure, body mass changes and water loss in lean healthy women'.

\begin{tabular}{lcc}
\hline $\mathrm{n}=24$ & Mean $\pm \mathrm{SD}$ & (ranges) \\
\hline Energy intake (MJ/d) & $8.5 \pm 1.0$ & $(6.1-10.4)$ \\
Resting metabolic rate $(\mathrm{MJ} / \mathrm{d})$ & $6.1 \pm 0.5$ & $(5.3-6.9)$ \\
Physical activity (counts/min) & $163 \pm 70$ & $(75-315)$ \\
Body mass change over the non- recording week $(\mathrm{kg})$ & $0.07 \pm 0.59$ & $(-0.96-1.36)$ \\
Body mass change over the recording week $(\mathrm{kg})$ & $-0.57 \pm 0.77^{*}$ & $(-2.53-0.93)$ \\
Reported water intake (l/d) & $2.3 \pm 0.5^{* *}$ & $(1.4-3.0)$ \\
Reported water intake + metabolic water ${ }^{2}(\mathrm{l} / \mathrm{d})$ & $2.6 \pm 0.5^{* *}$ & $(1.7-3.3)$ \\
Water loss (Vd) & $3.0 \pm 0.5$ & $(2.0-3.9)$ \\
\hline
\end{tabular}

1 Means are based on 7-day food diaries of 24 subjects and the ranges refer to differences among subjects.

2 Metabolic water was calculated from reported protein, fat and carbohydrate intakes derived from the 7 day food record and from the change in body mass ( $1 \mathrm{~kg}$ change is $0.75 \mathrm{~kg}$ fat mass and $0.25 \mathrm{~kg}$ fat free mass)

* Body mass change over the recording week was significantly different from body mass change over the nonrecording week ( $t$-test; $P<0.02$ ).

** Water intake was significantly different from water loss (t-test: $\mathrm{P}<0.01$ ) 


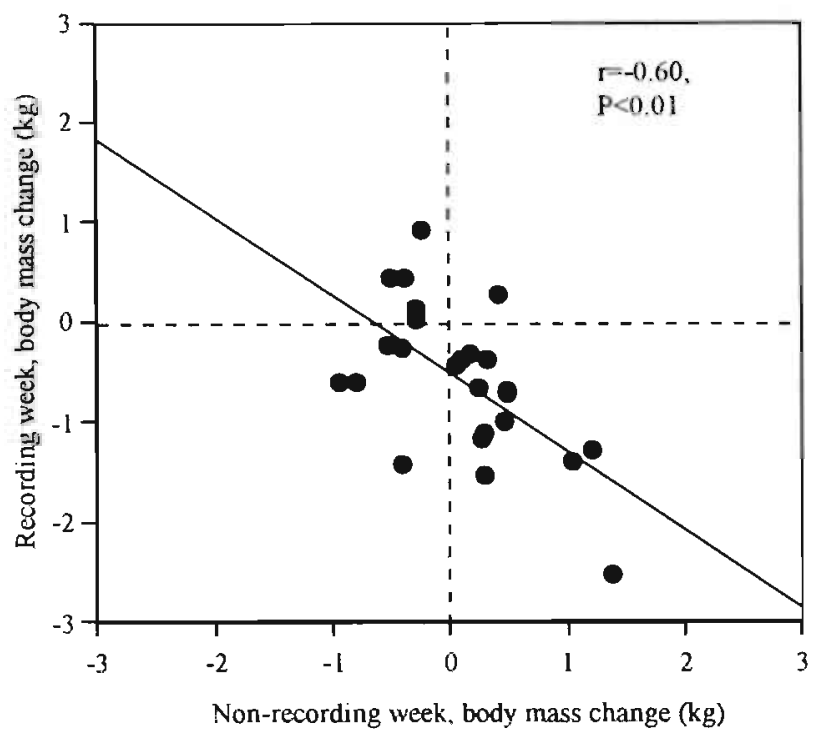

Figure 2.1: Individual body mass changes in lean healthy women $(n=24)$ over the nonrecording week, a week with no interventions, and over the recording week. a week in which subjects weighed and recorded their food intake.

Reported water intake plus calculated metabolic water correlated closely with measured water loss (water intake $=-0.29+0.99$ water loss; $r=0.92, \mathbf{P}<0.0001$ ), indicating a high recording precision. However, there was a significant difference of $0.3 \mathrm{l} / \mathrm{d}$ between total water loss and reported water intake plus the calculated amount of metabolic water (see discussion).

Resting metabolic rate, physical activity, and the change in body mass were all independently related to energy intake (table 2.2 ). Together they explained $66 \%$ of the variation in energy intake.

Table 2.2: The attribution of resting mctabolic rate. physical activity and body mass change over the recording week to energy intake in 24 lean healthy women and a simple and multiple regression analysis on energy intake.

\begin{tabular}{|c|c|c|}
\hline Energy intake & Explained variation (\%) & Significance, $\mathrm{P}<$ \\
\hline Resting metabolic rate (RMR) & 27 & 0.02 \\
\hline Physical activity (PA) & 27 & 0.02 \\
\hline$\Delta$ body mass over recording week & 25 & 0.01 \\
\hline $\mathrm{RMR}+\mathrm{PA}+\Delta$ body mass ${ }^{\top}$ & 65 & 0.001 \\
\hline
\end{tabular}

The following equation, which predicts energy intake. can be derived from the multiple regression analysis: 'Energy intake $(\mathrm{kJ} / \mathrm{d})=2815+0.84 \cdot \mathrm{RMR}(\mathrm{kJ} / \mathrm{d})+5.3 \cdot \mathrm{PA}($ counts $/ \mathrm{min})+669 \cdot \Delta$ body mass $(\mathrm{kg} / \mathrm{wk})$

The frequently adopted indicator for underreporting, EL/RMR, was positively related to body mass change $(r=0.61 ; \mathrm{P}<0.01)$ (figure 2.2 ). In a multiple regression analysis, PA explained an additional $17 \%$ of the variation.

The answers to the questionnaire subjects completed at the end of the recording week indicated that weighing and recording food intake for seven days was quite a burden. 
However, according to their answers, subjects did not change their food pattem during the recording week.

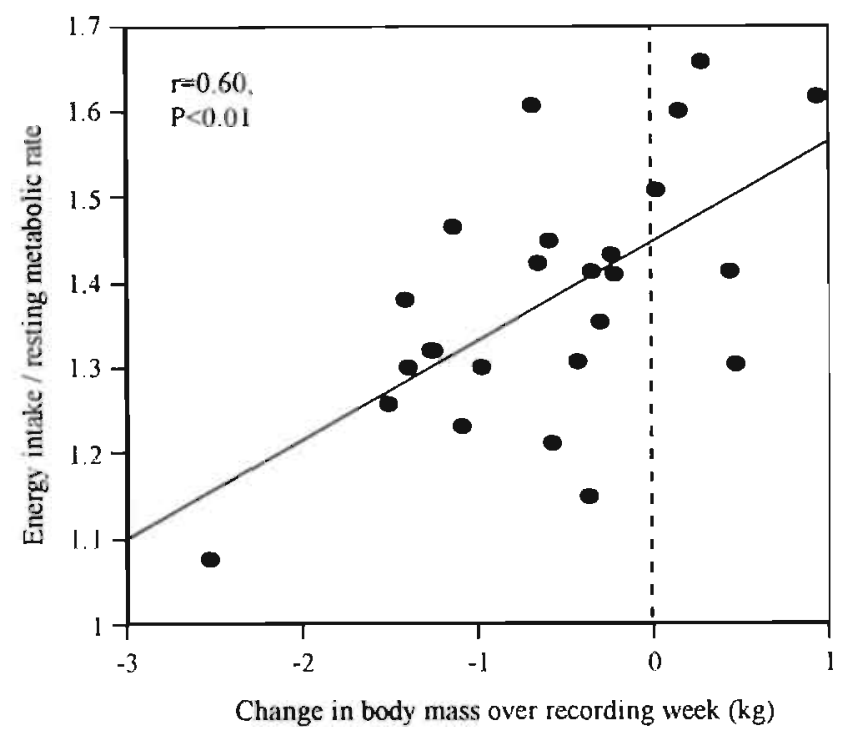

Figure 2.2: The contribution in lean healthy women $(n=24)$ of the change in body mass over the food-recording week to the energy intake/resting metabolic rate ratio, with the linear regression line; Energy intake/resting metabolic rate $=1.4+0.1 \cdot$ body mass change $(\mathrm{kg} / \mathrm{wk})$.

\section{Discussion}

In this study we found a discrepancy of $16 \%$ between reported energy intake and estimated energy expenditure. The level of underreporting of $16 \%$ falls in the range observed in other studies with lean subjects $(1,2,7,9,15,14,16,18,20,21,23,24$, 27). Here, underreporting could be attributed to undereating, because body mass declined significantly over the recording week.

The recording of food intake in this study was done accurately according to the measured water balance. The small shortage in water intake compared to water loss was also seen in other studies that measured the water balance $(29,30)$. The shortage in this study might be due to underestimation of the amount of calculated metabolic water or might be in the assumptions made on respiratory and cutaneous water loss and fractionation in the calculation of water loss. The amount of metabolic water was calculated from the carbohydrate, fat and protein intakes derived from the 7-day food record and from the change in body mass. To calculate the amount of metabolic water derived from the change in body mass. the mass ratio 75:25 for fat mass and fat free mass was used. This ratio of mobilisation or storage of energy between fat mass and fat free mass is not a constant and might introduce an error in the calculation of metabolic water (28). A good recording of water intake does not necessarily imply that the same holds for the recording of food intake. However, most foodstuffs contain a 
certain amount of water; therefore, it was concluded that the food recording was also done accurately.

Subjects changed their habitual food intake in the recording week; this was probably done unconsciously according to the answers on the questionnaire. To indicate undereating, body mass changes in the recording week were compared with body mass changes in the nonrecording week. Body mass might fluctuate from one week to another; thus, normal body mass changes were excluded from changes caused by undereating. Milne et al. measured body mass changes only over the recording week. A significant weight loss $(-0.28 \mathrm{~kg} / \mathrm{wk})$ from zero over the recording week was found. However, body mass was not measured in the morning after an overnight fast (with an empty stomach), which might give some error in the measured body mass changes over the recording week. The body mass changes were not related to energy intake, only in subgroups of large eaters vs. small eaters. It was therefore not entirely clear whether the body mass changes indicated undereating or whether they were simply normal weight fluctuations or measurement errors (17). Figure 2.1 presents changes in body mass over the nonrecording week and the recording week. The regression line goes not through zero, probably because of the intervention (weighing and recording food intake) in week two or because the time interval was too short to measure energy balance. Edholm et al. measured energy expenditure and food intake in individual men for 2 weeks and showed that mean energy expenditure was close to intake on a weekly and fortnightly basis. Individual intakes were highly variable from day to day and were often not in daily, weekly or even fortnightly balance with energy expenditure (8). Basiotis et al. found that the minimum time interval in which to measure habitual intake at an individual level was 31 days and 3 days at a group level (3). Seven days is the minimum number of days to measure mean energy balance and is probably the maximum number of days in which to keep a weighed food record; accuracy will drop if the time is extended because of declining motivation on the part of the subjects.

The ratio EE/RMR is known as physical activity level; if there is no underreporting, EE/RMR is equal to EI/RMR. The EI/RMR ratio is therefore often used in studies to identify underreporting. Goldberg et al. made cut-off limits to recognise underreporting at the group level (11). A physical activity level $<1.35$ is not very likely unless someone has a very inactive lifestyle. Therefore ratios of EI/RMR $<1.35$ indicate underreporting. But, as can be seen in figure 2.2 , there were subjects in this study with a ratio below and above 1.35 who lost weight. The ratio EL/RMR cannot identify all underreporters, only the very unlikely reporters. Black et al. compared the ratio El/RMR with El/EE and also arrived at the conclusion that the ratio EI/RMR cannot identify all underreporters; specific information about a person's physical activity is needed (4). Specific information about such physical activity was available in this study through the use of the Tracmor: thus conclusions could be made on individual level. The output of the Tracmor explained $27 \%$ of the variation in energy intake.

This study was done with dieticians, a population that would be expected to report very accurately. The results of this study can therefore not be used for other populations, but the methods used certainly apply to other studies.

In summary, underreporting of habitual food intake does not necessarily mean that subjects are dishonest about their food intake. In this study, we found that the recording precision of subjects was high, but they changed their food pattern and 
therefore lost weight. The underreporting of about $16 \%$ could be explained by undereating in this group of motivated, lean women.

\section{References}

1. Bandini, LG, Cyr, H, Must, A, and Dietz, WH. Validity of reported energy intake in preadolescent girls. Am J Clin Nutr 65: 1138S-1141S, 1997.

2. Bandini, LG, Schoeller, DA, Cyr, HN, and Dietz, WH. Validity of reported energy intake in obese and nonobese adolescents. Am J Clin Nutr 52: $42 \mathrm{i}-425,1990$

3. Basiotis, PP, Welsh, SO, Cronin, FJ, Kelsay, JL, and Mertz, W. Number of days of food intake records required to estimate individual and group nutrient intakes with defined confidence. $J \mathrm{Nutr}$ 117: 1638-1641, 1987

4. Black, AE, Bingham, SA, Johansson, G, and Coward, WA. Validation of dietary intakes of protein and energy against 24 hour urinary $\mathrm{N}$ and DLW energy expenditure in middle-aged women, retired men and post-obese subjects: comparisons with validation against presumed energy requirements. Eur J Clin Nutr 51: 405-413, 1997.

5. Bouten, CVC, Verboeket-van de Venne, WPHG, Westerterp, KR, Verduin, M, and Janssen, J Daily physical activity assessment: comparison between movement registration and doubly labeled water. J Appl Physiol 81: 1019-1026, 1996.

6. Buhl, KM, Gallagher, D, Hoy, K, Matthews, DE, and Heymsfield. SB. Unexplained disturbance in body weight regulation: diagnostic outcome assessed by doubly labeled water and body composition analyses in obese patients reporting low energy intakes. J Am Diet Assoc 95: 1393$1400,1995$.

7. Davies, PSW, Coward, WA, Gregory, J, White, A, and Mills, A. Total energy expenditure and energy intake in the pre-school child: a comparison. Br J Nutr 72: 13-20, 1994.

8. Edholm, OG, Fletcher, JG, Widdowson, EM, and McCance, RA. The energy expenditure and food intake of individual men. Br J Nutr 9: 286-300, 1955.

9. Edwards, JE, Lindeman, AK, Mikesky, AE, and Stager, JM. Energy balance in highly trained female endurance runners. Med Sci Sports Exerc 25: 1398-1404, 1993.

10. Fjeld, $\mathrm{CR}, \mathrm{Brown}, \mathrm{KH}$, and Schoeller, DA Validation of the deuterium oxide method for measuring average daily milk intake in infants. Am J Clin Nutr 48: 671-679, 1988.

11. Goldberg, GR, Black, AE, Jebb, SA, Cole, TJ, Murgatroyd, PR, Coward, WA, and Prentice, AM. Critical evaluation of energy intake data using fundamental principles of energy physiology: 1. Derivation of cut-off limits to identify under-recording. Eur J Clin Nutr 45: 569-581, 1991.

12. Kempen. KP, Saris, WH, and Westerterp. KR. Encrgy balance during an 8-wk energy-restricted diet with and without exercise in obese women. Am J Clin Nutr 62: 722-729, 1995.

13. Lichtman, SW, Pisarska, K, Raynes Berman, E. Pestone. M, Dowling. H. Offenbacher. E. Weisel. H, Heshka, S. Matthews, DE, and Heymsfield. SB. Discrepancy between self-reported and actual caloric intake and exercise in obese subjects. N Engl J Med 327: 1893-1898, 1992.

14. Livingstone, MBE, Prentice, AM, Coward, WA, Strain, JJ, Black, AE, Davies, PSW, Stewart. CM, McKenna, PG, and Whitehead, RG. Validation of estimates of energy intake by weighed dietary record and diet history in children and adolescents. Am J Clin Nutr 56: 29-35, 1992.

15. Livingstone, MBE. Prentice, AM, Strain, JJ, Coward, WA, Black, AE, Barker, ME, McKenna, $\mathrm{PG}$, and Whitehead. RG. Accuracy of weighed dietary records in studies of diet and health. $\mathrm{Br}$ Med J 300: 708-712, 1990

16. Martin, LJ, Su, W, Jones, PJ, Lockwood, GA, Tritchler, DL, and Boyd, NF. Comparison of energy intakes determined by food records and doubly labeled water in women participating in a dietary-intervention trial. Am J Clin Nutr 63: 483-490, 1996.

17. Milne, AC, McNeil, G, and Zakary, A. Weight change as an indicator of energy imbalance during 7 day weighed food intake studies. Ecol Food Nutr 26:281-289, 1991

18. Pannemans, DL, and Westerterp, KR. Estimation of energy intake to feed subjects at energy balance as verified with doubly labelled water: a study in the elderly. Eur J Clin Nutr 47: 490-496. 1993. 
19. Prentice, AM, Black, AE, Coward, WA, Davies, HL, Goldberg, GR, Murgatroyd, PR, Ashford, J, Sawyer, M, and Whitehead, RG. High levels of energy expenditure in obese women. Br Med J 292: 983-987, 1986.

20. Schoeller, DA. How accurate is self-reported dietary energy intake? Nutr Rev 48: 373-379, 1990.

21. Schoeller, DA, Bandini, LG, and Dietz, WH. Inaccuracies in self-reported intake identified by comparison with the doubly labelled water method. Can J Physiol Pharmacol 68: 941-949, 1990.

22. Schoffelen, PFM, Westerterp, KR, Saris, WHM, and ten Hoor, F. A dual-respiration chamber system with automated calibration. J Appl Physiol 83: 2064-2072, 1997.

23. Schulz, S, Westerterp, KR, and Bruck, K. Comparison of energy expenditure by the doubly labeled water technique with energy intake, heart rate, and activity recording in man. Am J Clin Nutr 49: 1146-1154, 1989.

24. Sjodin, AM, Andersson, AB, Hogberg, JM, and Westerterp, KR. Energy balance in cross-country skiers: a study using doubly labeled water. Med Sci Sports Exerc 26: 720-724, 1994.

25. Velthuis-te Wierik, EJ, Westerterp, KR, and van den Berg, H. Impact of a moderately energyrestricted diet on energy metabolism and body composition in non-obese men. Int $\mathbf{J}$ Obes Relat Metab Disord 19: 318-324, 1995.

26. Weir, JB. New methods for calculating metabolic rate with special reference to protein metabolism. J Physiol 109: 1-9, 1949.

27. Westerterp, KR. Verboeket-van de Venne, WPHG, Meijer, GAL, and ten Hoor, F. Self-reported intake as a mcasure for encrgy intake. A validation against doubly labelled water. Obes Eur 91: $17-22,1991$

28. Westerterp, KR, Donkers, JH, Fredrix, EW, and Boekhoudt, P. Energy intake, physical activity and body weight: a simulation model. Br J Nutr 73: 337-347, 1995.

29. Westerterp, KR, Kayser, B, Brouns, F, Herry, JP, and Saris, WHM. Energy expenditure climbing Mt. Everest. J Appl Physiol 73: 1815-1819, 1992.

30. Westerterp, KR, Robach, P, Wouters, L, and Richalet, JP. Water balance and acute mountain sickness before and after arrival at high altitude of 4,350 m. J Appl Physiol 80: 1968-1972, 1996.

31. Weststrate, JA, Weys, PJM, Poortvliet, EJ, Deurenberg. P. and Hautvast. JGAJ. Diumal variation in postabsorptive resting metabolic rate and dict-induced themogencsis. Am J Clin Nutr 50: 908$914,1989$. 

Chapter 3

Improved reporting of habitual food intake after confrontation with earlier results on food reporting

Annelies HC Goris, Klaas R Westerterp

Department of Human Biology, Maastricht University, The Netherlands

Published in: British Journal of Nutrition 2000: 83: 363-369. 


\section{Abstract}

The aim of the present study was to improve the reporting of food intake by confronting subjects with their way of reporting food intake, e.g., underrecording and/or undereating. To minimize portion size errors, 18 female dieticians were recruited as subjects. Energy- and water intake were measured for one week with a weighed dietary record. Resting metabolic rate was measured with an open-circuit ventilated hood indirect calorimeter, and physical activity was measured with an accelerometer for movement registration. Water loss was estimated with deuterium labelled water. Energy balance was checked for by measuring empty body weight one week before the start, at the start and at the end of the recording week. In the first part of the study, the change in body weight in the non-recording week was $0.14 \mathrm{~kg}$ and in the recording week $-0.45 \mathrm{~kg}(\mathrm{P}=0.02)$, indicating $12 \%$ undereating. Total water intake closely matched measured water loss, indicating a high recording precision. There was underreporting of habitual food intake that could be fully explained by undereating. In the second part of the study, subjects were confronted with these results and the protocol was repeated. This time there was no significant change in body weight in the recording week, indicating no undereating. The reporting of habitual food intake had been improved. In conclusion, in the studied group of highly motivated lean women, underreporting of habitual food intake (here due to undereating) could be eliminated by confrontation with the results of this phenomenon.

\section{Introduction}

Underreporting of habitual food intake is seen in many studies and in different populations. The most accurate way to measure habitual food intake is still not established and a valid method is much needed for nutrition research. Discrepancies between reported food intake and measured energy expenditure (with the doubly labelled water method) ranged from 20 to $50 \%$ in obese subjects $(3,5,8,14,15,22$, $24,25,32,36)$ and from 0 to $30 \%$ in lean subjects $(2,3,4,9,10,17,16,18,20,24$, $25,27,30,36$ ). Until recently it was not clear whether the discrepancy was due to underrecording (an energy intake below energy expenditure with no change in body mass), to undereating (an energy intake below energy expenditure accompanied by a decline in body mass) or to both. We were able to investigate both mentioned errors with simultaneous measurements of energy balance and water balance (13). Body mass decline over the reporting week, as a measure for energy balance, was an indication for undereating. Water loss in excess of reported water intake was an indication for underrecording. The recording precision of water intake was assumed to be representative for total food recording (13). This first study to enable the division of underreporting into undereating and underrecording also gave information for providing comments to the subjects. Feedback on the reporting of food intake can be useful to make subjects aware of their way of reporting food intake e.g., underrecording and/or undereating. After the feedback, a second period of food reporting might improve the reporting of habitual food intake. The aim of this present study was to improve the reporting of habitual food intake, by confronting subjects with the results of an earlier reporting of food intake. Food and water intake were 
measured with a seven day weighed food record and energy expenditure was calculated from measurement of resting metabolic rate and physical activity. Water loss was measured with deuterium elimination. The study was split into two parts; the first part was to investigate the two errors underrecording and undereating and the second part was to improve the reporting of habitual food intake. To be able to distinguish underrecording from undereating it was necessary to minimize portion size errors. Therefore, dieticians were chosen as subjects as they are familiar with weighing and reporting food items accurately.

\section{Subjects and methods}

\section{Prolocol}

Food intake was measured with a 7 day food record. Energy balance was monitored by measurement of body mass. Subjects were weighed one week before the start of the food recording week, and at the start and end of the recording week. Thus, possible weight fluctuations because of food recording could be compared with normal weight fluctuations. During the first week, the non-recording week, there were no further measurements. In the second week energy and water intake were measured with a weighed food record. Energy expenditure was estimated by two measurements of resting energy expenditure (at the start and end of the recording week) and by the assessment of physical activity during the whole recording week. Water loss was measured with deuterium elimination.

When all subjects had followed the protocol once, they came together 1 to 6 months later and were confronted with the qualitative and quantitative results on underrecording and/or undereating of the whole group and of themselves. They were given a detailed personal copy to take home as well. All subjects were asked to follow the same protocol again, independent of personal results of the reporting of food intake, and to do it better. The confrontation with the results should help the subjects to improve the reporting of food intake.

\section{Subjects}

Dieticians ( $\mathrm{n}=27$ ) were recruited, via letters and meetings, from Maastricht University, Maastricht University Hospital, home nursing association and dietician practices in Maastricht and surrounding area. Subjects were informed about the goal of the study to stimulate them to record their food intake accurately. All subjects were healthy women with a mean age of $34 \pm 9$ years (range 22-60) and a mean body mass index of $22.1 \pm 2.3$ $\mathrm{kg} / \mathrm{m}^{2}$ (range 17.4-26.0). Subjects who were pregnant, lactating or slimming were not included in the study. Two subjects were post-menopausal. The protocol was approved by the university ethics committee.

\section{Body mass}

Body mass was measured three times (with seven day intervals). Thus, possible weight fluctuations because of food recording can be compared with normal weight fluctuations. As weight fluctuations can be influenced by phase of menstrual cycle, the phase of the cycle was noted. Subjects were weighed (in underwear) in the moming 
before any drink or beverage consumption and after voiding, on a digital balance accurate to $\pm 0.01 \mathrm{~kg}$ (Sauter, Ebingen, Germany).

\section{Food and water intake}

A seven day weighed food record was chosen, because it does not rely on the memory of a subject and is commonly used for measuring habitual food intake of individuals and groups. Subjects were instructed to weigh everything they ate and drank on an electronic scale (EKS; Sélestat, Sweden; max. 2000g; accurate to $\mathrm{lg}$ ) and record it in a structured food diary. The food records were converted into intake of total energy and water with a computer program based on food tables (Becel Nutrition Program, Nederlandse Unilever Bedrijven B.V., Rotterdam, Netherlands, 1988).

The amount of metabolic water was estimated from protein, fat and carbohydrate intake derived from the 7-day food record and from the change in body mass. Oxidation of protein yields $0.41 \mathrm{ml}$ water $/ \mathrm{g}$, fat $1.07 \mathrm{ml} / \mathrm{g}$ and carbohydrate $0.6 \mathrm{ml} / \mathrm{g}$ (11). A change in body mass of $1 \mathrm{~kg}$ was assumed to be a change of $0.75 \mathrm{~kg}$ fat mass and $0.25 \mathrm{~kg}$ fat free mass (fat mass being pure fat and fat free mass being $73 \%$ water and $27 \%$ protein) (38).

\section{Energy expenditure}

Energy expenditure was estimated from measured resting metabolic rate (RMR) and physical activity (PA). Resting metabolic rate was measured by means of an open circuit ventilated hood system, in the morning in a fasting state while lying for $30 \mathrm{~min}$ in a supine position. Gas analyses were performed by a paramagnetic oxygen analyser and an infrared carbon dioxide analyser (Servomex type 500A; Crowborough, Sussex, UK), similar to the analysis system described by Schoffelen et al. (26). Weir's formulas were used for calculating RMR (35).

Physical activity was registered with a triaxial accelerometer for movement registration (Tracmor, Philips Research, Eindhoven, The Netherlands). The Tracmor was an improved version (same principle, but smaller $7 \times 2 \times 0.8 \mathrm{~cm}$ ) of the Tracmor used in previous studies (6). In short, the Tracmor measures accelerations in the anteroposterior, medio-lateral and vertical directions. The Tracmor has been validated against doubly labelled water. The Tracmor output explained $64 \%$ of the variation in the average daily metabolic rate adjusted for sleeping metabolic rate with a standard error of estimate of $0.9 \mathrm{MJ} /$ day (37). Subjects wore the Tracmor in a waist belt at the low back during waking hours and recorded the times when they got up, put the Tracmor on and off, and when they went to bed. The registered accelerations in counts/min were used as an objective measure for the physical activity level of each subject.

\section{Water loss}

Water loss over the recording week was measured with the deuterium elimination method (11). Subjects drank a deuterium $\left({ }^{2} \mathrm{H}_{2} \mathrm{O}\right)$ dilution $(70 \mathrm{~g}$ water with an enrichment of 5 atom percentage excess ${ }^{2} \mathrm{H}$ ) after voiding (baseline urine sample) the evening before the start of the recording week. Elimination was calculated from two urine samples directly after dosing (at day 1 in the morning and evening) and two at the end of the observation period (day 7 in the evening, day 8 in the morning). Deuterium content was measured in urine samples with an isotope ratio mass 
spectrometer (40). Water loss was calculated from ${ }^{2} \mathrm{H}$ elimination with the equation of Fjeld et al. (11), as described previously (39).

\section{Questionnaire}

At the end of the recording week subjects filled in a questionnaire about their experiences with food recording to determine if they always weighed and recorded their food intake and if they changed habitual food intake.

\section{Statistics}

Twenty-seven subjects participated in the first part of the study, of whom eighteen also participated in the second part of the study. Of the other nine subjects, one was pregnant during the second period of measurements, three subjects went abroad and five subjects found it too much of a burden to follow the protocol twice. There were no significant differences in body mass changes, body mass index, age, energy intake and resting metabolic rate, and percentage discrepancy between water intake and loss in the first part of the study, among the 5 subjects who did not want to participate twice and the other 22 subjects (ANOVA, $P>0.05$; data not shown). Also, no differences were found between the nine subjects who participated only once and the 18 subjects who participated twice (ANOVA, $\mathrm{P}>0.05$ ). The results presented here, therefore, are from the 18 subjects who followed the protocol twice. Mean values and standard deviations were calculated from the results of both parts of the study.

A one way repeated-measures ANOVA and a Scheffé test (post-hoc) were used to compare the three measurements of body mass on a within subject basis. The changes in body mass were compared with a paired t-test (two-sided). A factorial ANOVA test was used to measure the influence of the phase of the menstrual cycle on the body mass changes.

Measurements of RMR at the start and end of the recording week were compared with a paired t-test (two-sided) and means were calculated if both measurements did not differ significantly from each other.

RMR, PA and body mass changes are all independent measures for energy metabolism. Multiple and simple regression analyses were used to assess the contribution of these independent variables to reported energy intake. Results of both reporting weeks were compared with each other with a paired t-test (two-sided).

Significance was reached when $\mathrm{P}<0.05$. The StatView SE+ (1988, Abacus Concepts, Berkeley, CA, USA) was used for statistical analysis.

\section{Results}

\section{Part one of the study}

The mean results of the three body mass measurements were, in sequence of time, $59.5 \pm 7.1,59.7 \pm 7.1$ and $59.2 \pm 6.9 \mathrm{~kg}$. The last mean body mass differed significantly from the first two measurements $(P=0.03)$. Mean body mass changes over the nonrecording and recording week (table 3.1$)$ differed significantly $(\mathrm{P}=0.04)$. Subjects in the pre-ovulation period $(n=13)$ had a body mass change over the recording week of $0.67 \pm 0.78 \mathrm{~kg}$ and subjects in the post-ovulation period $(\mathrm{n}=5)$ had a body mass change of $0.14 \div 0.55 \mathrm{~kg}(\mathrm{P}=0.02)$. 
Table 3.1: Reported intake of energy, resting metabolic rate, physical activity counts and body mass changes of the first recording week (part one) and of the second recording week ${ }^{\ddagger}$ (part two) (Values are means and standard deviations for eighteen subjects)

\begin{tabular}{|c|c|c|c|c|}
\hline & \multicolumn{2}{|c|}{ Part one of the study } & \multicolumn{2}{|c|}{ Part two of the study } \\
\hline & Mean \pm SD & (ranges) & Mean \pm SD & (ranges) \\
\hline Energy intake (MJ/d) ${ }^{5}$ & $8.5 \pm 1.2$ & $(6.8-11.9)$ & $9.4^{\circ} \pm 1.4$ & $(7.1-12.1)$ \\
\hline Resting metabolic rate (MJ/d) & $5.9 \pm 0.4$ & $(5.3-6.4)$ & $6.0 \pm 0.5$ & $(4.9-6.7)$ \\
\hline Physical activity (counts/min) & $158 \pm 69$ & $(90-315)$ & $114 \pm 42$ & $(61-198)$ \\
\hline $\begin{array}{l}\text { Body mass change over } \\
\text { non-recording week }(\mathrm{kg})\end{array}$ & $0.14 \pm 0.67$ & $(-0.96-1.73)$ & $-0.23 \pm 0.49$ & $(-1.0-0.90)$ \\
\hline $\begin{array}{l}\text { Body mass change over } \\
\text { recording week }(\mathrm{kg})\end{array}$ & $-0.45^{\prime \prime} \pm 0.69$ & $(-1.42-0.93)$ & $-0.15 \pm 0.59$ & $(-1.15-0.95)$ \\
\hline Total water intake $(\mathrm{l} / \mathrm{d})$ & $2.8 \pm 0.8$ & $(1.7-5.4)$ & $2.9 \pm 0.8$ & $(1.9-5.7)$ \\
\hline Total water loss $(1 / d)$ & $3.1 \pm 0.8$ & $(2,0-5,7)$ & $3.0 \pm 0.9$ & $(2.1-5.9)$ \\
\hline
\end{tabular}

The second recording week was after subjects were confronted with the results of the first food recording week.

${ }^{5}$ Values are means based on 7 day food diaries of 18 female subjects and ranges refer to differences among subjects.

Mean value was significantly different from that in part one of the study: $P<0.04$.

"Mean value was significantly different from that in the non-recording week: $P<0.04$

The mean body mass loss of $0.45 \pm 0.69 \mathrm{~kg}$ over the recording week, which implied undereating, represented $13.4 \pm 20.7 \mathrm{MJ}$ [ $1 \mathrm{~kg}$ body mass was assumed to be equivalent to $30 \mathrm{MJ}(38)$ ] or $1.9 \pm 3.0 \mathrm{MJ} / \mathrm{d}$. The undereating amounted to $12 \pm 30 \%$ of the energy requirement calculated as energy intake plus the energy equivalent of the body mass loss. Reported water intake plus metabolic water was closely correlated with measured water loss $(r=0.98, P=0.0001)$, indicating a high recording precision. The difference between water loss and total water intake was not related to the average of water loss and intake $\left(\mathrm{r}^{2}=0.08, \mathrm{P}=0.27\right)(1)$. The relative bias (the average of the difference between water loss and intake) was $0.32 \mathrm{~V} / \mathrm{d}$ and the estimate of error (SD of the difference) was $0.16 \mathrm{l} / \mathrm{d}$. The relative bias of $0.32 \mathrm{l} / \mathrm{d}$ was significantly different from zero (see Discussion). The answers on the questionnaire subjects filled in at the end of the recording week indicated that subjects did not change their food pattern during the recording week. However, weighing and recording food intake for seven days was experienced as quite a burden.

\section{l'art two of the siudy}

In the second part of the study, the results of the three body mass measurements were, in sequence of time, $60.0 \pm 6.8,59.8 \pm 6.6$ and $59.6 \pm 6.5 \mathrm{~kg}$. The last mean body mass differed significantly from the first measurement $(\mathrm{P}=0.02)$. Body mass changes over the non-recording week and recording week (both independent of the phase of the menstrual cycle) did not differ significantly from each other and did not differ from zero ( $\mathrm{P}=0.7$, table 3.1 ).

Mean daily energy intake was $9.4 \pm 1.4 \mathrm{MJ}$ (table 3.1 ) and was $0.8 \pm 1.2 \mathrm{MJ}$ higher than the reported energy intake in part one of the study $(\mathrm{P}=0.04)$. The higher energy intake of $11 \pm 17 \%$ of reported energy intake of the first part, was not due to a higher physical activity in part two of the study. Physical activity was lower in part two compared with part one of the study $(\mathrm{P}=0.01)$. The higher energy intake in part two was related to the change in body mass of the first part (figure 3.1). This was a negative relationship; from the subjects who lost body mass in the first part of the study, those who lost most 
body mass showed the largest increase in energy intake. This relation remained significant when data from the five subjects who gained body mass in the first part of the study were excluded. All, except one subject, increased their energy intake (relative to part one). Subjects who gained weight in the first part of the study showed a small increase in energy intake $(n=4)$ or decrease in energy intake $(n=1)$ in part two. The subject who had an increase of about $75 \%$ in energy intake in the second part of the study relative to the first part of the study overrecorded her food intake (see below). Excluding these data did not change the correlation between the $\%$ extra energy intake and change in body mass over the first recording week.

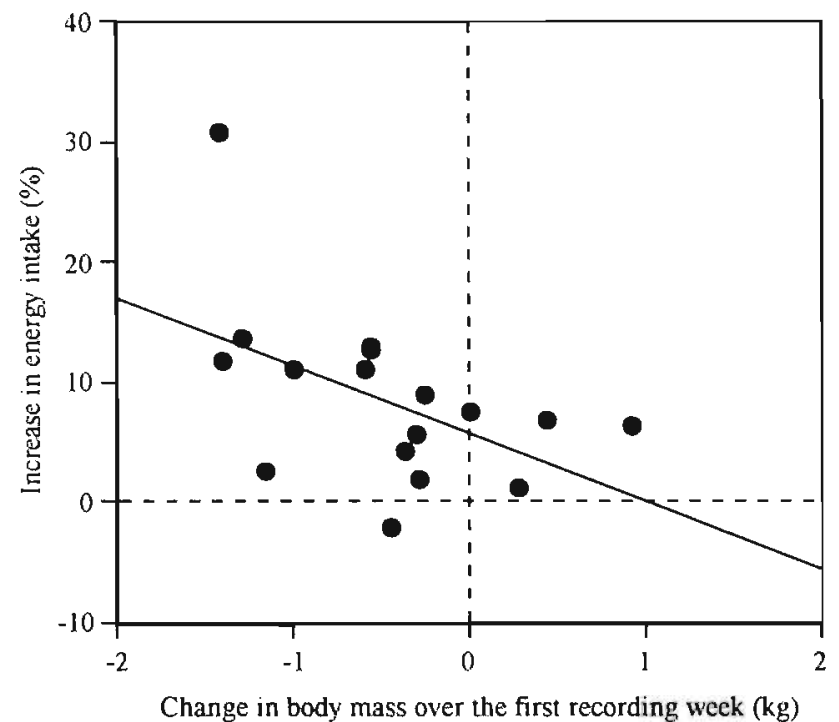

Figure 3. 1: Improved reporting of food intake after confrontation with earlier results on food reporting: the relationship between the change in body mass during the first food recording week (part one) and the percentage increase in energy intake in the second food recording week (part two) compared with the first (part one) $(r=-0.51, p=0.04)$

Measured water loss was fully explained by reported water intake and the amount of metabolic water $(\mathrm{r}=0.98 ; \mathrm{P}=0.0001)$. There was no difference $(\mathrm{P}=0.09)$ between water loss $(3.0 \pm 0.9 \mathrm{~V} / \mathrm{d})$ and water intake $(2.9 \pm 0.8 \mathrm{~V} / \mathrm{d})$, so the reporting of water intake was done very accurately. However, 2 subjects had a discrepancy between water intake (reported intake + metabolic water) and water loss of more than $10 \%$ of water loss. One subject over- and one subject underrecorded the water intake (and thus the food intake). These two subjects have been excluded from the regression analysis on energy intake, because of the over (/under)-recording, as their energy intake could not be explained by measures of energy. Energy intake was explained by resting metabolic rate $(\mathrm{P}=0.01)$, physical activity $(\mathrm{P}=0.03)$ and the change in body mass over the recording week $(\mathrm{P}=0.05$, table 3.2$)$. Resting metabolic rate and physical activity were independently related to energy intake. In a simple regression analysis the change in body mass was not related to energy intake. 
Table 3.2. The attribution of resting metabolic rate, physical activity and the change in body mass over the recording week to energy intake in a simple and in a multiple regression analysis on energy intake (part two of the study, $\mathrm{n}=16$ ).

\begin{tabular}{lcc}
\hline Energy intake & Explained variation (\%) & $\mathrm{P}=$ \\
\hline Resting metabolic rate (RMR) & 37 & 0.01 \\
Physical activity (PA) & 24 & 0.05 \\
$\Delta$ Body mass & 17 & 0.1 \\
RMR + PA $+\Delta$ body mass* & 66 & 0.004 \\
\hline * Multiple regression equation: Energy intake $(\mathrm{kJ} / \mathrm{d})=-738+1.46 \cdot \mathrm{RMR}(\mathrm{kJ} / \mathrm{d})+12.8 \cdot \mathrm{PA}$ \\
(counts/min) $+720 \cdot \Delta$ body mass $(\mathrm{kg} / \mathrm{wk})$.
\end{tabular}

Subjects did not change their food pattern during the recording week, according to their answers on the questionnaire. Subjects $(50 \%)$ subjects answered that the confrontation with the results of the first recording week made them more careful to maintain their habitual food pattern. The higher energy intake in the second part of the study was due to a higher carbohydrate (part one: $250 \mathrm{~g}$ vs. part two: $275 \mathrm{~g}, \mathrm{P}=0.03$ ) and fat intake (part one: $73 \mathrm{~g}$ vs. part two $83 \mathrm{~g}, \mathrm{P}=0.02$ ). Subjects ate less carbohydrate- and fat-containing foodstuffs during the first recording week than during the second recording week.

\section{Discussion}

This present study is, to our knowledge, the first attempt to improve the reporting of habitual food intake. Subjects showed $12 \%$ underreporting of food intake at the first time of food recording, which could be fully explained by undereating. Individual confrontation with this phenomenon improved the reporting of habitual food intake the second time. Information about the sort of errors made (e.g., undereating and/or underrecording) helped subjects to improve the reporting of habitual food intake. In most studies subjects receive instructions on weighing and recording food intake. A few studies $(23,28,29,33)$ also mentioned explicitly that subjects were instructed not to lose or gain weight during the recording period. The instructions provided to the subjects in the first part of this study were not very different from other studies. Subjects were informed about the aim of the study, and were asked not to change their activity-, eating- and behaviour patterns during the food recording interval. The instructions were obviously not sufficient to avoid underreporting of food intake in the present study and in earlier studies. Subjects changed their food intake in the first part of the study, probably unconsciously, according to the answers on the questionnaire. Confronting subjects with their own behaviour on food reporting seems to be a way to get reliable data on habitual food intake. There was a direct relationship between the change in body mass over the recording week in part one of the study and the increase in energy intake in part two compared with part one of the study. The more subjects lost weight in the first part of the study, the more they ate in the second part of the study. The answers subjects gave to the questionnaire after the second recording period revealed that fifty per cent of all the subjects did notice that they ate more during the second recording period. They answered that they improved the reporting of habitual food intake this time. 
The improvement in the reporting of habitual food intake could have been a learning effect rather than a confrontation effect. However, in another study with subjects before and after a training intervention they found no underreporting of food intake before the intervention and a $19 \%$ underreporting after the intervention. The reporting of food intake several times was perceived as quite a burden by the subjects and this probably caused the underreporting the second time (36). In the case of a learning effect, the reporting of the food intake should have been improved and this was not the case. The dieticians in this study were familiar with reporting of food intake and a learning effect would not be very likely.

In the first part of the study, three out of the five women in the post-ovulation phase showed an increase in body mass over the recording week (for women in the preovulation phase this was 2 out of the 13 women). In the post-ovulation period progesterone, a general metabolic stimulant, is increased. However, the consequent increase in energy intake and expenditure is at the same magnitude and subjects remain in energy balance (7). The higher body mass during the post-ovulation period is probably due to water retention. Body mass declines again before the onset of the menses and is stable during the pre-ovulation period $(7,12,19,31,34)$. Thus, the body mass loss of the women in the pre-ovulation period and of the two post-menopausal women seen in this study can only be explained by undereating.

The recording of food intake was done accurately in both parts of the study. The small shortage in water intake compared to water loss in part one was also seen in other studies that measured the water balance $(13,39,40)$. This small shortage might be due to underestimation of the amount of calculated metabolic water. The amount of metabolic water was calculated from the carbohydrate, fat and protein intakes derived from the 7 day food record and from the change in body mass (part one of the study). In part two of the study there was no significant difference between water loss and intake. Subjects had no change in body mass over the recording week this time and probably weighed and recorded their food intake even more accurately than the first time. However, there were two subjects who had a difference of more than $10 \%$ between water intake and loss. Their food intake could not be explained by measures of energy metabolism (e.g., RMR, PA, change in body mass), because of under- or overrecording of the food intake. Water loss, as an indicator of recording precision, could discriminate the under- or overrecorders of food intake from the accurate recorders of food intake.

A good recording of water intake does not necessarily imply that the same holds for the recording of food intake. However, most foodstuffs contain a certain amount of water; therefore, it was concluded that the food recording was also done accurately. In a recent study by Poppitt et al. selective underreporting of snacks was found by obese and non-obese women in a metabolic facility. The women stayed for 24-hour in a metabolic facility and had ad libitum food intake (which was covertly measured). The next day subjects had to write down what they ate and drank the previous 24-hour. Food items eaten during a meal were reported well, but the between-meal snack foods were underreported. The snacks provided were mostly carbohydrate-rich and they found selective underreporting of carbohydrate (21). Measurements of 24-hour food intake in a metabolic facility are difficult to compare with a 7-day weighed food record. This latter method does not rely on the memory of subjects. It is less likely to cause omission of recording the various snacks consumed between the meals, unless 
recording is delayed. Still, selective underrecording of foods might introduce a small error in the measurement of total water intake and thus in the measurement of underrecording.

In conclusion, the significant body mass loss over the recording week indicated undereating. The measured water balance showed no sign of underrecording. In the first part of the study the underreporting of food intake was fully explained by undereating. After confrontation with these results the subjects were able to improve the reporting of food intake. There was no significant body mass loss over the second recording week and water balance was stable. Physical activity was decreased, but energy intake was significantly higher than found in the first recording. Measurements of energy- and water balance to detect underreporting, undereating and underrecording can be used as key information to inform subjects about their way of food reporting. The lean, motivated women in this study were, with this information, able to improve the reporting of habitual food intake.

\section{References}

1. Altman. DG. and Bland, JM. Measurement in medicine: the analysis of method comparison studies. Statistician 32: 307-317. 1983.

2. Bandini, LG. Cyr, H, Must, A, and Dietz, WH. Validity of reported energy intake in preadolescent girls. Am J Clin Nutr 65: 1138S-1141S, 1997.

3. Bandini, LG, Schoeller, DA, Cyr, HN, and Dietz, WH. Validity of reported energy intake in obese and nonobsse adolescents. Am J Clin Nutr 52: 421-425, 1990

4. Black, AE, Bingham, SA, Johansson, G, and Coward. WA. Validation of dietary intakes of protein and energy against 24 hour urinary $N$ and DLW energy expenditure in middle-aged women. retired men and post-obese subjects: comparisons with validation against presumed energy requirements. Eur J Clin Nutr 51: 405-413, 1997.

5. Black, AE, Prentice, AM, Goldberg, GR, Jebb, SA, Bingham, SA, Livingstone, MB, and Coward, WA. Measurements of total energy expenditure provide insights into the validity of dietary measurements of energy intake. J Am Diet Assoc 93: 572-579. 1993.

6. Bouten, C. Verboeket-van de Venne, W, Westerterp, K, Verduin, M, and Janssen, J. Daily physical activity assessment: comparison between movement registration and doubly labeled water. J Appl Physiol 81: 1019-1026, 1996.

7. Buffenstein, R. Poppitt, SD, McDevitt, M, and Prentice, AM. Food intake and the menstrual cycle a retrospective analysis, with implications for appetite research. Physiol Behav 58: 1067-1077. 1995.

8. Buhl, KM, Gallagher, D, Hoy, K, Matthews, DE, and Heymsfield, SB. Uncxplained disturbance in body weight regulation: diagnostic outcome assessed by doubly labeled water and body composition analyses in obese patients reporting low energy intakes. J Am Diet Assoc 95: 1393 1400, 1995

9. Davies, PSW, Coward, WA, Gregory, J, White, A, and Mills, A. Total energy expenditure and energy intake in the pre-school child: a comparison. Br J Nutr 72: 13-20, 1994.

10. Edwards, JE, Lindeman, AK, Mikesky, AE, and Stager, JM. Energy balance in highly trained female endurance runners. Med Sci Sports Exerc 25: 1398-1404, 1993.

11. Fjeld, CR, Brown, KH, and Schoeller, DA. Validation of the deutcrium oxide method for measuring average daily milk intake in infants. Am J Clin Nutr 48: 671-674. 1988.

12. Gong. EJ, Garrel, D. and Calloway, DH. Menstrual cycle and voluntary tood intake. Am J Clin Nutr 49: 252-258, 1989

13. Goris, AHC, and Westerterp, KR. Underreporting of habitual food explained by undercating in motivated lean women. J Nutr 129: 878-882, 1999. 
14. Kempen, KP, Saris, WH, and Westerterp, KR. Energy balance during an 8-wk energy-restricted diet with and without exercise in obese women. Am J Clin Nutr 62: 722-729, 1995.

15. Lichtman, SW, Pisarska, K, Raynes Berman, E, Pestone, M, Dowling, H, Offenbacher, E, Weisel, H, Heshka, S, Matthews, DE, and Heymsfield, SB. Discrepancy between self-reported and actual caloric intake and exercise in obese subjects. N Engl J Med 327: 1893-1898, 1992.

16. Livingstone, MBE, Prentice, AM, Coward, WA, Strain, JJ, Black, AE, Davies, PSW, Stewart, CM, McKenna, PG, and Whitehead, RG. Validation of estimates of energy intake by weighed dietary record and diet history in children and adolescents. Am J Clin Nutr 56: 29-35, 1992.

17. Livingstone, MBE, Prentice, AM, Strain, JJ, Coward, WA, Black, AE, Barker, ME, McKenna, PG, and Whitehead, RG. Accuracy of weighed dietary records in studies of diet and health. $\mathrm{Br}$ Med J 300: 708-712, 1990.

18. Martin, LJ, Su, W, Jones, PJ, Lockwood, GA, Tritchler, DL, and Boyd, NF. Comparison of energy intakes determined by food records and doubly labeled water in women participating in a dietary-intervention trial. Am J Clin Nutr 63: 483-490, 1996.

19. Meijer, GA, Westerterp, KR, Saris, WH, and ten Hoor, F. Slecping metabolic rate in relation to body composition and the menstrual cycle. Am J Clin Nutr 55: 637-640, 1992.

20. Pannemans, DL, and Westerterp, KR. Estimation of energy intake to fecd subjects at energy balance as verified with doubly labelled water: a study in the elderly. Eur J Clin Nutr 47: 490-496, 1993.

21. Poppitt, SD, Swann, D, Black, AE, and Prentice. AM. Assessment of selective under-reporting of food intake by both obese and non-obese women in a metabolic facility. Int J Obes 22: 303-311, 1998

22. Prentice, AM, Black. AE, Coward, WA, Davies, HL, Goldberg, GR, Murgatroyd, PR, Ashford, J, Sawyer, $\mathrm{M}$, and Whitehead. RG. High levels of energy expenditure in obese women. $\mathrm{Br}$ Med $\mathrm{J}$ 292: 983-987, 1986.

23. Sawaya, AL, Tucker, K, Tsay, R, Willett, W, Saltzman, E, Dallal, GE, and Roberts, SB. Evaluation of four methods for determining energy intake in young and older women: comparison with doubly labeled water measurements of total energy expenditure. Am J Clin Nutr 63: 491-499. 1996

24. Schoeller. DA. How accurate is self-reported dietary energy intake"? Nutr Rev 48: 373-379, 1990

25. Schoeller, DA. Bandini. LG, and Dietz, WH. Inaccuracies in self-reported intake identified by comparison with the doubly labelled water method. Can J Physiol Pharmacol 68: 941-949, 1990.

26. Schoffelen, PFM. Westerterp. KR. Saris, WHM, and Hoor ten, F. A dual-respiration chamber system with automated calibration. J Appl Physiol 83: 2064-2072, 1997.

27. Schulz, S, Westerterp, KR, and Bruck, K. Comparison of energy expenditure by the doubly labeled water technique with energy intake, heart rate, and activity recording in man. Am J Clin Nutr 49: 1146-1154, 1989

28. Seale, JL. Energy expenditure measurements in relation to energy requirements. Am J Clin Nutr 62: 1042S-1046S, 1995.

29. Seale, JL, and Rumpler. WV. Comparison of energy expenditure measurements by diet records, energy intake balance. doubly labeled water and room calorimetry. Eur J Clin Nutr 51: 856-863, 1997

30. Sjödin, AM, Andersson, AB, Hogberg. JM, and Westerterp, KR. Energy balance in eross-country skiers: a study using doubly labeled water. Med Sci Sports Exerc 26: 720-724, 1994.

31. Tarasuk, V, and Beaton. GH. Menstrual-cycle patterns in energy and macronutrient intake. Am J Clin Nutr 53. 442-447. |09)1.

32. Velthuis-tc Wicrik. EJ. Westurterp. KR and van den Berg, H. Impact of a moderately energyrestricted diet on encrgy metabolism and body composition in non-obese men. Int $\mathrm{J}$ Obes Relat Mctab Disord 19: 318-324, 1465.

33. Vries. JHMd. Zock, PL. Mensink, RP. and Katan. MB. Underestimation of energy intake by 3-d records compared with energy intake to maintain body weight in 269 nonobese adults. Am J Clin Nutr 60: 855-860, 1994.

34. Webb, P. 24-hour energy expenditure and the menstrual cycle. Am J Clin Nutr 44: 614-619, 1986.

35. Weir, JBd. New methods for calculating metabolic rate with special reference to protein metabolism. J Physiol 109: 1-9, 1949. 
36. Westerterp, K, Verboeket-van de Venne, W, Meijer, G, and ten Hoor, F. Self-reported intake as a measure for energy intake. A validation against doubly labelled water. Obes Eur 91: 17-22, 1991.

37. Westerterp, KR, and Bouten, CVC. Physical activity assessment: comparison between movement registration and doubly labeled water method. Z Emahrungswiss 36: 263-267, 1997.

38. Westerterp, KR, Donkers, JH, Fredrix, EW, and Boekhoudt, P. Energy intake, physical activity and body weight: a simulation model. Br J Nutr 73: 337-347, 1995.

39. Westerterp, KR, Kayser, B, Brouns, F, Herry, JP, and Saris, WH. Energy expenditure climbing Mt. Everest. J Appl Physiol 73: 1815-1819, 1992.

40. Westerterp, KR, Robach, P, Wouters, L, and Richalet, JP. Water balance and acute mountain sickness before and after arrival at high altitude of 4,350 m. J Appl Physiol 80: 1968-1972, 1996. 
Chapter 4

Undereating and underrecording of habitual food intake in obese men: selective under-reporting of fat intake

Annelies HC Goris, Margriet S Westerterp-Plantenga, Klaas R Westerterp Department of Human Biology, Maastricht University, The Netherlands

Published in: American Journal of Clinical Nutrition 2000: 71: 130-134. 


\section{Abstract}

Underreporting of food intake is common in obese subjects. One aim of this study was to assess to what extent underreporting by obese men is explained by underrecording (failure to record in a food diary everything that is consumed) or undereating. Another aim of the study was to find out whether there was an indication for selective underreporting. Subjects were 30 obese men with a mean ( \pm SD) body mass index (in $\mathrm{kg} / \mathrm{m}^{2}$ ) of $34 \pm 4$. Total food intake was measured over one week. Energy expenditure (EE) was measured with the doubly labelled water method and water loss was estimated with deuterium labelled water. Energy balance was checked for by measuring body weight at the start and end of the food recording week and one week after the recording week. Mean energy intake and EE were $10.4 \pm 2.5$ and $16.7 \pm 2.4$ $\mathrm{MJ} /$ day, respectively; underreporting was $37 \pm 16 \%$. The mean body mass loss of $1.0 \pm 1.3 \mathrm{~kg}$ over the recording week was significantly different $(\mathrm{P}<0.05)$ from the change in body mass over the non-recording week, and indicated a $26 \%$ undereating. Water intake (reported + metabolic water) and water loss were significantly different from each other and indicated $12 \%$ underrecording. The reported percentage of energy from fat was a function of the level of underreporting: percentage of energy from fat $=$ $46-0.2 \times \%$ ounderreporting $\left(\mathrm{r}^{2}=0.28 ; \mathrm{P}=0.003\right)$. Total underreporting by the obese men was explained by underrecording and undereating. The obese men selectively underreported fat intake.

\section{Introduction}

In many western societies, the prevalence of obesity has increased (26) and the relatively high energy intakes might be partly due to a high fat intake (34). However, food intake is hard to measure, especially in obese subjects $(22,26)$. Discrepancies between reported energy intakes and measured energy expenditures (with the doubly labelled water method) of about $20-50 \%$ have been described in obese subjects $(3,7$, $14,15,21,24,25,27,30)$. The degree of underreporting is positively correlated with body mass index $(10,13,19,24,25,30)$. The aim of the present study was to assess whether this underreporting (i.e., a discrepancy between energy intake and expenditure) is also selective for macronutrients, meal types and snacks. A second aim of the study was to assess to what extent underreporting in obese subjects is explained by underrecording or undereating. We defined underrecording (the failure to record in a food diary everything that is consumed) as a discrepancy between reported energy intake and measured energy expenditure without a change in body mass; we defined undereating as the consumption of less than usual because of the requirement to record food intake, with a resultant decline in body mass (9). Compliance with food recording was checked with the water balance technique, as we described previously (9). Briefly, healthy subjects are in water balance. The recording of water intake appears to represent total food recording; thus, a recorded water intake below the measured water loss indicates the underrecording of water and food intakes (9). In an earlier study in a group of lean, motivated women, the underreporting of habitual food intake was entirely explained by undereating. Subjects changed their food patterns during the 
recording period (9). In obese subjects reporting their total food intake, underrecording and undereating have not yet been distinguished.

\section{Subjects and methods}

\section{Subjects}

Thirty obese men with a mean ( \pm SD) age of $44 \pm 7$ years and body mass index (in $\mathrm{kg} / \mathrm{m}^{2}$ ) of $34.1 \pm 3.9$ (range: $29.5-44.8$ ) participated in the study. Subjects were recruited by advertisements in a local newspaper and on local television for a weight-loss intervention study. The results presented are baseline measurements, made before the intervention started. The protocol was approved by the Medical Ethical Committee of the University of Maastricht.

\section{Protocol}

The study included a two week observation period for the measurement of energy expenditure. Food intake, water intake and water loss were measured over the first week. Energy balance was checked for by measuring body weight changes over each of the two weeks separately. Thus, possible weight fluctuations resulting because subjects consumed less when they had to record their food intake could be compared with normal weight fluctuations measured over a nonrecording week.

\section{Food and water intake}

Total food intake was estimated with use of a 7-day dietary record. Subjects received instructions from a dietician on how to keep a food record and were asked not to change their habitual food intakes. The data on the food records were used to calculate intakes of total energy, protein, fat, carbohydrate and water with a computer program based on food tables (Becel Nutrition Program, 1988; Nederlandse Unilever Bedrijven BV, Rotterdam, Netherlands) (28). Total water intake was calculated from reported food and water intakes and the calculated amount of metabolic water. The amount of metabolic water was calculated by multiplying energy expenditure by the percentages of energy from protein, fat and carbohydrate (from the 7-day food record). Oxidation water is $0.41 \mathrm{ml} / \mathrm{g}$ for protein, $1.07 \mathrm{ml} / \mathrm{g}$ for fat and $0.6 \mathrm{ml} / \mathrm{g}$ for carbohydrate (8).

\section{Energy expenditure and water loss}

Energy expenditure was measured with the doubly labelled water method according to Westerterp et al. (33). Water loss was calculated from the deuterium elimination as included in the doubly labelled water method.

Subjects were given, on the evening of day 0 , a weighed dose of a mixture of 99.84 atom $\%{ }^{2} \mathrm{H}_{2} \mathrm{O}$ in 10.05 atom $\% \mathrm{H}_{2}{ }^{18} \mathrm{O}$, such that baseline levels were increased to $\geq 150$ ppm for ${ }^{2} \mathrm{H}$ and $\geq 300 \mathrm{ppm}$ for ${ }^{18} \mathrm{O}$. A background urine sample was collected on the evening of day 0 . Additional urine samples were collected on day 1 (from the second void) on the evening of day 1 , the morning and evening of day 8 , and the morning and evening of day 15 . 


\section{Body mass:}

Body mass was measured 3 times at 7 day intervals. Subjects were weighed (in underwear) in the morning, before any food or beverage consumption and after voiding, on a digital balance accurate to $0.1 \mathrm{~kg}$ (Seca, Almere, Netherlands). Body composition was determined by underwater weighing as described elsewhere (32).

\section{Statistics:}

The results are presented as means \pm SDs for 30 subjects. Simple regression analyses were performed for energy intake and expenditure and water intake and loss. A onefactor analysis of variance for repeated measures and a post hoc Scheffé test were used to compare the three measurements of body mass. Changes in body mass were compared with a paired t-test.

Underreporting, underrecording were calculated as follows:

Underreporting $=[($ Energy intake - Energy expenditure $) /($ Energy expenditure $)]{ }^{*} 100 \%$. Underrecording $=[($ Water intake - water loss $) /($ Water loss $)] * 100 \%$.

Undereating $=[($ Body mass change recording week * $30 \mathrm{MJ} / 7$ days $) /($ Energy expenditure) $]^{*} 100 \%$, where $1 \mathrm{~kg}$ body mass was assumed to be equivalent to $30 \mathrm{MJ}$ (31).

Simple regression analyses were also conducted by using the percentage of underreporting and reported percentages of energy from protein, fat and carbohydrate to determine whether there was selective underreporting. Calculations of the percentages of energy from protein, fat and carbohydrate included the amount of energy derived from alcohol. Significance was set at $\mathrm{P}<0.05$. The StatView SE+ $(1988$, Abacus (oncepts, Inc., Berkeley, CA, USA) was used for the statistical analysis.

\section{Results}

Reported food intake and measured energy expenditure are presented in table 4.1. Most subjects had a reported energy intake below the measured energy expenditure. Only one subject had a reported energy intake within $10 \%$ of the measured energy expenditure. The average percentage underreporting was $37 \pm 16 \%$ in this group. There was no relation between the reported energy intake and the measured energy expenditure $\left(r^{2}=0.05, P=0.2\right.$; simple regression analysis $)$.

Table 4.1: Reported food intake and measured energy expenditure and water loss.

\begin{tabular}{llll}
\hline $\mathrm{n}=30$ & mean & \pm & $\mathrm{SD}$ \\
\hline Energy intake $(\mathrm{MJ} / \mathrm{d})$ & 10.4 & \pm & 2.5 \\
Energy expenditure $(\mathrm{MJ} / \mathrm{d})$ & 16.7 & \pm & 2.4 \\
Body mass change in non-recording week $(\mathrm{kg} / \mathrm{wk})$ & 0.0 & \pm & 1.0 \\
Body mass change in recording wcek $(\mathrm{kg} / \mathrm{wk})$ & -1.0 & \pm & 1.3 \\
Recorded water intake (L/d) & 2.8 & \pm & 0.9 \\
Recorded + metabolic water intake $(\mathrm{L} / \mathrm{d})$ & 3.3 & \pm & 0.9 \\
Water loss (L/d) & 3.7 & \pm & 0.5 \\
\hline
\end{tabular}

The three body mass measurements were, in sequence of time, 108.8 \pm 14.7 , $108.1 \pm 14.7$ and $107.7 \pm 14.8 \mathrm{~kg}$. The first body mass measurement differed significantly from the last two measurements $(P=0.0001$, one-factor analysis of 
variance and a post hoc Scheffe test). Changes in body mass over the non-recording and recording weeks also differed significantly ( $\mathrm{P}=0.02$, paired $t$-test; table 4.1 ). The percentage of undereating, based on the body mass change over the recording week, was $26 \pm 33 \%$.

Fifty-five percent of the variation in total water intake (recorded + metabolic) was explained by water loss (regression equation: total water intake $(L / d)=1.35 \mathrm{x}$ water loss $(\mathrm{L} / \mathrm{d})-1.7 ; \mathrm{P}=0.0001)$. The percentage of underrecording, based on the negative water balance, was $12 \pm 16 \%$.

The reported percentages of energy from protein [(-0.04 $\times \%$ underreporting $)+14.3$; $\left.\mathrm{r}^{2}=0.11, \mathrm{P}=0.07\right]$ and carbohydrate $\left(\mathrm{r}^{2}=0.1\right)$ were not significantly related to the percentage of underreporting (simple regression analysis). The reported percentage of energy from fat was related to the percentage of underreporting (figure 4.1). The intercept of the regression line, which indicates the percentage of energy from fat in the case of no underreporting, was $46 \%$ of energy from fat. The $95 \%$ confidence intervals for the adjusted $46 \%$ of energy from fat were $41 \%$ and $51 \%$. The mean reported percentage of energy from fat was $39 \pm 6 \%$. The reported percentages of energy from fat and carbohydrate were not significantly related to the percentage of undereating $\left[r^{2}=0.01(P=0.96)\right.$ and $r^{2}=0.0(P=0.9)$, respectively] or to the percentage of underrecording $\left[\mathrm{r}^{2}=0.01 \quad(\mathrm{P}=0.6)\right.$ and $\mathrm{r}^{2}=0.01 \quad(\mathrm{P}=0.6)$, respectively]. The reported percentage of energy from protein was positively related to the percentage of undereating $\left(r^{2}=0.22, P=0.009\right)$, but not to the percentage of underrecording $\left(r^{2}=0.03\right.$; $\mathrm{P}=0.4)$.

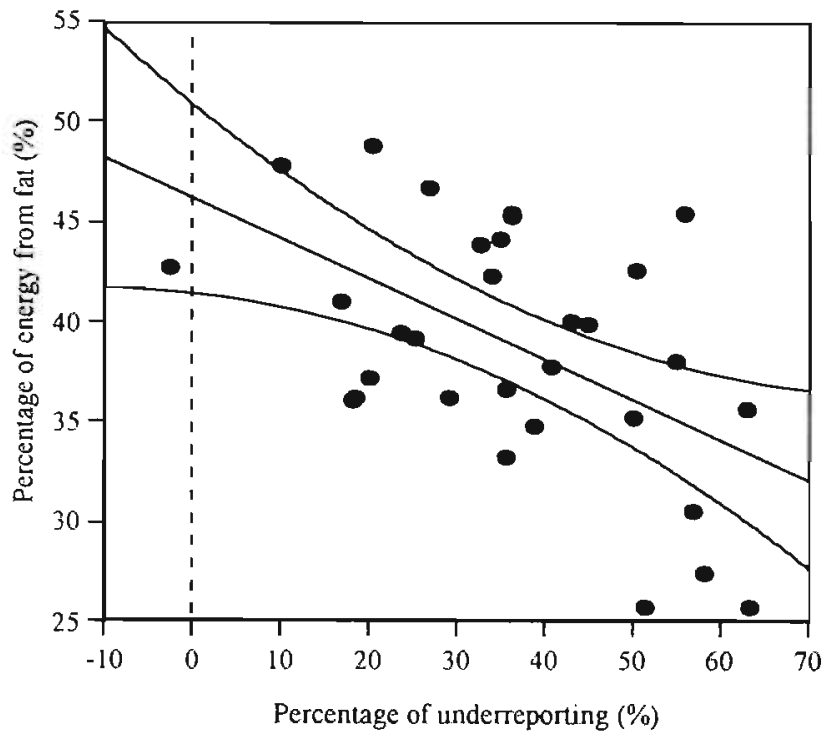

Figure 4.1: Pcrcentage of energy from fat (reported) as a function of the percentage of underreporting in obese men $(n=30)$. Linear regression line $\%$ encrgy from fat $=46-0.2 \times \%$ underreporting $\left(r^{2}=0.28, P=0.003\right)$. 
The reported percentages of energy from fat at the different meals were related to the percentages of underreporting (figure 4.2). The same relation was found for the reported percentages of energy from fat from the afternoon- and evening snacks ( simple regression analysis: $\mathrm{r}^{2}=0.12 ; \mathrm{r}^{2}=0.13$, respectively, $\mathrm{P}=0.05$ ). The results a simple regression analysis on reported energy intakes at the different meals and the percentage of underreporting are shown in table 4.2. The reported energy intakes at lunch, dinner and the evening snack were related to the total percentage of underreporting. The reported energy intake in the morning (breakfast and morning snack) was not significantly related to the total percentage of underreporting.

Table 4.2: Simple regression analysis of reported energy intakes at different meals (y) and the percentage of underreporting $(x)$ in 30 obese men.

\begin{tabular}{lcc}
\hline$y=$ & $\mathrm{r}$ & $\mathrm{p}$ \\
\hline Reported energy intake from breakfast & 0.19 & 0.3 \\
Reported energy intake from morning snack & 0.17 & 0.4 \\
Reported energy intake from lunch & 0.59 & 0.0006 \\
Reported energy intake from afternoon snack & 0.01 & 0.95 \\
Reported energy intake from dinner & 0.56 & 0.001 \\
Reported energy intake from evening snack. & 0.47 & 0.009 \\
\hline
\end{tabular}

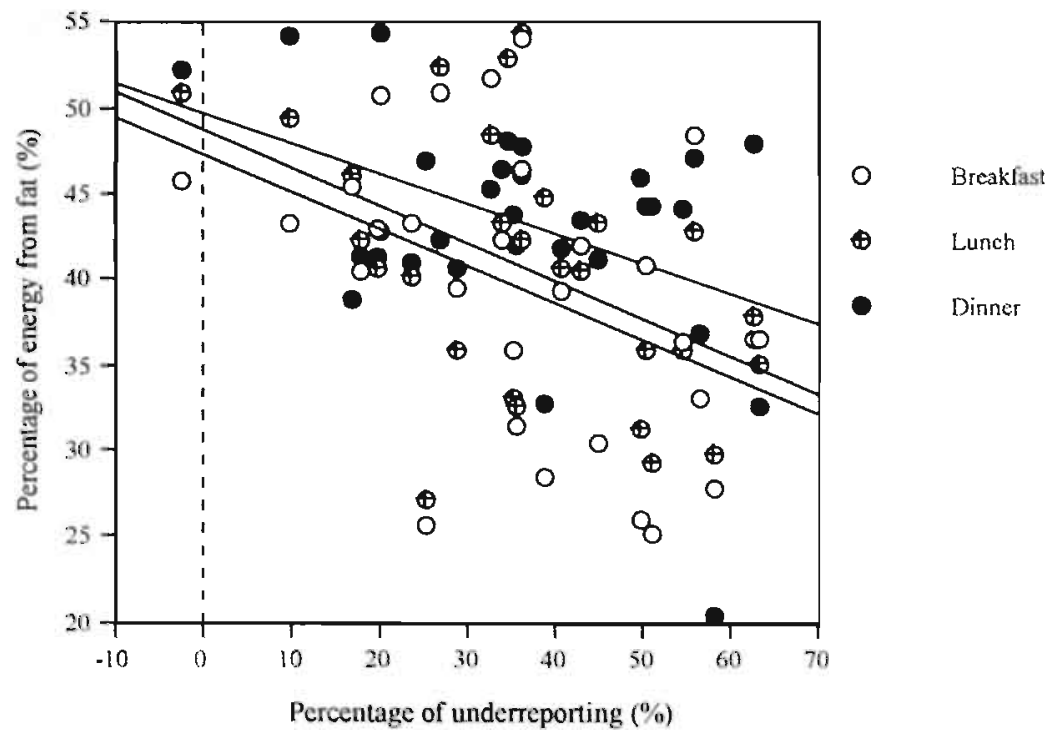

Figure 4.2: Percentage of energy from fat reported at breakfast, lunch and dinner as a function of the percentage of underreporting in obese men $(n=30)$. The linear regression lines are as follows: $\%$ energy from fat reported at breakfast $=46-0.2 \times \%$ underreporting $\left(r^{2}=0.19, P=0.02\right), \%$ energy from fat reported at lunch $=49-0.2 \times \%$ underreporting $\left(r^{2}=0.23, P=0.008\right)$, and $\%$ energy from fat reported at dinner $=50-0.2 \times \%$ underreporting $\left(r^{2}=0.19, P=0.02\right)$. 


\section{Discussion}

The results of this study showed a $37 \%$ underreporting by male obese subjects. The mean body mass loss over the recording week indicated $26 \%$ undereating and the discrepancy between total water intake and water loss indicated $12 \%$ underrecording. The recording of water does not necessarily represent the recording of food intake. However, most foodstuffs contain a certain amount of water; therefore, it was concluded that the underrecording of food intake was identical to the underrecording of water intake.

About $70 \%$ of the total underreporting was due to a diminished intake of food over the recording period. In an earlier study with lean women, total underreporting $(16 \%)$ was entirely explained by undereating (16). The present study also indicated that recording itself is a useful tool for losing body mass: $70 \%$ of the total amount of underreporting was undereating. The level of underreporting found in this study $(37 \%)$ was of the same magnitude as found in other studies of obese subjects $(3,7,14,15,21,24,25$, 27,30 ).

Besides this total underreporting of $37 \%$, there was also a selective underreporting of fat intake. The reported percentage of energy from fat was negatively correlated with the amount of underreporting, and, in the case of no underreporting, the percentage of energy from fat would be $46 \pm 5 \%$. The reported energy percentage from fat of $39 \pm 6 \%$ was relatively high (higher than the recommended dietary guidelines of $30-35 \%$ ), although not higher than that reported previously in a sample of 34 obese subjects partly controlled for underreporting (34). In a representative sample of the Dutch population $(n=2625)$ the average percentage of energy from fat, measured with a 2 day dietary record, was $40 \%$ for men (12). This value may have been underestimated because of the underreporting of food intake.

Selective underreporting of fat intake was also found in the study by Voss et al. (29), in which the percentage of energy from fat decreased with lower quintiles of the ratio of energy intake to basal metabolic rate. Food intake in this study was measured with a food frequency questionnaire, and energy expenditure was estimated from calculations of basal metabolic rate (with use of age and weight) and from the assessment of physical activity by using a questionnaire.

Lissner and Lindroos (17) compared reported intakes from two dietary assessment methods. Reported energy intakes differed with the two methods, but the various macronutrients did not. They concluded that there was no qualitative underreporting of food intake in obese men and women. Rutishauser (23) performed a similar analysis in lean and obese adults and found significantly different percentages of energy from fat and carbohydrate but no significant differences in reported energy intakes between the methods used. External validation was needed in those studies because dietary assessment methods are mostly subject to the same errors.

Specific information on the energy expenditure of subjects was available in our study and this made it possible to compare the reported percentages of energy from the macronutrients with an external validation, the percentage of underreporting. In a study by Heitmann and Lissner (10), reported intakes were compared with nitrogen loss and estimated energy expenditure in 323 men and women (lean and obese). The underreporting of protein was disproportional to the underreporting of energy, suggesting a selective underreporting of fat and carbohydrate-rich foods. The degree of 
obesity also influenced the dietary reporting both quantitatively and qualitatively (10). Livingstone et al. (18) suggested in their study that the underreporting of total food intake was explained by a selective underreporting of snacks. However, subjects who underreported total food intake did not report a significant lower snack intake. Further analysis to determine any selective underreporting were not done.

In a study by Poppitt et al. (20), non-obese women stayed for $24 \mathrm{hr}$ in a metabolic facility and had ad libitum food intake, which was covertly measured. The next day, subjects had to write down what they ate and drank the previous $24 \mathrm{hr}$. Food items eaten during a meal were reported accurately, but the between meal snacks foods were underreported. The snacks provided were mostly carbohydrate rich and there was a selective underreporting of carbohydrate, but not of fat and protein. In our study, there was no selective omission of snacks in the reporting of food intake. In general, the foods consumed in the morning (breakfast and morning snack) were reported accurately. Subjects reported the foods consumed at lunch, at dinner and in the evening less accurately (higher values of underreporting were associated with lower reported energy intakes at those meals). The reported percentages of energy from fat at the different meals were higher in subjects with a lower percentage of underreporting. Why would subjects selectively underreport their fat intakes? In general, 30\% underrecording of underreporting does not show a complete lack of compliance. Obese subjects might often consume energy-dense foods (foods with a high percentage of fat according to the Atwater factors) in larger than culturally determined portion sizes (34). Therefore, when they report a normal portion of an energy-dense food with a high fat content, they might in fact consume a portion that is normal to them, but should be recorded as "large" by the dietician. A selective underreporting of fat intake at the meals would be the consequence.

Thus, a simple energy intake adjustment would not solve the problem of underreporting for estimation of energy intake. Selective underreporting might have more severe implications than would nonselective underreporting in a dietary survey of obese subjects $(4,16)$.

The national health campaigns aimed at lowering fat intakes are thought to be successful because results from national food consumption measurements have shown a decline in reported fat intake over several years $(1,5,11)$. However, has there been a true decline in reported fat intakes or has there been a selective underreporting of fat intake, as was found in the present study. Results from the third National Health and Nutrition Examination Survey (NHANES III, phase I (1988-91)) show a decline in the reported percentage of energy from fat, an increase in reported energy intakes, and an increase in the prevalence of overweight compared with NHANES II (1976-80) $(1,2$, 6). The ratio of reported energy intake to estimated basal metabolic rate was 1.36 for the total population (age $>20 y$ ) in NHANES III. For a sedentary population, one would expect a ratio between 1.50 and 1.55 , which indicates that energy intake was underreported (6). This underreporting of energy was also probably associated with a selective underreporting of macronutrients, at least in obese participants.

In conclusion, we observed $37 \%$ underreporting of energy intake in obese men, consisting of $26 \%$ undereating and $12 \%$ underrecording. Selective underreporting of fat intake as observed in the obese men in the present study might throw a different light on the outcome of dietary surveys. 


\section{Acknowledgement}

We thank Tanja Hermans-Limpens and Chris Hukshorn for assistance during the experiments.

\section{References}

1. Anonymous. Daily dietary fat and total food-energy-intakes--Third National Health and Nutrition Examination Survey, Phase 1, 1988-91. Morb Mortal Wkly Rep 43: 116-117 123-115, 1994.

2. Anonymous. Prevalence of overweight among adolescents--United States, 1988-91. Morb Mortal Wkly Rep 43: 818-821, 1994.

3. Bandini, LG, Schoeller, DA, Cyr, HN, and Dietz, WH. Validity of reported energy intake in obese and nonobese adolescents. Am J Clin Nutr 52: 421-425, 1990.

4. Bellach, B, and Kohlmeier, L. Energy adjustment does not control for differential recall bias in nutritional epidemiology. J Clin Epidemiol 51: 393-398, 1998.

5. Breedveld, BC, and Hulshof. KFAM. Hoe goed voedt de gerniddelde Nederlander zich? Voeding 1: 11-15, 1998.

6. Briefel, R, McDowell, M, Alaimo, K, Caughman, C. Bischof, A, Carroll, M, and Johnson, C. Total energy intake of the US population: the third National Health and Nutrition Examination Survey, 1988-1991. Am J Clin Nutr 62: 1072S-1080S, 1995.

7. Buhl, KM, Gallagher, D, Hoy, K, Matthews, DE, and Heymsfield, SB. Unexplained disturbance in body weight regulation: diagnostic outcome assessed by doubly labeled water and body composition analyses in obese patients reporting low energy intakes. J Am Diet Assoc 95: 13931400,1995

8. Fjeld, CR, Brown, $\mathrm{KH}$, and Schocller. DA. Validation of the deuterium oxide method for measuring average daily milk intake in infants. Am J Clin Nutr 48: 67I-679, 1988.

9. Goris, AHC, and Westerterp, KR. Underreporting of habitual food explained by undereating in motivated lean women. J Nutr 129: 878-882. 1999

10. Heitmann, BL, and Lissner, L. Dietary underreporting by obese individuals - is it specific of nonspecific. Br Med J 311: 986-989, 1995

11. Heitmann, BL, Lissner, L and Osler, M. Do we eat Icss fat, or just report so? Int J Obesity 22 : s41. 1998 .

12. Hulshof. KFAM. Lowik. MRH. Kistemaker. C. Hermus, RJJ, Hoor ten, F, and Ockhuizen, T. Comparison of dietary intake data with guidelines: some potential pitfalls (Dutch Nutrition Surveillance System). J Am Coll Nutr 12: 176-185, 1993.

13. Johnson. RK, Goran. MI. and Poehlman. ET. Correlates of over- and underreporting of energy intake in healthy older men and women. Am J Clin Nutr 59: 1286-1290, 1994.

14. Kempen. KP. Saris. WH, and Westerterp. KR. Energy balance during an 8-wk energy-restricted diet with and without exercise in obese women. Am J Clin Nutr 62: 722-729, 1995.

15. Lichtman. SW, Pisarska, K, Raynes Berman, E, Pestone, M, Dowling, H, Offenbacher, E, Weisel, H, Heshka, S, Matthews, DE, and Heymsfield, SB. Discrepancy between self-reported and actual caloric intake and exercise in obese subjects. N Engl J Med 327: 1893-1898, 1992

16. Lissner, L. Heitmann, BL, and Lindroos, AK. Measuring intake in free-living human subjects: a question of bias. Proc Nutr Soc 57: 333-339, 1998.

17. Lissner, L, and Lindroos, AK. Is dietary underreporting macronutrient-specific. Eur J Clin Nutr 48: 453-454, 1994

18. Livingstone, MBE, Prentice, AM, Strain. JJ, Coward, WA, Black, AE, Barker, ME, McKenna, $P G$, and Whitehead, RG. Accuracy of weighed dietary records in studies of diet and health. $\mathrm{Br}$ Med J 300: 708-712, 1990

19. Pannemans, DL, and Westerterp, KR. Estimation of energy intake to feed subjects at energy balance as verified with doubly labelled water. a study in the elderly. Eur J Clin Nutr 47: 490-496, 1993. 
20. Poppitt, SD, Swann, D, Black, AE, and Prentice, AM. Assessment of selective under-reporting of food intake by both obese and non-obese women in a metabolic facility. Int J Obes 22: 303-311, 1998.

21. Prentice, AM, Black, AE, Coward, WA, Davies, HL, Goldberg, GR, Murgatroyd, PR, Ashford, J. Sawyer, M, and Whitehead, RG. High levels of energy expenditure in obese women. Br Med J 292: 983-987, 1986.

22. Roberts, SB, Pi-Sunyer, FX, Dreher, M, Hahn, R, Hill, JO, Kleinman, RE, Peters. JC, Ravussin. E, Rolls, BJ, Yetley, E, and Booth, SL. Physiology of fat replaciment and fat reduction: effects of dietary fat and fat substitutes on energy regulation. Nutr Rev 56: S29-S49, 1998.

23. Rutishauser, IHE. Is dietary underreporting macronutrient specific? Eur J Clin Nutr 49: 219-220, 1995.

24. Schoeller, DA. How accurate is self-reported dietary energy intake? Nutr Rev 48: 373-379, 1990

25. Schoeller, DA, Bandini, LG, and Dietz. WH. Inaccuracies in self-reported intake identified by comparison with the doubly labelled water method. Can J Physiol Pharmacol 68: 94 I-949, 1990.

26. Seidell, JC. Dietary fat and obesity: an epidemiologic perspective. Am J Clin Nutr 67: 546S-550S, 1998.

27. Velthuis-te Wierik, EJ, Westerterp, $\mathrm{KR}$, and van den Berg, H. Impact of a moderately energyrestricted diet on energy metabolism and body composition in non-obese men. Int $\mathrm{J}$ Obes Rclat Metab Disord 19: 318-324, 1995.

28. Voeding, Vvd. Nevo Tabel. Den Haag: Nederlandsvoedingsstoffenbestand, 1993.

29. Voss, S, Kroke, A, Klipstein-Grobusch, K, and Boeing, H Is macronutrient composition of dietary intake data affected by underreporting? Results from the EPIC-Potsdam study. Eur J Clin Nutr 52 : 119-126, 1998.

30. Westerterp, K, Verboeket-van de Venne. W, Meijer, G, and ten Hoor, F. Self-reported intake as a measure for energy intake. A validation against doubly labelled water. Obes Eur 91: 17-22, 199]

31. Westerterp, KR, Donkers, JH, Fredrix, EW, and Boekhoudt, P. Energy intake, physical activity and body weight: a simulation model. Br J Nutr 73: 337-347, 1995.

32. Westerterp, KR, Meijer, GA, Janssen, EM, Saris, WH, and ten Hoor, F. Long-term effect of physical activity on energy balance and body composition. Br J Nutr 68: 21-30, 1992.

33. Westerterp, KR, Wouters, L, and van Marken Lichtenbelt, W. The Maastricht protocol for the measurement of body composition and energy expenditure with labeled water. Obes Res 3 suppl 1 49-57, 1995.

34. Westerterp-Plantenga, MS, Pasman, WJ, Yedema, MJW, and Wijckmans-Duijsens, NEG. Energy: intake adaptation of food intake to extreme energy densities of food by obese and non-obese women. Eur J Clin Nutr 50: 401-407, 1996. 
Chapter 5

Postabsorptive respiratory quotient and food quotient - an analysis in lean and obese men and women

Annelies HC Goris, Klaas R Westerterp

Department of Human Biology, Maastricht University, The Netherlands

Published in: European Journal of Clinical Nutrition. 2000: 54:546-550 


\section{Abstract}

Macronutrient intake is difficult to measure under free-living conditions, because of errors in the reporting of food intake. The aim of the current study was to assess whether postabsorptive respiratory quotient $(R Q)$ is indicative for the food quotient (FQ), with other factors, such as body composition and energy balance, taken into account. Thirty lean subjects (age $31 \pm 9$ years, body mass index (BMI) $22.0 \pm 2.1 \mathrm{~kg} / \mathrm{m}^{2}$ ) and 20 obese subjects (age $48 \pm 12$ years, BMI $33.3 \pm 4.4 \mathrm{~kg} / \mathrm{m}^{2}$ ) participated in the study. Body mass changes were determined over a 7-day period before the measurement of postabsorptive RQ and in this period subjects reported their total food intake in a dietary record. A subgroup of twelve lean subjects was supplied with their total food intake in this period (twice with different diets). Food quotients were calculated from the valid food records $(<10 \%$ underrecording and undereating). Body composition was estimated using the three-compartment model of Siri. Postabsorptive $R Q$ was not related to $F Q(n=31 r=-0.24, P=0.2)$ and no difference was observed between the 2 diet periods $(\mathrm{n}=12$ paired $\mathrm{t}$-test $\mathrm{P}=0.9)$. Postabsorptive $R Q$ was related to the change in body mass $(r=0.57, \mathrm{P}=0.0001)$, but not to $\mathrm{BMI}$, fat mass or fat free mass. In the present study, the energy balance over the days prior to the measurement was the most important factor influencing postabsorptive RQ. Postabsorptive RQ was not a reliable indicator for habitual FQ even when corrected for energy balance and body composition.

\section{Introduction}

Postabsorptive respiratory quotient (RQ) is often related to measures of body composition $(2,13,16)$ and / or used as a predictor for future weight gain or weight loss $(15,17)$. In some studies subjects with a higher fat mass (FM) were found to have a lower postabsorptive RQ $(2,16)$. A large fat mass, as a consequence of a positive energy balance, might increase fasting free fatty acids levels and the rate of fat turnover until fat oxidation is commensurate with dietary fat intake $(2,3,16)$. Other studies found a negative relation between postabsorptive RQ and fat free mass (FFM) $(13,18)$. The FFM is a more metabolically active compartment of the body than fat mass and is therefore responsible for the fat oxidation. The interindividual variability in postabsorptive RQ seems to be only partly explained by differences in the amounts of FM and / or FFM. The role of the macronutrient ratio of the food intake, i.e. the food quotient (FQ), is also thought to influence postabsorptive RQ (11). Normally, subjects who are in energy balance are also in substrate balance; the RQ measured over a 24-hour period is equal to FQ (5). Whether or not postabsorptive RQ is also related to FQ is not clear. The FQ is difficult to measure, because of errors in the reporting of food intake. In a previous study with obese men we found a selective underreporting of fat intake with the use of a 7-day dietary record (7). Obviously, other methods to assess habitual macronutrient intake are needed for nutrition research.

The aim of this study was to assess whether postabsorptive RQ is indicative for $F Q$, with other factors, such as body composition and energy balance, taken into account. We hypothesized that postabsorptive RQ is related to $F Q$, and that postabsorptive RQ will change when FQ changes. Measurements were done in lean subjects and obese subjects (before and at the end of a weight loss intervention). The energy balance was 
measured over a one week interval and in the obese subjects also over a 10 week. weight loss intervention interval.

\section{Subjects and methods}

\section{Design}

For a first study, thirty lean subjects $\left(B M \mathrm{~K}<27 \mathrm{~kg} / \mathrm{m}^{2}\right.$ ), a group of dieticians and a group of students were recruited from the university and the university hospital in Maastricht. For a second study twenty obese subjects $\left(B M I>27 \mathrm{~kg} / \mathrm{m}^{2}\right)$, were recruited from a weight loss intervention of the local home nursing association in Maastricht. They were studied before the start and at the end of the intervention. The weight loss intervention consisted of weekly group meetings under supervision of a dietician who gave information about nutrition and who weighed the subjects. For all subjects, body mass changes were determined over a 7 day period before the measurement of postabsorptive $\mathrm{RQ}$ and in this period subjects reported their total food intake in a dietary record. A subgroup of twelve lean subjects followed the protocol twice and received two different diets from the university. The formation of this subgroup made it possible to study the effect of a change in diet on the postabsorptive RQ. Physical activity was measured to control for differences in physical activity which might influence the $R Q$ measurement. The protocol was approved by the university ethics committee.

\section{Food intake}

A 7 day weighed food record was used to measure habitual macronutrient intake. The reporting of food intake was checked for underrecording and undereating (6). Recording was checked with the water balance technique, as described previously (6, 7). Briefly, healthy subjects are in water balance and water intake matches water loss. A water intake, corrected for metabolic water, lower than water loss indicates underrecording of water intake. The recording of water intake appeared to be representative for total food recording, thus a reported water intake below water loss indicates underrecording of food intake. Water loss was measured with the deuterium elimination method (4). Subjects drank a deuterium $\left({ }^{2} \mathrm{H}_{2} \mathrm{O}\right)$ dilution $(70 \mathrm{~g}$ water with an enrichment of 5 atom\% excess ${ }^{2} \mathrm{H}$ ) after voiding (baseline urine sample) the evening before the start of the recording week. Elimination was calculated from two urine samples directly after dosing (at day 1 in the morning and evening) and two samples at the end of the observation period (day 7 in the evening, day 8 in the morning). Deuterium content was measured in urine samples with an isotope ratio mass spectrometer (Aqua Sira, VG Isogas, Middlewich, Cheshire, UK (21)). Water loss was calculated from ${ }^{2} \mathrm{H}$ elimination with the equation of Fjeld et al. (4), as described previously (20). Undereating was checked by comparing the body mass change over the recording week with the body mass change over a non-recording week. A significantly higher body mass loss over the recording week indicates undereating (6). Food quotients were calculated from the valid food records $(50 \%$ of the food records were judged valid, i.e. less than $10 \%$ underrecording and undereating). The data of the food records were used to calculate intakes of fat, carbohydrate and protein with a computer program based on food tables (Becel Nutrition Program, 1988, Nederlandse 
Unilever Bedrijven BV, Rotterdam, The Netherlands). The food quotient was then calculated using the following equations: $\mathrm{O}_{2}$ consumption $(\mathrm{L} / \mathrm{d})=(0.966 \mathrm{x}$ protein intake $)+(2.019 \times$ fat intake $)+\left(0.829 \times\right.$ carbohydrate intake), and $\mathrm{CO}_{2}$ production $(\mathrm{L} / \mathrm{d})=(0.774 \mathrm{x}$ protein intake $)+(1.427 \mathrm{x}$ fat intake $)+(0.829 \times$ carbohydrate intake $)$, where the intake of protein, fat and carbohydrate is expressed in grams per day; $\mathrm{FQ}=$ $\mathrm{VCO}_{2} / \mathrm{VO}_{2}(9)$.

A subgroup of 12 lean subjects received over two 4 day intervals a diet with a fixed macronutrient composition (each interval a diet with a different composition). One diet according to the habitual macronutrient composition, as estimated with a dietary history, and one diet with more / less fat than the habitual diet ( \pm 0.04 of habitual FQ). Subjects could choose the food items and meals they preferred for the next four days, from a list with a fixed FQ. Foods and drinks were given ad libitum. The interval between the two diets was at least 4 days.

\section{Subsirate oxidation}

Postabsorptive RQ ( $\mathrm{ml} \mathrm{CO} / \mathrm{ml} \mathrm{O}_{2}$ ) was measured by means of an open circuit ventilated hood system while subjects were lying in the supine position. Gas analyses were performed by a paramagnetic oxygen analyzer (Servomex type 500A, Crowborough Sussex, UK) and an infrared carbon dioxide analyzer (Servormex type $500 \mathrm{~A}$ ), similar to the analysis system described by Schoffelen et al. (14). Measurements were performed in the morning in a fasting state for about 45 minutes. The last 30 minutes were used to calculate postabsorptive RQ. Subjects slept the night before the measurement at the university $(n=22)$ or else they were asked to come by car or public transport to the university $(n=28)$ and to perform as little activity as possible. They lay down for 15 minutes before the start of the measurements.

\section{Body composition}

Subjects were weighed (in underwear) in the morning, before any beverage or food consumption and after voiding, on a digital balance accurate to $0.01 \mathrm{~kg}$ (Sauter, Ebingen, Germany). Body composition was estimated from the three-compartment model of Siri. Body density was determined by underwater weighing with simultaneous assessment of residual lung volume with the helium dilution technique using a spirometer (Volugraph 2000, Mijnhardt, The Netherlands). Total body water was measured by deuterium dilution following the Maastricht protocol (22). The evening prior to the underwater weighing subjects drank a deuterium dilution ( $70 \mathrm{~g}$ water with an enrichment of 5 atom $\%$ excess ${ }^{2} \mathrm{H}$ ) after voiding. Deuterium enrichment was measured in urine from the second voiding of the following morning. For comparison between individuals, corrections for differences in body height were made by calculating the fat mass index $\left(F M I=\mathrm{kg} \mathrm{FM} / \mathrm{m}^{2}\right)$ and fat free mass index $(\mathrm{FFMl}=$ $\mathrm{kg} \mathrm{FFM} / \mathrm{m}^{2}$ ).

\section{Physical activity}

Physical activity was assessed with a CSA accelerometer (Computer Science and Applications Inc., Shalimar, U.S.A.), which subjects wore during waking hours in a belt at the back of the waist (12). The registered counts/minute were used as an objective measure for the individual's physical activity level. 


\section{Statistics}

Mean values and standard deviations $( \pm$ ) were calculated for the total group of 50 subjects and for the obese and lean subjects separately. For the subjects with a reliable FQ (i.e. subjects with a valid food record and the subjects who received their diet from. the university), simple regression analysis was done for posiabsorptive $\mathrm{RQ}$ and $\mathrm{FQ}$. For the subjects who were supplied with food only the 'habitual' FQ (i.e. the FQ of the supplemented diet according to the macronutrient composition of the dietary history) +. corresponding $R Q$ was used for this analysis. The measurements of postabsorptive $R Q$ after the two different diets were compared with a paired $t$-test. In the obese subjects the relationship of a change in body mass after 10 weeks and postabsorptive $R Q$ was: tested with a simple regression analysis. The influence of body mass index (BMD), FMI and FFMI on postabsorptive RQ was analyzed with a simple regression.

\section{Results}

\section{Body composition}

Subjects' characteristics are shown in table 5.1. The mean change in body mass over the 5-7 days before the RQ measurement was, for the lean and obese subjects respectively, $-0.38 \pm 0.77 \mathrm{~kg}$, and $-0.27 \pm 1.09 \mathrm{~kg}$ (one factor ANOVA, $\mathrm{P}=0.69$ ). The body mass change of the lean subjects was significantly different from zero (one group $t$-test, $P=0.012$ ). There was no difference in mean body mass change between the two diet periods in the subgroup of 12 subjects (paired t-test, $\mathrm{P}=0.7$ ). The obese subjects lost on average $5.2 \pm 3.3$ (range $0.58-10.0) \mathrm{kg}$ after 10 weeks of participation in a weight loss program.

\section{Physical activity}

The mean physical activity was $82.6 \pm 32.9$ counts/minute for the lean subjects and $66.5 \pm 18.9$ counts/minute for the obese subjects $(\mathrm{P}=0.055)$. Physical activity was not related to postabsorptive RQ. For the subjects who were supplied with food, there were no differences in physical activity (counts per minute) between the two periods with different diets.

Table 5.1: Age, body mass, fat mass, fat free mass, body mass index, fat mass index and fat free mass index for obese and lean subjects, mean values, standard deviations and ranges

\begin{tabular}{lccccc}
\hline & \multicolumn{2}{c}{ Lean subjects $(\mathrm{n}=30)$} & \multicolumn{2}{c}{ Obese subjects $(\mathrm{n}=20)$} & Total group \\
\hline Male / female & \multicolumn{2}{c}{$4 / 26$} & \multicolumn{2}{c}{$5 / 15$} & $9 / 41$ \\
Age & $31 \pm 9$ & $(21-60)$ & $48 \pm 12^{*}$ & $(25-63)$ & $38 \pm 13$ \\
Body mass $(\mathrm{kg})$ & $62.6 \pm 9.0$ & $(47.1-92.7)$ & $92.8 \pm 13.8^{*}$ & $(68.0-115.5)$ & $75.2 \pm 18.7$ \\
Fat mass $(\mathrm{kg})$ & $16.8 \pm 4.9$ & $(8.0-26.7)$ & $40.9 \pm 10.1^{*}$ & $(28.3-60.7)$ & $26.8 \pm 14.1$ \\
Fat-free mass $(\mathrm{kg})$ & $45.8 \pm 7.5$ & $(35.6-68.4)$ & $52.0 \pm 8.6^{*}$ & $(36.0-68.9)$ & $48.4 \pm 8.4$ \\
Body mass index $\left(\mathrm{kg} / \mathrm{m}^{2}\right)$ & $22.0 \pm 2.1$ & $(18.1-26.1)$ & $33.3 \pm 4.4^{*}$ & $(27.0-43.9)$ & $26.5 \pm 6.4$ \\
Fat mass index $\left(\mathrm{kg} / \mathrm{m}^{2}\right)$ & $5.9 \pm 1.7$ & $(2.5-9.5)$ & $14.6 \pm 3.9^{*}$ & $(9.1-23.0)$ & $9.6 \pm 5.2$ \\
Fat-free mass index $\left(\mathrm{kg} / \mathrm{m}^{2}\right)$ & $16.0 \pm 1.4$ & $(13.3-19.0)$ & $18.5 \pm 1.8^{*}$ & $(15.5-2.1 .7)$ & $17.0 \pm 2.0$ \\
\hline
\end{tabular}

$* \mathrm{P}<0.05$ 


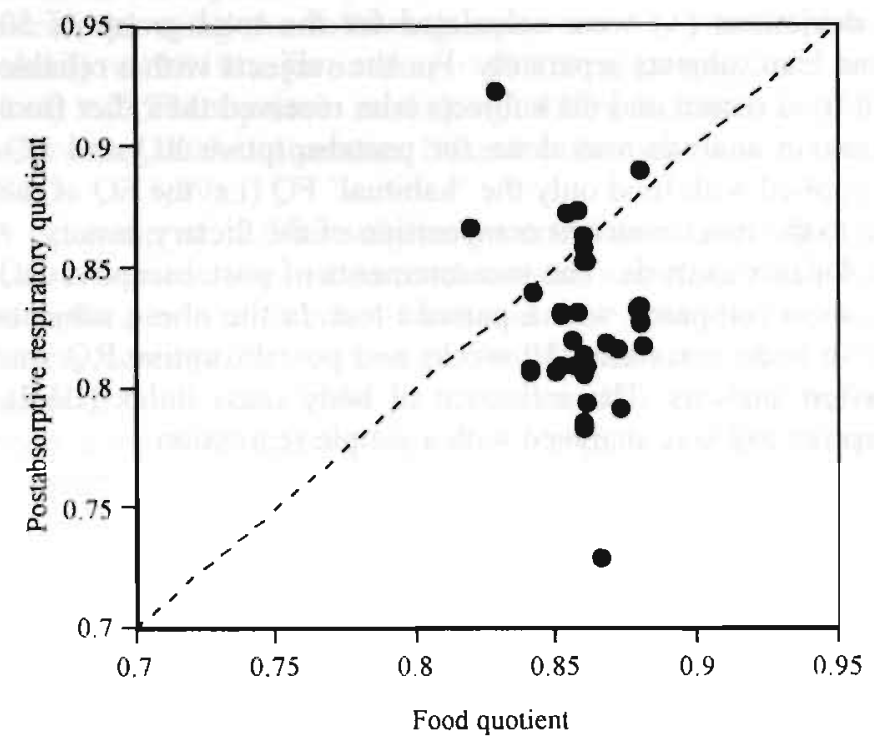

Figure 5.1: Postabsorptive respiratory quotient (RQ) in relation to the food quotient (FQ) of 31 subjects, with the line of identity plotted (simple regression analysis: $r=-0.24, P=0.2$ )

\section{Substrate oxidation}

Figure 5.1 shows RQ plotted against FQ for the subjects with a valid food record and the subjects who were supplied with food $(r=-0.236, P=0.2)$. RQ was significantly lower than $F Q$ (paired t-test $P=0.0003$ ) and had also a wider range than $F Q$. The $F Q$ range of 0.82- 0.88 corresponded with an energy percentage fat in the diet of 27-44 and an energy percentage carbohydrate in the diet of 40-64. The postabsorptive RQ was related to the body mass change over the week before the measurement $(\mathrm{I}=0.42$, $\mathrm{P}=0.024$ for the subjects with a valid food record and $\mathrm{r}=0.57, \mathrm{P}=0.0001$ for all subjects, figure 5.2). A high RQ was observed in subjects with a weight gain and vice versa. $\mathrm{FQ}$ was also not significant related to postabsorptive $R Q$ in a multiple regression analysis on RQ, with body mass change and FQ as independent factors. Figure 5.3 shows the postabsorptive RQ measured after a low fat diet and after a high fat diet for the 12 lean subjects who were supplied with their food for four days. Postabsorptive $\mathrm{RQ}$ did not differ between the two periods (paired t-test $\mathrm{P}=0.88$ ) and was not influenced by $F Q$ (simple regression analysis on low $F Q, r^{2}=0.2, P=0.15$; and on high $\mathrm{FQ}, \mathrm{r}^{2}=0.11, \mathrm{P}=0.3$ ).

The results of simple regression analysis of BMI, FMI and FFMI on postabsorptive RQ are shown in table 5.2. RQ was not related to BMI, FMl or FFMI in the whole group. In the obese group RQ was significantly related to BMI and FMI.

Table 5.2: Simple regression analysis of pastabsorptive RQ on BMI. FMI and FFMI.

\begin{tabular}{llll} 
& Lean subjects $(\mathrm{n}=30)$ & Qbese subjects $(\mathrm{n}=20)$ & Total group \\
\hline BMI $\left(\mathrm{kg} / \mathrm{m}^{2}\right)$ & $\mathrm{r}=-0.29 \mathrm{P}=0.12$ & $\mathrm{r}=-0.54 \mathrm{P}=0.01$ & $\mathrm{r}=-0.04 \mathrm{P}=0.77$ \\
FMI $\left(\mathrm{kg} / \mathrm{m}^{2}\right)$ & $\mathrm{r}=-0.03 \mathrm{P}=0.88$ & $\mathrm{r}=-0.53 \mathrm{P}=0.02$ & $\mathrm{r}=-0.03 \mathrm{P}=0.85$ \\
FFMI $\left(\mathrm{kg} / \mathrm{m}^{2}\right)$ & $r=-0.26 \mathrm{P}=0.18$ & $r=-0.16 \mathrm{P}=0.49$ & $\mathrm{r}=-0.04 \mathrm{P}=0.80$
\end{tabular}




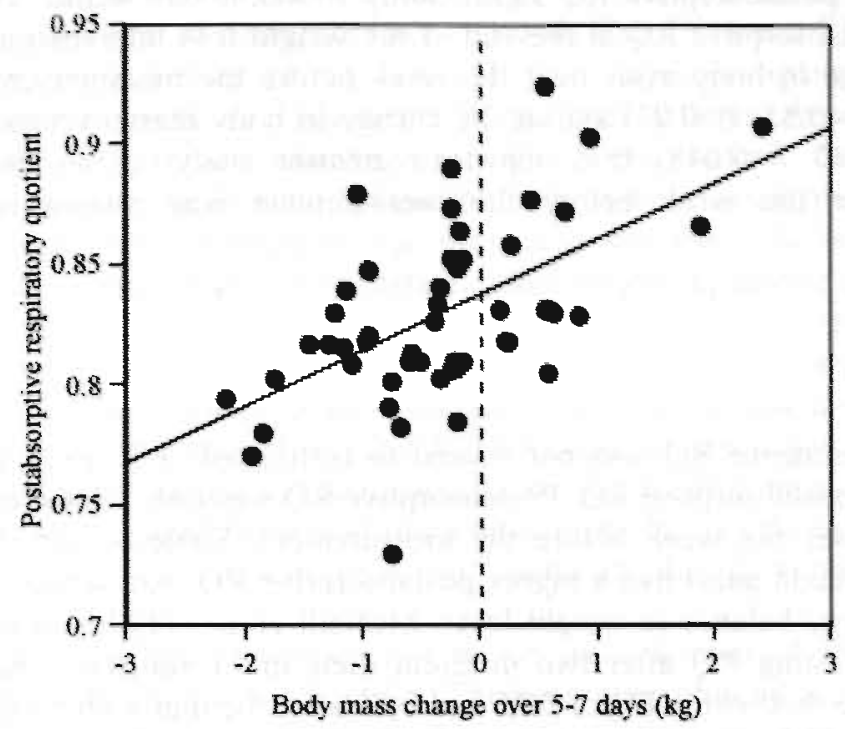

Figure 5.2: Postabsorptive respiratory quotient (RQ) as a function of the body mass change ( $\triangle B M)$ in 50 subjects (linear regression line: postabsorptive $\mathrm{RQ}=0.023 * \Delta \mathrm{BM}+0.837: r=0.57, \mathrm{P}=0.0001)$.

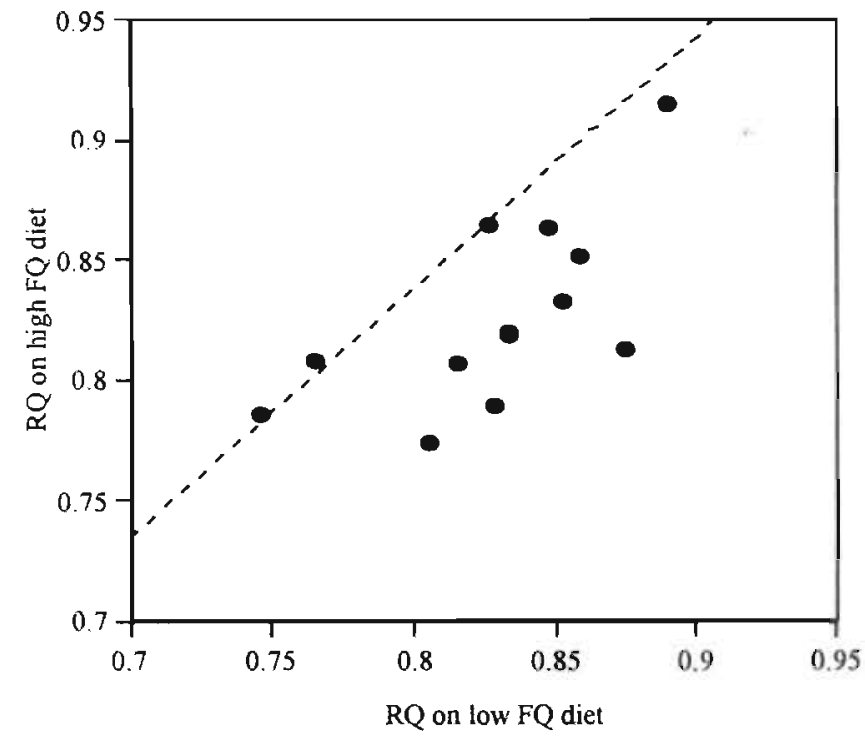

Figure 5.3: Postabsorptive respiratory quotient (RQ) of 12 subjects after a diet with a low food quotient (FQ) and after a diet with a high food quotient (dashed line is difference in FQ of 0.04 of the diets). 
The body mass change over the 10 weeks weight loss intervention in the obese subjects did not change the postabsorptive RQ significantly $(0.832 \pm 0.039$ before vs $0.818 \pm 0.035$ after). The postabsorptive RQ at the end of the weight loss intervention was a function of the change in body mass over the week before the measurement (simple regression analysis $\mathrm{r}=0.53, \mathrm{P}=0.02$ ) and of the change in body mass over the ten weeks intervention ( $\mathrm{r}=0.47, \mathrm{P}=0.048)$. In a stepwise regression analysis, only the change in body mass over the week before the measurement was related to postabsorptive RQ.

\section{Discussion}

In the present study, postabsorptive RQ was not related to (estimated) FQ. Even a change in diet did not affect postabsorptive RQ. Postabsorptive RQ was only related to the change in body mass over the week before the measurement. Subjects with a positive energy balance (a weight gain) had a higher postabsorptive RQ than subjects who were in a negative energy balance (a weight loss). McNeill et al. (11) found in their study a difference in fasting RQ after two different diets in 11 subjects. The fasting RQ was 0.82 after the diet with a FQ of 0.85 and 0.85 after the diet with a FQ of 0.88 (11). Figure 5.3 shows that in the current study only 5 out of the 12 subjects had a higher postabsorptive RQ after the diet with the high FQ than after the diet with the low FQ. A measurement of a fasting RQ is not sufficient to get an indication of someone's habitual FQ. One reason could be that fasting RQ represents only a short period of the day. The measurement of a 24 -hour RQ is probably more indicative for habitual FQ $(1,(8)$. Verboeket- van de Venne et al. observed a relation between 24hour RQ and FQ as measured with a 3 day dietary record before the measurement of 24-hour RQ (19). However a 24-hour RQ measurement in a respiration chamber is not a very practical method to get an indication of someone's habitual FQ. A second reasun for the lack of a relation between postabsorptive RQ and FQ might be the time of measurement. Lean and James (10) observed diurnal changes in postabsorptive RQ with a minimum during the early night (0.00-3.00 hours) and a rise in RQ during the later part of the night. The systematic change of RQ was more marked in the obese and post-obese subjects (10). All subjects in the current study were measured after an overnight fast between 7.00 and 9.00 o'clock in the morning. Thus differences in fasting RQ between lean and obese subjects might not have been discovered. Twentyeight out of the 50 subjects (both obese and lean subjects) had to come by car or public transport to the university, which might have influenced the measurement of postabsorptive RQ. However, all subjects were within $30 \mathrm{~min}$ drive from the university.

The relation between postabsorptive RQ and FQ was analyzed in a group of subjects of whom the FQ was calculated from a food record and in a group of subjects of whom the FQ was calculated from the provided diet. FQ was only calculated from the food records if the underrecording and undereating was less than $10 \%$. A correct reported energy intake gives no guarantee for correct reported macronutrient intakes, but a selective underrecording of, for example fat intake has then to be accompanied by an overrecording of carbohydrate / protein intake. This is not very likely. Besides, the 
result of the analysis of postabsorptive $\mathrm{RQ}$ and $\mathrm{FQ}$ was not different for the total group and for the 12 subjects who received their diet from the lab.

The relation of postabsorptive RQ with FM, FFM and BMI as reported before could not be confirmed $(2,13,16,18)$. Only in the subgroup of obese subjects did we observe a negative relation of FMI and BMI with postabsorptive RQ.

The body mass change over the week before the measurement influenced postabsorptive RQ more than the body mass change over the past 10 weeks of the weight loss intervention for the obese subjects. The weight loss over a 10-week interval is probably not constant, which might explain the greater influence of the body mass change over the week prior to the measurement on postabsorptive RQ. The obese subjects who lost weight before the first measurement of postabsorptive RQ were also the subjects who lost most weight during the weight loss intervention. They started with a lower postabsorptive RQ (because of the negative energy balance) than the subjects who did not loose weight before the first measurement and maintained this lower RQ until the end of the intervention. This might explain why no difference was observed in postabsorptive RQ between the start and end of the weight loss intervention.

The body mass change prior to the measurement of RQ was probably due to the recording of the food intake. The recording of food intake for a week is known to change eating habits $(6,7)$. It is unlikely that the change in body mass was due to changes in the degree of hydration of the body or differences in gut content in this study. The body mass was always measured at the same time for each subject before any beverage or food consumption and after voiding. Most people have a regular defecation pattern and the gut content will not much differ between the two measurements. The measurement of body mass changes is necessary in the interpretation of postabsorptive $R Q$, even if there is no significant change in body mass on a group level. The wide range in postabsorptive RQ found in this study was related to the body mass change, which ranged from -2.2 to $+2.4 \mathrm{~kg} /$ week .

In conclusion, in the present study the energy balance over the days prior to the measurement was the most important factor influencing postabsorptive RQ. Postabsorptive RQ is not a reliable indicator for habitual FQ even when corrected for energy balance and body composition.

\section{References}

1. Astrup, A. Dietary composition, substrate balances and body fat in subjects with a predisposition to obesity. Int J Obes 17: S32-S36, 1993.

2. Astrup, A, Buemann, B, Western, P, Toubro, S, and Raben, A. Obesity as an adaptation to a highfat diet: evidence from a cross-sectional study. Am J Clin Nutr 59: 350-355, 1994.

3. Astrup, A, and Raben, A. Obesity: an inherited metabolic deficiency in the control of macronutrient balance? Eur J Clin Nutr 46: 611-620, 1992.

4. Fjeld, CR, Brown, KH, and Schoeller, DA. Validation of the deuterium oxide method for measuring average daily milk intake in infants. Am J Clin Nutr 48: 67!-679, 1988.

5. Flatt, JP. Dietary fat, carbohydrate balance, and weight maintenance. Ann N Y Acad Sci 683: 122140. 1993.

6. Goris, AHC, and Westerterp, KR. Underreporting of habitual food explained by undereating in motivated lean women. J Nutr 129: 878-882, 1999. 
7. Goris, AHC, Westerterp-Plantenga, MS, and Westerterp, KR. Undereating and underrecording of habitual food intake in obese men; selective underreporting of fat intake. Am J Clin Nutr 71: 130$134,2000$.

8. Hill, JO, Peters, JC, Reed, GW, Schlundt, DG, Sharp, T, and Greene, HL. Nutrient balance in humans: effects of diet composition. Am J Clin Nutr 54: 10-17, 1991.

9. Jequier, E, Acheson, $\mathrm{K}$, and Schutz, $\mathrm{Y}$. Assessment of energy expenditure and fuel utilization in man. Ann Rev Nutr 7: 187-208, 1987.

10. Lean, MEJ, and James, WPT. Metabolic effects of isoenergetic nutrient exchange over 24 hours in relation to obesity in women. Int J Obes 12: 15-27, 1988.

11. McNeill, G, Bruce, AC, Ralph, A, and James, WPT. Inter-individual differences in fasting nutrient oxidation and the influence of diet composition. Int J Obes 12: 455-463, 1988.

12. Melanson, EL, and Freedson, PS. Validity of the computer science and applications, inc. (CSA) activity monitor. Med Sci Sports Exerc 27: 934-940, 1995.

13. Nagy, TR, Goran, MI, Weinsier, RL, Toth, MJ, Schutz, Y, and Poehlman, ET Determinants of basal fat oxidation in healthy Caucasians. J Appl Physiol 80: 1743-1748, 1996.

14. Schoffelen, PFM, Westerterp, KR, Saris, WHM, and ten Hoor, F. A dual-respiration chamber system with automated calibration. J Appl Physiol 83: 2064-2072, 1997.

15. Schutz, Y. Abnormalities of fuel utilization as predisposing to the development of obesity in humans. Obes Res 3: 173S-178S, 1995.

16. Schutz, Y, Tremblay, A, Weinsier, RL, and Nelson, KM. Role of fat oxidation in the long-term stabilization of body weight in obese women. Am J Clin Nutr 55: 670-674, 1992.

17. Seidell, JC, Muller, DC, Sorkin, JD, and Andres, R. Fasting respiratory exchange ratio and resting metabolic rate as predictors of weight gain: the Baltimore Longitudinal Study on Aging. Int J Obes 16: 667-674, 1992.

18. Toth, MJ, Sites, CK, and Poehlman, ET. Hormonal and physiological correlates of energy expenditure and substrate oxidation in middle-aged premenopausal women. J Clin Endocr Met 84: 2771-2775, 1999.

19. Verboeket-van de Venne, W, Westerterp, K, Hermans-Limpens, T, Graaf de, C, Hof van het, K, and Weststrate, J. Long-term effects of consumption of full-fat or reduced-fat products in healthy non-obese volunteers: assessment of energy expenditure and substrate oxidation. Metabolism 45: 1004-1010, 1996.

20. Westerterp, KR, Kayser, B, Brouns, F, Herry, JP, and Saris, WH. Energy expenditure climbing Mt. Everest. J Appl Physiol 73: 1815-1819, 1992.

21. Westerterp, KR, Robach, P, Wouters, L, and Richalet, JP. Water balance and acute mountain sickness before and after arrival at high altitude of 4,350 m. J Appl Physiol 80: 1968-1972, 1996.

22. Westerterp, KR, Wouters, L, and van Marken Lichtenbelt, W. The Maastricht protocol for the measurement of body composition and energy expenditure with labeled water. Obes Res 3 suppl 1: 49-57, 1995. 
Chapter 6

\section{Use of a triaxial accelerometer to validate reported food intakes}

Annelies HC Goris, Erwin P Meijer, Arnold Kester*, Klaas R Westerterp Department of Human Biology and Department of Methodology and Statistics*, Maastricht University, The Netherlands

In press: American Journal of Clinical Nutrition. 


\section{Abstract}

An easy and cheap method for validating reported energy intake (EI) is needed. Reported EI was compared with calculated energy expenditure $\left(\mathrm{EE}_{\mathrm{calc}}\right)$ and with energy expenditure measured by the doubly labelled water method $\left(\mathrm{EE}_{\mathrm{DL}} \mathrm{W}\right)$. EE was calculated on the basis of basal metabolic rate (BMR) measured with the ventilatedhood technique and physical activity measured with a triaxial accelerometer ( $\left.\mathrm{EE}_{\mathrm{VH}+\mathrm{PA}}\right)$ and on the basis of BMR estimated by using WHO equations and PA ( $\left.\mathrm{EE}_{\mathrm{WHO}+\mathrm{PA}}\right)$ : $\mathrm{EE}_{\text {calc }}=-1.259+1.55^{*} \mathrm{BMR}+0.076^{*}$ counts/minute $\left(\mathrm{r}^{2}=0.90, \mathrm{P}=0.0001\right.$, from a validation against $\mathrm{EE}_{\mathrm{DLW}}$ in an earlier study). Subjects $[\mathrm{n}=12$ men and 12 women; age: $60 \pm 3$ years; body mass index (in $\mathrm{kg} / \mathrm{m}^{2}$ ): $26 \pm 4$ ] reported their food intake for 7 days with simultaneous assessment of $\mathrm{EE}_{\mathrm{DLW}} \mathrm{EE}_{\mathrm{VH}+\mathrm{PA}}$ and $\mathrm{EE}_{\mathrm{WHO}+\mathrm{PA}}$. Reported $\mathrm{EI}(9.0 \pm 2.1$ $\mathrm{MJ} / \mathrm{d})$ was lower $(\mathrm{P}<0.0001)$ than $\mathrm{EE}_{\mathrm{DLW}}(11.3 \pm 2.3 \mathrm{MJ} / \mathrm{d}), \mathrm{EE}_{\mathrm{VI}+\mathrm{PA}}(10.8 \pm 1.7 \mathrm{MJ} / \mathrm{d}$; $\left.\mathrm{BMR}_{\mathrm{VH}}+\mathrm{PA}\right)$, and $\mathrm{EE}_{\mathrm{WHO}+\mathrm{PA}}\left(10.8 \pm 1.8 \mathrm{MJ} / \mathrm{d} ; \mathrm{BMR}_{\mathrm{WHO}}+\mathrm{PA}\right)$. Underreporting was $19.4 \pm 14.0 \%, 16.7 \pm 13.6 \%$ and $16.4 \pm 15.5 \%$ on the basis of $E_{\mathrm{DLW}}, E E_{\mathrm{VH}+\mathrm{PA}}$ and $\mathrm{EE}_{\mathrm{WHO}+1 \mathrm{~A}}$, respectively. The difference of $2.7 \pm 8.0 \%$ between $\mathrm{EE}_{\mathrm{DLW}}$ and $\mathrm{EE}_{\mathrm{VH}+\mathrm{PA}}$ was not related to the average of both percentages and was not significantly different from zero. The percentage of underreporting calculated with $\mathrm{EE}_{\mathrm{WHO}+\mathrm{PA}}$ was not significantly different from that calculated with $\mathrm{EE}_{\mathrm{DLW}}(3.0 \pm 11 \%)$. The use of a combination of BMR (measured or estimated) and PA is a good method for validating reported El. There was no significant difference between the percentage of underreporting calculated with $\mathrm{EE}_{\mathrm{VH}+\mathrm{PA}}, \mathrm{EE}_{\mathrm{WH}(+\mathrm{PA}}$ or $\mathrm{EE}_{\mathrm{DLW}}$.

\section{Introduction}

Food intake by humans is often related to health or disease indexes in epidemiologic studies and is used as a measure (outcome) in intervention studies. Meassurements of food intake with use of dietary records. food-frequency questionnaires, dietary history's or 24-h recalls are mostly unreliable because of underrecording, undereating, or both $(4,14)$. A reporting bias in measured food intake can attenuate or exaggerate associations with nutrition and obesity-related disease or disturb the outcome of intervention studies $(3,17)$. Underreporting of habitual food intake was measured in both obese and lean subjects $(2,14,15,20,26)$. Thus, measured food intake in nutrition research needs to be validated to ensure that the right conclusions are drawn. The reporting of total food intake can be checked by validating reported energy intake (EI). Several methods for validating reported EI have been used with varying degrees of success. The doubly labelled water method, which measures total energy expenditure (EE) of subjects in free-living situations, is the most reliable method for validating reported EI. However, it is very expensive (oxygen-18 water is not readily available) and is thus not practical in large studies. Total EE is the sum of basal metabolic rate (BMR), physical activity (PA) and diet induced energy expenditure (a constant fraction of about $10 \%$ of $\mathrm{EI}$ and. when subjects are in energy balance, of total EE) and can serve to validate reported EI. BMR can be measured with a ventilated hood or calculated with formulas that use age, sex, height, and weight or with formulas that use body composition. The most variable part is the PA, which can be measured 
with activity diaries, questionnaires, heart rate monitoring or accelerometers. The triaxial accelerometer seems to give the most objective measure of individual $P A$ in free-living situations $(18,25)$.

The ratio of EE to BMR is known as physical activity level (PAL); if there is no underreporting, EE:BMR equals EI:BMR. Goldberg et al. set cutoff limits for EI:BMR to recognize underreporting at the group level (10). However, the proposed cutoff limits for the ratio EI:BMR have failed to identify underreporters of food intake at the individual level $(6,14)$. The cutoff limits are based on minimum PALs for subjects and do not take variation in individual PALs into account.

An easy, cheap and valid method for validating individual reported EIs in large surveys is needed. Estimated or measured BMR in combination with PA assessed with a triaxial accelerometer might be such a method. We present the results of a validation study in which the reported EI of elderly subjects was compared with calculated EE $\left(\mathrm{EE}_{\mathrm{zalc}}\right)$ and with $\mathrm{EE}$ measured by the doubly labelled water method $\left(\mathrm{EE}_{\mathrm{DL}}\right)$.

\section{Subjects and methods}

\section{Subjects}

Thirty subjects ( 14 women and $16 \mathrm{men}$ ) with a mean ( \pm SD) age of $60 \pm 4$ y (range 55$74 \mathrm{y}$ ) and a mean body mass index (BMI) of $26.3 \pm 3.6 \mathrm{~kg} / \mathrm{m}^{2}$ (range 19.4-34.1 kg/m participated in the study. They were recruited for an exercise intervention by advertisements in local newspapers. Results presented here are baseline measurements, which were made before the intervention began. The protocol was approved by the Medical Ethical Committee of the University of Maastricht.

\section{Food and water intake}

Food and water intake were measured with a 7 day dietary record. Subjects received instructions from a dietician on how to keep a food record and were asked not to change their habitual food intakes. The data on the food records were used to calculate intakes of total energy, protein, fat, carbohydrate, and water with a computer program based on food tables (Becel Nutrition Program, 1988; Nederlandse Unilever bedrijven BV, Rotterdam, Netherlands). Total water intake was calculated from reported food and water intakes and the calculated amount of metabolic water. The amount of metabolic water was calculated by multiplying energy expenditure by the fraction of energy from protein, fat and carbohydrate (from the 7-d food record). The oxidation of protein, fat and carbohydrate gives $0.41 \mathrm{~mL} / \mathrm{g} .1 .07 \mathrm{~mL} / \mathrm{g}$ and $0.6 \mathrm{~mL} / \mathrm{g}$ water. respectively (9).

\section{Energy expenditure and water loss}

Energy expenditure was measured with the doubly labelled water method according to Westerterp et al. (27). The estimated coefficient of variation for energy expenditure is $6 \%(21)$. Water balance was assessed to measure the percentage of underrecording (i.e. the failure to record in a food diary everything that is consumed, (14)). Water loss was calculated by using the deuterium elimination method, which has an estimated coefficient of variation of $7 \%(21)$. In the evening on day 0 , subjects were given a 
weighed dose of a mixture of 99.84 atom $\%{ }^{2} \mathrm{H}_{2} \mathrm{O}$ in 10.05 atom $\% \mathrm{H}_{2}{ }^{18} \mathrm{O}$, such that ${ }^{2} \mathrm{H}$ and ${ }^{18} \mathrm{O}$ increased from baseline by $\geq 150 \mathrm{ppm}$ and $\geq 300 \mathrm{ppm}$, respectively. A background urine sample was collected in the evening of day 0 . Additional urine samples were collected on day 1 (from the second void of the day and during the evening) and in the morning and evening of days 8 and 15 . $\mathrm{EE}_{\mathrm{DLW}}$ was calculated over the $2^{\text {nd }}$ week during which subjects recorded their food intakes.

BMR was measured by means of an open-circuit, ventilated hood system $\left(B M R_{\mathrm{VH}}\right)$ in the morning while subjects lay for $30 \mathrm{~min}$ in a supine position. Subjects had slept at the university the night before this measurement was made and were in a fasting state. The estimated coefficient of variation for $\mathrm{BMR}_{\mathrm{VH}}$ is $4 \%$ (11). Gas analyses were made with a paramagnetic oxygen analyzer (Servomex type 500A, Crowborough Sussex, UK) and with an infrared carbon dioxide analyzer (Servomex type 500A), similar to the system described by Schoffelen et al. (22). Weir's equations were used to calculate BMR (24). BMR was also estimated by using equations from the World Health Organisation (BMR $\mathrm{wio}_{\mathrm{H}}$ ), in which age, sex, body mass and height are incorporated (8). PA was assessed with a triaxial accelerometer for movement registration (Tracmor, Philips Research, Eindhoven, The Netherlands). The triaxial accelerometer was an improved version (smaller $7 \times 2 \times 0.8 \mathrm{~cm}, 30 \mathrm{~g}$ ) of the triaxial accelerometer used in previous studies $(7,27)$. Subjects wore the triaxial accelerometer on a belt at the back of their waist during waking hours and recorded the times at which they awoke in the moming, put the triaxial accelerometer on and off, and went to bed. Total counts per day were divided by the amount of time subjects wore the triaxial accelerometer to get an average number of counts/minute. The triaxial accelerometer measures accelerations in the anteroposterior, mediolateral and vertical directions of the trunk and was validated against the doubly labelled water method in another study ( $\mathrm{K}$ Westerterp, U Ekelund, unpublished observations, 2000) in 16 men and women with a mean $( \pm \mathrm{SD}$ ) body mass of $92.2 \pm 25.2 \mathrm{~kg}$, PAL of $1.76 \pm 0.14$ and age of $20 \mathrm{yr}$. This validation resulted in the following equation in which triaxial accelerometer counts and $\mathrm{BMR}$ were used for total $\mathrm{EE}_{\text {calc: }} \mathrm{EE}=-1.259+1.55 * \mathrm{BMR}+0.076 *$ counts/minute (regression analysis $\mathrm{r}^{2}=0.90, \mathrm{P}=0.0001$; residual $\mathrm{SD}=0.809 \mathrm{MJ} / \mathrm{d}$ ). Other validations of the triaxial accelerometer output with the doubly labelled water method showed similar correlations $(7,27)$. EE calculated on the basis of $\mathrm{BMR}_{\mathrm{VH}}$ and $\mathrm{PA}$ is referred to as $E_{\mathrm{VH}+\mathrm{PA}}$ and $\mathrm{EE}$ calculated on the basis of $\mathrm{BMR}_{\mathrm{WHO}}$ and $\mathrm{PA}$ is referred to as

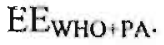

\section{Body mass}

Energy balance was checked for by measuring changes in body weight over each of the 2 weeks separately. Thus, possible weight changes resulting from a change in diet while reporting food intakes could be compared with normal weight fluctuations. Subjects were weighed (in underwear) in the morning on day 1 , before any food or beverage consumption and after voiding, with a digital balance accurate to $0.01 \mathrm{~kg}$ (Sauter, Ebingen, Germany) and on days 8 and 15 with a digital balance accurate to $0.1 \mathrm{~kg}$ (Seca. Almere, The Netherlands). Both balances were calibrated with four 20$\mathrm{kg}$ weights. 


\section{Statistics}

Means and standard deviations were calculated for subjects who had 7 days of physical activity registration and who recorded their food intake for 7 days. Reported EI was compared with $\mathrm{EE}_{\mathrm{DLW}}, \mathrm{EE}_{\mathrm{VH}+\mathrm{PA}}$ and $\mathrm{EE}_{\mathrm{WHO}+\mathrm{PA}}$ by using paired t-tests with Bonferroni correction. Prediction margins for reported EI versus EE $E_{\mathrm{VH}, \mathrm{PA}}$ were calculated as \pm 2 times the residual SD of the value obtained in a previous validation study (K Westerterp, U Ekelund, unpublished observations, 2000). The percentage underreporting of food intake was calculated by using $\mathrm{EE}_{\mathrm{DLW}}, \mathrm{EE}_{\mathrm{VH}+\mathrm{PA}}, \mathrm{EE}_{\mathrm{WHO}}+\mathrm{PA}$ ( \% underreporting ${ }_{\mathrm{DLW}}, \%$ underreporting $\mathrm{VH}_{\mathrm{PA}}$ and $\%$ underreporting $\left.\mathrm{WHO}_{\mathrm{PA}}\right)$ as follows:

Underreporting $=[(\mathrm{EI}-\mathrm{EE}) /(\mathrm{EE})]) \times 100 \%$.

The calculated percentages underreporting were compared by using Bland Altman analysis and t-tests (1).

Changes in body mass over the recording week were compared with changes over the non-recording week by using a paired t-test with Bonferroni correction and were compared with zero by using an one-sample group t-test. Total water intake (WI) was compared with water loss (WO) by using a paired t-test with Bonferroni correction. The \% underrecording and undereating were calculated if a significant difference was found between $\mathrm{WI}$ and $\mathrm{WO}$ and if a significant change was found in body mass over the recording week:

Underrecording $=[(\mathrm{WI}-\mathrm{WO}) /(\mathrm{WO})]) \times 100 \%$

Undereating $=[($ body mass change recording week $\times 30 \mathrm{MJ} / 7 \mathrm{~d}) /(\mathrm{EE})]) \times 100 \%$ Significance was set at $P<0.05$. The STATVIEW program (1992-98; SAS Institute lnc. North Carolina, USA) was used for the statistical analysis.

\section{Results}

Thirty subjects participated in the baseline measurements; six subjects were excluded from the statistical analysis because of missing PA data during the recording week. The 24 subjects with complete data had a mean age of $60 \pm 3$ (55-65) years and a mean body mass index of $26.1 \pm 3.5(19.4-32.7) \mathrm{kg} / \mathrm{m}^{2}$. Values for EI, EE, BMR, PA, WO, and $\mathrm{WI}$ are presented in table 6.1.

$\mathrm{BMR}_{W H O}$ was not significantly different from $B \mathrm{BR}_{\mathrm{YH}}$ (paired t-test, $\mathrm{P}=0.99$ ). The mean differences of $0.45 \mathrm{MJ} / \mathrm{d}$ between $E E_{\mathrm{DLW}}$ and $E E_{\mathrm{VH}+\mathrm{PA}}$ and of $0.47 \mathrm{MJ} / \mathrm{d}$ between $E E_{D L W}$ and $E E_{W H O+P_{A}}$ were not significant. The reported $E I$ of $9.0 \mathrm{MJ} / \mathrm{d}$ was significantly lower than $\mathrm{EE}_{\mathrm{DLW}}, \mathrm{EE}_{\mathrm{VH}+\mathrm{PA}}$ and $\mathrm{EE}_{\mathrm{WHO}+\mathrm{PA}}$. The correlation between reported $\mathrm{EI}$ and $E E_{\mathrm{VH}+\mathrm{PA}}$ is shown in figure 6.1 ; the line of identity and $95 \%$ prediction margins are also shown. Twelve of the 24 subjects were identified as underreporters; i.e. they reported an EI below the prediction margin. 
Table 6.1: Energy intake (EI), energy expenditure (EE), basal metabolic rate (BMR), physical activity (PA), water intake (WI), water loss (WO) and metabolic water values of the total group of subjects $(n=24)^{1}$.

\begin{tabular}{|c|c|c|}
\hline & Mean \pm SD & (ranges) \\
\hline EI $(\mathrm{MJ} / \mathrm{d})$ & $9.0 \pm 2.1$ & $(5.3-14.5)$ \\
\hline $\mathrm{EE}_{\mathrm{DL}} \mathrm{w}(\mathrm{MJ} / \mathrm{d})$ & $11.3 \pm 2.3^{2}$ & $(7.5-14.6)$ \\
\hline $\mathrm{BMR}_{\mathrm{VH}}(\mathrm{MJ} / \mathrm{d})$ & $6.6 \pm 1.1$ & $(4.7-8.8)$ \\
\hline $\mathrm{BMR}_{\text {WHO }}(\mathrm{MJ} / \mathrm{d})^{3}$ & $6.6 \pm 1.2$ & $(5.0-9.2)$ \\
\hline PA (counts/min.) & $24.2 \pm 10$ & $(10.7-48.6)$ \\
\hline $\mathrm{EE}_{\mathrm{VH}+\mathrm{PA}}(\mathrm{MJ} / \mathrm{d})^{4}$ & $10.8 \pm 1.7^{2}$ & $(8.2-14.0)$ \\
\hline $\mathrm{EE}_{\text {WHO+PA }}(\mathrm{MJ} / \mathrm{d})^{5}$ & $10.8 \pm 1.8^{2}$ & $(8.3-14.6)$ \\
\hline WI $(\mathrm{l} / \mathrm{d})$ & $2.2 \pm 0.6$ & $(1.0-3.6)$ \\
\hline Metabolic water $(\mathrm{l} / \mathrm{d})$ & $0.3 \pm 0.06$ & $(0.2-0.4)$ \\
\hline WO $(1 / d)$ & $3.2 \pm 0.7^{6}$ & $(1.8-4.1)$ \\
\hline
\end{tabular}

${ }^{1}$ DLW, doubly labelled water method; VH, ventilated-hood technique; WHO, World Health Organisation equations; PA, triaxial accelerometer assessed physical activity.

${ }^{2}$ Significantly different from $\mathrm{EI}, \mathrm{P}=0.0007$.

${ }^{3}$ Estimated with an equation including age, sex, body mass and height (8).

${ }^{4} \mathrm{EE}_{\mathrm{VH}+\mathrm{PA}}=-1.259+1.55 * \mathrm{BMR}_{\mathrm{VH}}+0.076$ counts/minute (PA).

${ }^{5} \mathrm{EE}_{\mathrm{WHO}+\mathrm{PA}}=-1.259+1.55 * \mathrm{BMR}_{\mathrm{WHO}}+0.076$ counts/minute (PA).

${ }^{6}$ Significantly different from the sum of WI and metabolic water, $\mathrm{P}=0.0007$.

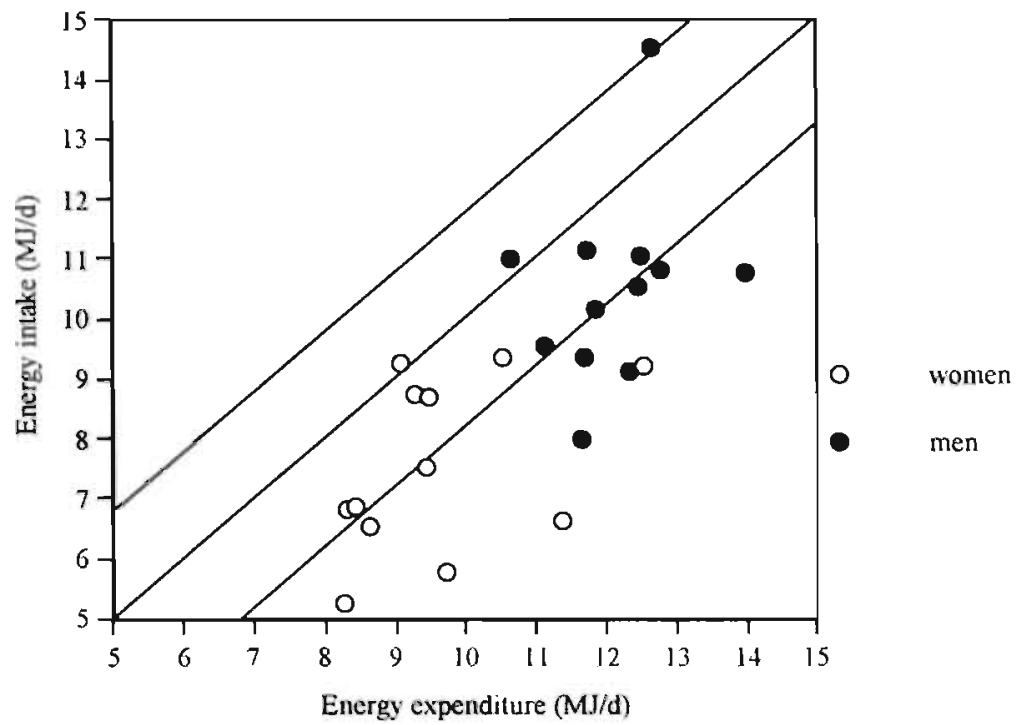

Figure 6.1: Correlation between reported energy intakes plotted and energy expenditure (calculated by using measured basal metabolic rate and triaxial accelerometer assessed physical activity) in elderly menand women. The line of identity and $95 \%$ prediction margins are shown.

Values for \%underreporting $g_{D L W}$ \%underreporting ${ }_{V H+P A}$, and \%underreporting ${ }_{W H O}+P_{A}$ were $19.4 \pm 14 \%, 16.7 \pm 13.6 \%$, and $16.4 \pm 15.5 \%$, respectively. A Bland Altman plot of the difference between $\%$ underreporting $\mathrm{DL}_{\mathrm{W}}$ and $\%$ underreporting $\mathrm{AH}_{\mathrm{PA}}$ against the mean \%underreporting is shown in figure 6.2. The difference was not related to the mean in a simple regression analysis $(r=0.06, P=0.78)$. The relative bias was $2.7 \%$ $(P=0.12)$ and the SD of the mean difference was $8.0 \%$. The four subjects clustered in 
the bottom left of figure 6.2 were men with a relatively high PAL (2.0 compared with 1.6 for the other 20 subjects). The difference between \%underreporting $\mathrm{DLw}_{\text {w }}$ and \%underreporting ${ }_{\mathrm{WHO}+\mathrm{PA}}$ was also not related to the mean of both percentages (simple regression analysis, $\mathrm{r}=0.15 ; \mathrm{P}=0.49)$. The relative bias was $3.0 \%(\mathrm{P}=0.18)$ and the $\mathrm{SD}$ of the mean difference was $11 \%$.

The mean of the three body mass measurements were $76.5 \pm 11.4$ on day $1,77.1 \pm 11.7$ on day 8 , and $76.8 \pm 11.7$ on day 15 . The change in body mass over the non-recording week was $0.62+0.74 \mathrm{~kg}$ and over the recording week was $-0.24 \pm 0.66 \mathrm{~kg}(\mathrm{P}=0.01)$. The change in body mass over the recording week was not significantly different from zero $(\mathrm{P}=0.10)$ and indicated no undereating. The energy equivalent of the change in body mass over the recording week was $-0.8 \pm 2.6 \mathrm{MJ} /$ day ( $1 \mathrm{~kg}$ body mass was assumed to be $30 \mathrm{MJ} ;(22))$. The reported water intake plus calculated metabolic water was $2.6 \pm 0.7 \mathrm{Vd}$ and was significantly different from the measured water loss of $3.2 \pm 0.7 \mathrm{l} / \mathrm{d}$ $(\mathrm{P}=0.0007)$. The calculated \%underrecording was $19.5 \pm 11.2 \%$.

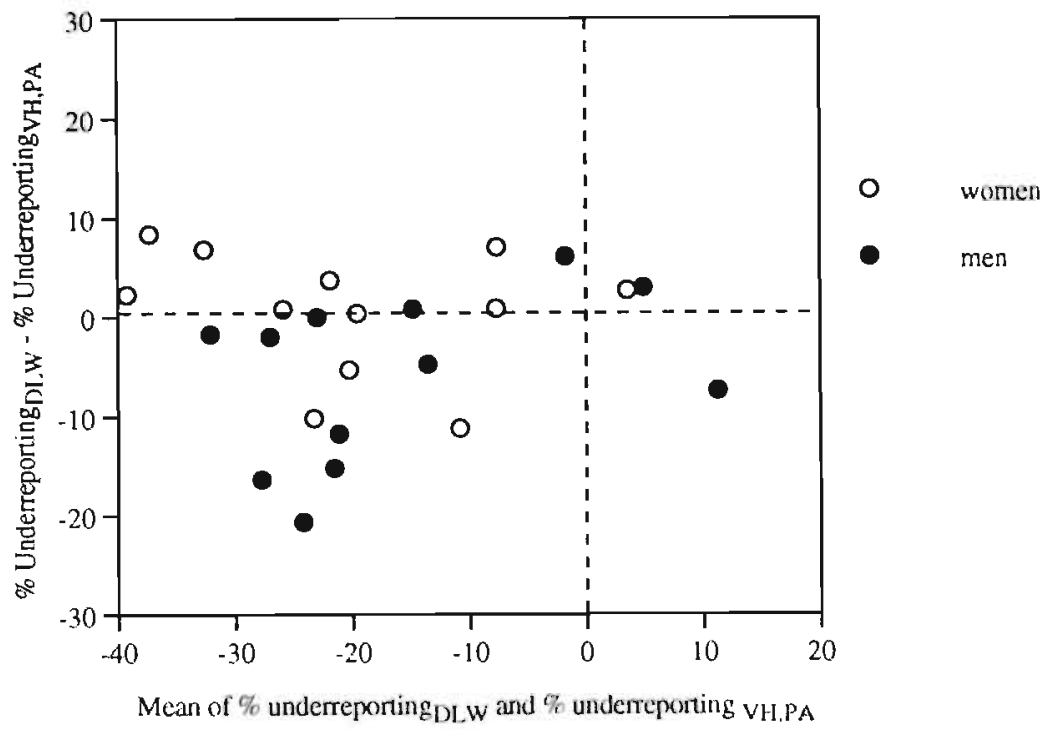

Figure 6.2: Difference between the percentage underreporting by elderly men and women calculated on the basis of energy intake and energy expenditure measured with the doubly labelled water method (\%underreporting $\mathrm{DLW}_{\mathrm{W}}$ ) and the percentage underreporting calculated on the basis of energy intake and energy expenditure measured by using triaxial accelerometer-assessed physical activity (PA) and basal netabolic rate measured with a ventilated-hood (VH) technique (\%underreporting VH $_{\text {PA) }}$ ) plotted against the mean of the \%underreporting DL and \%onderreporting ${ }_{\mathrm{VH}+\mathrm{PA}}$ values.

\section{Discussion}

The use of a combination of PA and BMR $\mathrm{WHO}_{\mathrm{WH}}$ or $\mathrm{BMR} \mathrm{VH}_{\mathrm{VH}}$ values was found to be a good validation method for reported EI given that no significant difference was found between \%underreporting ${ }_{V H}+P_{A}$. \%underreporting ${ }_{W H O}+P A$, and \%underreporting ${ }_{U L W}$. 
The relative bias between the percentages underreporting $g_{L W}$ and underreporting:H: $\mathrm{P}_{\mathrm{i}}$ might be higher for subjects with PALs $>2.0$ than for subjects with PALs $<2.0$. However, because only 4 subjects in this study had a PAL of \pm 2.0 , no conclusions can be drawn from this.

The triaxial accelerometer used in this study is a miniaturized version (based on same principle) of the triaxial accelerometer which was used in previous studies $(7,27)$. Thus, the smaller triaxial accelerometer required a new EE equation, which was developed in a previous, unpublished study. The equation was derived from a younger population but, as shown in the present study, is also valid for older populations. A few of the accelerometers used in the present study did not registrar any activity, because of problems with battery contact; the data of 6 subjects had to be excluded from the statistical analysis.

In previous studies, the output of the triaxial accelerometer for movement registration was found to be a good discriminator between PALs (27). However, additional studies with groups of subjects with a wider range of PALs than in the subjects of the present study is advised to assess the use of a combination of BMR and PA to validate reported EI.

The triaxial accelerometer gives an objective measurement of the PA of subjects in their natural environment, which is not true of diaries or questionnaires (18). Subjects completing activity diaries may alter their normal activity patterns or overreport their activity. In a group of obese subjects, who failed to lose weight under a physician's care, overreporting of up to $51 \%$ of PA, assessed with activity diaries, was found (16). In the present study, \%underreporting $( \pm 18 \%)$ was comparable with values found in other studies $(2,14,15,20,26)$. In these other studies, the \%underreporting was explained on a group level by underrecording (i.e. the compliance with food recording) and not by undereating as in our two previous studies $(14,15)$. In the present study, \%underrecording was calculated by using the water balance method, but water balance was not corrected here for eventual water input from atmospheric exchange. The water input from atomospheric exchange can account for 3 to $10 \%$ of water turnover depending on the inspired air volume and absolute humidity, which would result in an increase in total water intake (21). A higher total water intake would mean a smaller difference between water intake and water loss and the \%underrecording would be reduced to 17 or $10 \%$.

A reported energy intake outside the prediction interval of the calculated EE (figure 6.1) indicated underreporting. A simple adjustment of food intake for these underreporters is no solution because of selective underreporting (3). Recent studies showed selective underreporting of fat intake by both obese and lean subjects $(15,19$, 23). The reported protein intake can be validated with urine nitrogen analysis (5), but there is no validation method for the reported carbohydrate and fat intakes (13). A possible method to solve the problem of underreporting is confronting subjects with the accuracy of their recordings: whether they ate less during the recording period (undereating) or whether they did not write down everything they consumed (underrecording). The subjects would then be asked to rerecord their food intake. In a previous study of.lean women, this method resulted in improved food recording by 16 of the 18 subjects (12). More studies other populations are necessary to validate this method for improving the accuracy of food records (12). 
This study and other studies of underreporting of food intake make it clear that the design of a nutrition study should include a validation method for reported food intakes as well as a strategy for dealing with possible underreporting of food intake (2, $14,15,20,26)$. The triaxial accelerometer for the assessment of physical activity proved to be an easy and valid method for the determination of underreporting of food intake at the individual level.

\section{References}

1. Altman. DG, and Bland JM. Measurement in medicine: the analysis of method comparison studies. Statistician 32: 307-317, 1983.

2. Bandini, LG, Schoeller, DA, Cyr, HN, and Dietz, WH. Validity of reported energy intake in obese and nonobese adolescents. Am J Clin Nutr 52: 421-425, 1990.

3. Bellach, B, and Kohlmeier, L. Energy adjustment does not control for differential recall bias in nutritional epidemiology. J Clin Epidemiol 51: 393-398, 1998.

4. Bingham, SA. Limitations of the various methods for collecting dietary intake data. Ann Nutr Metab 35: 117-127, 1991.

5. Bingham, $\mathrm{SA}$, and Cummings, $\mathrm{JH}$. Urine nitrogen as an independent validatory measure of dietary intake: a study of nitrogen balance in individuals consuming their normal diet. Am J Clin Nutr 42 : 1276-1289, 1985.

6. Black, AE, Bingham, SA, Johansson, G, and Coward, WA. Validation of dietary intakes of protein and energy against 24 hour uninary $\mathrm{N}$ and DLW energy expenditure in middle-aged women, retired men and post-obese subjects: comparisons with validation against presumed energy requirements. Eur J Clin Nutr 51: 405-413, 1997

7. Bouten, C, Verboeket-van de Venne, W, Westerterp, K, Verduin, M, and Janssen, J. Daily physical activity assessment: comparison between movement registration and doubly labelled water. J Appl Physiol 81: 1019-1026, 1996.

8. FAO/WHO/UNU. Energy and protein requirements. World Health Organisation, Geneva, 1985.

9. Fjeld, CR, Brown, $\mathrm{KH}$, and Schoeller, DA. Validation of the deuterium oxide method for measuring average daily milk intake in infants. Am J Clin Nutr 48: 671-679, 1988.

10. Goldberg, GR, Black, AE, Jebb, SA, Cole, TJ, Murgatroyd, PR, Coward, WA, and Prentice, AM. Critical evaluation of energy intake data using fundamental principles of energy physiology: 1 . Derivation of cut-off limits to identify under-recording. Eur J Clin Nutr 45: 569-581, 1991.

11. Goran, MI. Variation in total energy expenditure in humans. Obes Res 3: 59-66, 1995.

12. Goris, AHC, and Westerterp, KR. Improved reporting of habitual food intake after confrontation with earlier results on food reporting. British Joumal of Nutrition 83: 363-369, 2000.

13. Goris, AHC, and Westerterp, KR. Postabsorptive respiratory quotient and food quotient - an analysis in lean and obese men. Eur J Clin Nutr 54: 546-550, 2000.

14. Goris, AHC, and Westerterp, KR. Underreporting of habitual food explained by undereating, in motivated lean women. J Nutr 129: 878-882, 1999.

15. Goris, AHC, Westerterp-Plantenga, MS, and Westerterp, KR. Undereating and underrecording, of habitual food intake in obese men; selective underreporting of fat intake. Am J Clin Nutr 71: 130134,2000 .

16. Lichtman, SW, Pisarska, K, Raynes Berman, E, Pestone, M, Dowling, H, Offenbacher, E, Weisel, $H$, Heshka. S. Matthews, DE. and Heymsfield, SB. Discrepancy betwcen self-rcported and actual caloric intake and exercise in obese subjects. N Engl J Med 327: 1893-1898, 1992.

17. Lissncr. L, Heitmann, BL, and Lindroos, AK. Measuring intake in free-living human subjects: a question of bias. Proc Nutr Soc 57: 333-339, 1998.

18. Melanson, EL, and Freedson, PS. Physical activity assessment: a review of methods. Cnit Rev F Sc Nutr 36: 385-396, 1996. 
19. Schaefer, E, Augustin, J, Schaefer, M, Rasmussen, H, Ordovas, J, and Dallal, G. Lack of efficacs of a food-frequency questionnaire in assessing dietary macronutrient intakes in subjects consuming diets of known composition. Am J Clin Nutr 71: 746-751, 2000.

20. Schoeller, DA. How accurate is self-reported dietary energy intake? Nutr Rev 48: 373-379, 1990)

21. Schoeller, DA, and Santen, Ev. Measurement of energy expenditure in humans by doubly labelled water method. J. Appl. Physiol. 53: 955-959, 1982.

22. Schoffelen, PFM, Westerterp, KR, Saris, WHM, and ten Hoor, F. A dual-respiration chamber system with automated calibration. J Appl Physiol 83: 2064-2072, 1997

23. Tomoyasu, N, Toth, M, and Poehlman, E. Misreporting of total energy intake in older African Americans. Int J Obes 24: 20-26, 2000.

24. Weir, JB. New methods for calculating metabolic rate with special reference to protein metabolusm. J Physiol 109: 1-9, 1949.

25. Westerterp, K. Assessment of physical activity level in relation to obesity: current evidence and research issues. Med Sci Sports Exerc 31: S522-S525, 1999.

26. Westerterp, K, Verboeket-van de Venne, W, Meijer, G, and ten Hoor, F. Self-reported intake as a measure for energy intake. A validation against doubly labelled water. Obcs Eur 9l: 17-22. 1991

27. Westerterp, KR, and Bouten, CVC. Physical activity assessment: comparison between movement registration and doubly labelled water method. Z Emahnungswiss 36: 263-267, 1997.

28. Westerterp, KR, Donkers, JH, Fredrix, EW, and Boekhoudt, P. Energy intake, physical activity and body weight: a simulation model. Br J Nutr 73: 337-347, 1995. 
Chapter 7

Repeated measurement of habitual food intake increases underreporting and induces selective underreporting

Annelies HC Goris, Erwin P Meijer, Klaas R Westerterp

Department of Human Biology, Maastricht University, The Netherlands

In Press: British Journal of Nutrition 


\section{Abstract}

The aim of the current study was to measure differences in reporting behaviour between a first time of 7 day food recording and a second time of 7 day food recording, after 12 weeks, in a group of elderly men $(n=17)$ and women $(n=17)$. Half the group followed an exercise intervention. The mean age was $61 \pm 5$ years and mean BMI was $26.2 \pm 3.8 \mathrm{~kg} / \mathrm{m}^{2}$. Reported energy intake was compared with energy expenditure as calculated from measured basal metabolic rate and physical activity assessed with a triaxial accelerometer for movement registration. Total underreporting was divided into undereating and underrecording. Undereating was calculated from the change in body mass over the recording week and the underrecording was measured using the water balance technique. In the first period, the total underreporting was $21 \%$ and increased to $27 \%$ in the second period $(\mathrm{P}=0.03)$. In the first period there was no indication for subjects eating less during the recording week, however, in the second period subjects lost body mass during the food recording indicating undereating. The amount of underrecording was calculated at $21 \%$ in the first period and $18 \%$ in the second period of recording $(\mathrm{P}=0.28)$. During the second period subjects selectively underreported their fat intake and overreported their protein intake. In conclusion, repeated assessment of food intake caused a higher quantitative and a qualitative underreporting of food intake. The effect of interventions (dietary or otherwise) on habitual food intake might be confounded by changes in food reporting behaviour.

\section{Introduction}

In intervention studies on diet components or behaviour one often studies effects on food intake. However, the aimed effects of the intervention on the food intake are probably not only due to the intervention, but also due to changes in food intake reporting. It is known that underreporting can range from $0-50 \%$ and is observed in both obese and lean subjects (1)) $(6,7,12,16)$. The underreporting might be due to undereating, subjects consuming less while food recording, or to underrecording, failure to record in a food diary everything that is consumed. Earlier studies showed in a group of lean women a $16 \%$ underreporting due to undereating and in a group of obese men a $37 \%$ underreporting which could be divided into $26 \%$ undereating and $12^{\circ} .0$ underrecording $(6,7)$. A second time of reporting food intake might change the proportions of undereating and underrecording. Previous studies that have measured food intake both before and after an intervention have not made the distinction between underrecording and undereating. Westerterp et al. (1991) measured food intake ( 7 day dietary record) and energy expenditure (with doubly labelled water) in 16 non-obese men and women before and after a 40 -week exercise intervention. Before the start of the intervention the difference between energy intake and energy expenditure was $-5 \pm 28 \%$ and after the 40 weeks ( 13 subjects completed the training intervention) the difference had increased to $-19 \pm 17 \%$. The subjects perceived the reporting of food intake for the fourth time (subjects also reported food intake two times during the intervention) as a real burden (16).

Insight into the reporting of habitual food intake (undereating vs underrecording and selective underreporting) is needed to be able to detect changes in the food intake after 
an intervention. The aim of the present study was to measure differences in reporting behaviour between a first time of 7 day food recording and a second time of 7 day food recording in a group of men and women. Half of the group followed an exercise intervention of 12 weeks and the other half served as a control group. The percentages underreporting, undereating and underrecording were measured before and at the end of the 12 weeks. Reported energy intake was compared with energy expenditure as calculated from measured basal metabolic rate and physical activity assessed with a triaxial accelerometer for movement registration. Undereating was calculated from the change in body mass over the recording week and the underrecording was measured with the water balance technique as described recently (6).

\section{Materials and methods}

\section{Subjects}

Twenty-six men and twenty-three women were recruited for a controlled exercise intervention study by advertisements in local newspapers. Forty-nine subjects participated in the baseline measurements of whom 3 subjects dropped out of the study because of personal reasons. From the forty-six subjects, 12 subjects had a missing physical activity registration in the first and / or second period. The results presented here are therefore from 34 subjects $(9$ men and 10 women in the exercise group and 8 men and 7 women in the control group). They had a mean age of $61 \pm 5$ years and a mean body mass index of $26.2 \pm 3.8 \mathrm{~kg} / \mathrm{m}^{2}$. Baseline characteristics were the same for both groups. The protocol was approved by the Medical Ethical Committee of the Maastricht University.

\section{Prolocol}

The subjects were studied before the start of the exercise intervention (in the autumn) and during the final phase of the 12 weeks exercise intervention (in the winter). The measurements were performed in a two week period. Food and water intake were measured over the second week simultaneously with the assessment of physical activity and water loss. Basal metabolic rate was measured in the first week. Body mass changes were determined over the first week and over the second week, the recording week, to control for changes in the diet (i.e. undereating) during the recording period (see (6)). The water balance was also assessed over the recording week to measure the underrecording (i.e. the failure to record in a food diary everything that is consumed) (6).

\section{Food and water intake}

Subjects recorded for 7 days everything they consumed in a structured food diary. They received instructions from a dietician on how to fill in the diary (they did not have to weigh everything) and were asked not to change their dietary habits. The data on the food records were used to calculate intakes of total energy, protein. fat, carbohydrate and water with a computer program based on food tables (Becel nutrition program, 1988, Nederlandse Unilever bedrijven BV, Rotterdam, The Netherlands). Total water intake was calculated from reported food and water intakes and the calculated amount of metabolic water. The amount of metabolic water was estimated 
from protein, fat and carbohydrate intake derived from the 7 day food diary. Oxidation water is $0.4 \mathrm{l} \mathrm{nl} / \mathrm{g}$ for protein, $1.07 \mathrm{ml} / \mathrm{g}$ for fat and $0.6 \mathrm{ml} / \mathrm{g}$ for carbohydrate (3).

\section{Einergy expenditure and water loss}

Energy expenditure was derived from basal metabolic rate (BMR) and physical activity (PA) as assessed with a triaxial accelerometer for movement registration. BMR was measured by means of a computerised open circuit ventilated hood system, in the morning in a fasting state (subjects slept the night before at the university) while subjects were lying for $30 \mathrm{~min}$ in supine position. Gas analyses were performed by a paramagnetic oxygen analyser (Servomex type 500A, Crowborough Sussex, UK) and an infrared carbon dioxide analyser (Servomex, type 12-X1), similar to the analysis system described by Schoffelen et al (1997) (13). Weir's formulas were used for calculating BMR (15).

Physical activity was assessed with a triaxial accelerometer for movement registration, the Tracmor (Philips Research, Eindhoven, The Netherlands). The Tracmor is a small device $(7 \times 2 \times 0.8 \mathrm{~cm}, 30 \mathrm{~g})$ and measures accelerations in the anteroposterior, mediolateral and vertical directions of the trunk. Subjects wore the Tracmor during waking hours and recorded the time they put on and off the Tracmor. Total counts per day were divided by the time subjects wore the Tracmor to get average counts/minute (2). Total energy expenditure (EE) was calculated with the formula: $E E(M J / d)=-$ $1.259+1.55 * \mathrm{BMR}+0.076 * \mathrm{PA}$ (counts $/ \mathrm{min})\left(\mathrm{r}^{2}=0.90, \mathrm{p}<0.0001 ; \mathrm{SD}=0.809 \mathrm{MJ} / \mathrm{d}\right.$, derived from a validation against doubly labelled water) (4).

Water loss was measured with deuterium labelled water $\left({ }^{2} \mathrm{H}_{2} \mathrm{O}, 70 \mathrm{~g}\right.$ water with an enrichment of 5 atom $\%$ excess ${ }^{2} \mathrm{H}$ ). Subjects drank this dilution after voiding (baseline urine sample) the evening before the start of the two week period. More urine samples were collected in the morning and evening of day 1 , evening of day 7 , morning of day 8 , evening of day 14 and morning of day 15 . Deuterium content was measured in urine samples with an isotope mass spectrometer (19). Water loss was calculated over the second week from ${ }^{2} \mathrm{H}$ elimination with the equation of Fjeld et al. (1988), as described previously (18).

\section{Body mass}

Subjects were weighed (in underwear) in the morning before any food or beverage consumption and after voiding on day 1 , on a digital balance accurate to $0.01 \mathrm{~kg}$ (Sauter, Ebingen, Germany) and day 8 and 15, because of practical reasons, on a digital balance accurate to $0.1 \mathrm{~kg}$ (Seca, Almere, The Netherlands). Both balances were calibrated and gave the same results.

\section{Exercise intervention}

Subjects of the exercise group trained twice a week, for one hour, on non-consecutive days for 12 weeks. All training sessions were performed at a fitness centre and supervised by a fitness instructor. The intensity of the training program was approximately $50 \%$ of heart rate reserve.

\section{Statistics}

Means and standard deviations were calculated. Body mass changes over the nonrecording week and over the recording week were compared with paired t-tests (two- 
sided) and the body mass change over the recording week was also compared with zero in an one-sample t-test (two-sided). Energy intake and energy expenditure, water intake and water loss were compared with each other in a paired t-test (two-sided). Non-parametric tests were used in case data was not normally distributed.

The underreporting, underrecording and undereating were calculated for the exercise, control and total group separately and were calculated as follows:

$\%$ underreporting $=[($ energy intake - energy expenditure $) /($ energy expenditure $)] * 100 \%$ $\%$ undereating $=[(\text { body mass change } * 30 \mathrm{MJ} / 7 \mathrm{~d}) /(\text { energy expenditure })]^{*} 100 \%$ $\%$ underrecording $=[($ water intake - water loss $) /($ water loss $)] * 100 \%$.

The different parameters measured in period one and two were compared with paired t-test (two-sided) and/or simple regression analysis. Significance was set on $\mathrm{P}<0.05$. The STATVIEW program (1992-98; SAS Institute Inc. North Carolina, USA) was used for the statistical analysis.

\section{Results}

Table 7.1 shows the mean results of reported energy intake (EI), basal metabolic rate, physical activity counts and calculated energy expenditure (EE) of period one and two for both the exercise and control group. No differences in energy intake and expenditure were found between the exercise and control group. The calculated percentages underreporting were also not significantly different between the two groups (table 7.3).

Table 7. I: Body mass (BM), body mass index (BMI), reported energy intake (EI), basal metabolic rate (BMR), physical activity (PA) and total calculated energy expenditure (EE) for two repeated measurements (period 1 and period 2, with a time lapse of 12 weeks between). (Values are means and standard deviations for 19 subjects in the exercise group and 15 subjects in the control group)

\begin{tabular}{|c|c|c|c|c|c|c|}
\hline & \multicolumn{3}{|c|}{ Period I } & \multicolumn{3}{|c|}{ Period 2} \\
\hline & Exercise & Control & Total & Exercise & Control & Total \\
\hline & Mean \pm SD & Mean $\pm \underline{\text { SD }}$ & Mean $\pm S D$ & Mean \pm SD & Mean SD & Mean SD \\
\hline BM (kg) & $74.3 \pm 11.0$ & $75.7 \pm 11.8$ & $74.9 \pm 11.2$ & $74.6 \pm 10.8$ & $76.7 \pm 11.7$ & $75.5 \pm 11.1$ \\
\hline BMI $\left(\mathrm{kg} / \mathrm{m}^{2}\right)$ & $26.1 \pm 3.1$ & $26.3 \pm 4.6$ & $26.2 \pm 3.8$ & $26.2 \pm 3.0$ & $26.6 \pm 4.5$ & $26.4 \pm 3.7$ \\
\hline $\mathrm{EI}(\mathrm{MJ} / \mathrm{d})$ & $8.0 \pm 2.2^{\circ}$ & $9.3 \pm 2.6^{\circ}$ & $8.6 \pm 2.4^{\circ}$ & $7.5 \pm 2.0^{\circ}$ & $8.9 \pm 2.1^{\circ}$ & $8.1 \pm 2.2^{\circ}$ \\
\hline BMR $(\mathrm{MJ} / \mathrm{d})$ & $6.5 \pm 1.1$ & $6.7 \pm 1.2$ & $6.6 \pm 1.1$ & $6.5 \pm 1.0$ & $6.9 \pm 1.1^{\circ}$ & $6.7 \pm 1.0$ \\
\hline $\begin{array}{l}\text { PA } \\
\text { (counts/min) }\end{array}$ & $25.3 \pm 10.6$ & $26.7 \pm 11.4$ & $25.9 \pm 10.8$ & $25.1 \pm 7.4$ & $29.6 \pm 11.2$ & $27.1 \pm 9.4$ \\
\hline $\mathrm{EE}(\mathrm{MJ} / \mathrm{d})$ & $10.7 \pm 1.9$ & $11.1 \pm 1.7$ & $10.9 \pm 1.8$ & $10.7 \pm 1.6$ & $11.7 \pm 1.9^{\circ}$ & $11.1 \pm 1.8$ \\
\hline
\end{tabular}

${ }^{t}$ Energy expenditure was calculated from basal metabolic and physical activity counts.

EI was significantly lower than EE $(\mathrm{P}<0.05)$

“ Significant difference between period 1 and $2(\mathrm{P}<0.05)$

Figure 7.1 shows the \% underreporting in period two plotted against the \% underreporting in period one for the total group (simple regression analysis; $r^{2}=0.73$, $\mathrm{P}<0.0001$ ). The degree of underreporting remains rather constant within subjects. Individual changes in reported energy intake were due to individual differences in the amount of underreporting between period 1 and 2 (figure 7.2; simple regression analysis $r^{2}=0.77, P<0.0001$ ). 


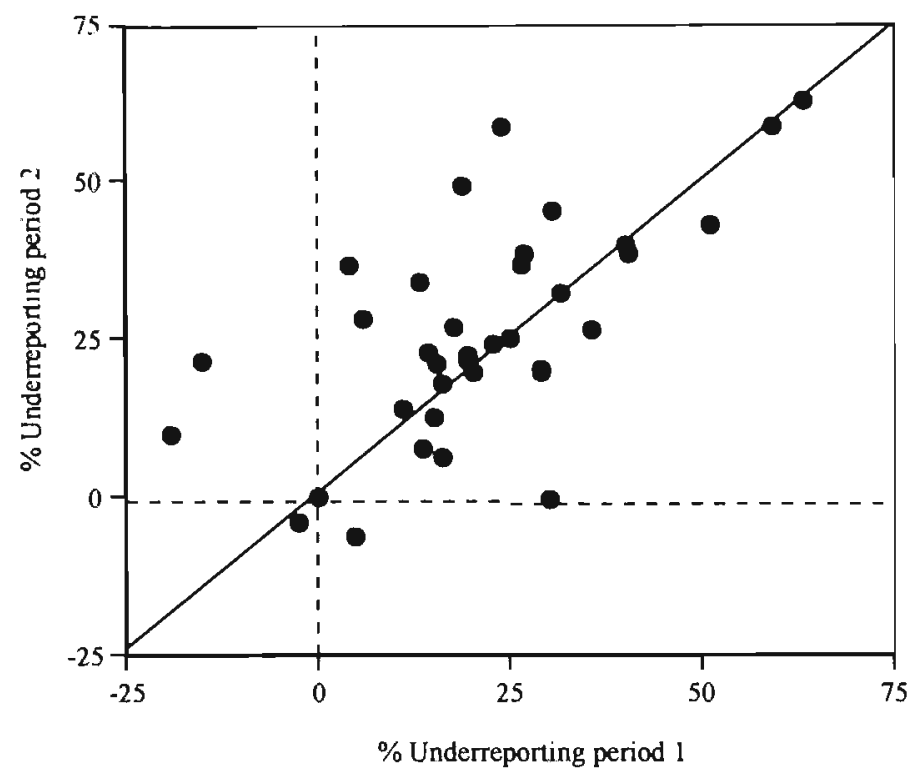

Figure 7.1. The $\%$ underreporting during the second period plotted against the $\%$ underreporting during the first period of 7-d food recording, with the calculated regression line: \%underreporting second period $=0.98 \% \%$ underreporting first period $+0.81(r=0.85, P<0.0001)$.

The body mass change over the first recording week was not different from zero for the total group (one sample t-test. $\mathrm{P}=0.16$ ) and also for the exercise (one sample sign test, $\mathrm{P}-0.33$ ) and control group (one sample sign test, $\mathrm{P}=0.30$ ) separately (table 7.2) and there was no undereating in the first period. In the second period the body mass change over the recording week was significantly different from zero for the total group (one sample t-test, $\mathrm{P}=0.03$ ) and from the body mass change over the nonrecording week in the second period of $0.23 \pm 0.64 \mathrm{~kg}$ (paired t-test, $\mathrm{P}=0.01$ ). The body mass change over the second recording week for the exercise and control group were not significantly different from zero (one sample sign test, exercise group $\mathrm{P}=0.08$ control group $\mathrm{P}=0.18$ ). The $\%$ undereating was in the second period $15.4 \pm 18.1 \%$ for the total group (table 7.3). The body mass change of $-0.62 \pm 1.9 \mathrm{~kg}$ between period one and two was not significantly different from zero (one sample t-test, $\mathrm{P}=0.72$ ).

The results on total water intake (reported + metabolic) and water loss for the exercise, control and total group are described in table 7.2. Total water intake was significantly lower (paired $\mathrm{t}$-tests, $\mathrm{P}<0.0001$ for all groups) than measured water loss indicating underrecording (table 7.3).

The \% underreporting and underrecording in period one did not differ from each other in a paired t-test for the total group $(\mathrm{P}=0.82)$ and in a paired sign test for the exercise $(\mathrm{P}=0.36)$ and for the control group $(\mathrm{P}=0.61)$ (table 7.3$)$. The sum of the $\%$ undereating and underrecording for the total group in period two was also not significantly different from the total \% underreporting in period two $(\mathrm{P}=0.06$. exclusion of one outlier $\mathrm{P}=0.11$ ). The outlier mentioned was a subject from the exercise group who lost 
$1.8 \mathrm{~kg}$ over the second recording week. The \% underreporting and underrecording in period 2 were significantly different from each other in the exercise group (paired sign test, $P=0.02$ ), but not in the control group (paired sign test, $P>0.999$ ). The difference between underreporting and underrecording in period 2 for the exercise group was probably due to a small amount of undereating which did not reach significance (body mass change over the recording week for the exercise groups was not different from zero; $\mathrm{P}=0.08$ ).

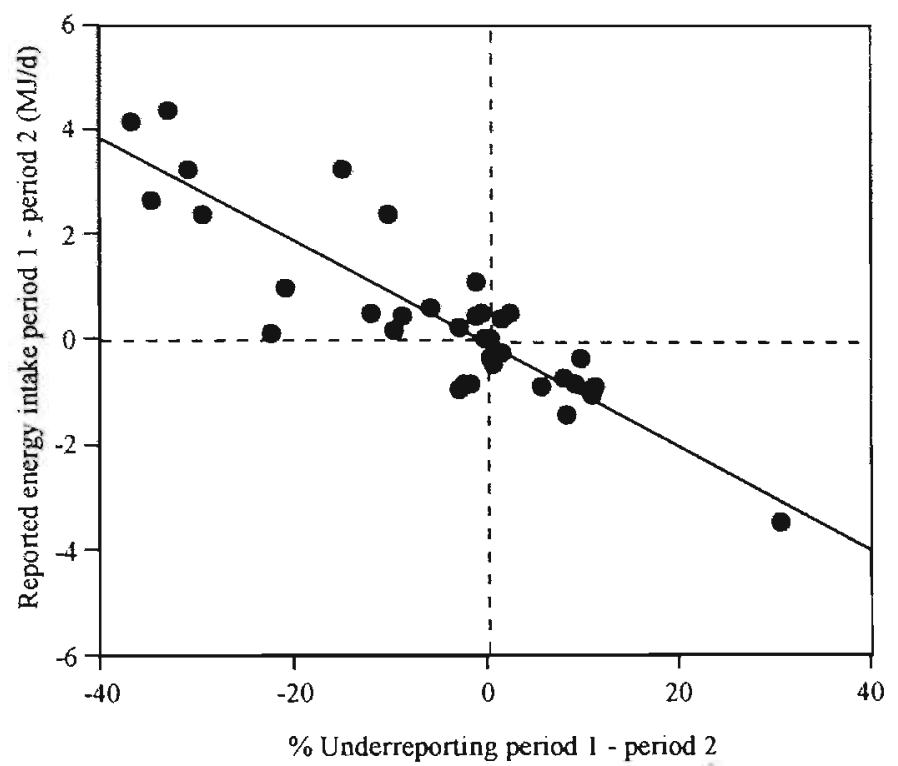

Figure 7.2. The difference of reported energy intake between period one and two plotted against the difference of the $\%$ underreporting between period one and two, with the calculated regression line: difference energy intake $=-0.1 *$ difference in \%underreporting -0.09 ( $r=0.88, \mathrm{P}<0.0001)$.

Table 7.2: The body mass change over the recording week $(\triangle \mathrm{BM})$, total water intake plus metabolic water (WI), water loss (WO) for two repeated measurements (period 1 and pieriod $2^{\mathrm{j}}$ ). (Values are means and standard deviations for 19 subjects in the exercise group and 15 subjects in the control group)

\begin{tabular}{l|ccc|ccc} 
& $\begin{array}{c}\text { Exercise } \\
\text { Mean } \pm \text { SD }\end{array}$ & $\begin{array}{c}\text { Period I } \\
\text { Control } \\
\text { Mean } \pm \text { SD }\end{array}$ & $\begin{array}{c}\text { Total } \\
\text { Mean } \pm \text { SD }\end{array}$ & $\begin{array}{c}\text { Exercise } \\
\text { Mean } \pm \text { SD }\end{array}$ & $\begin{array}{c}\text { Controd 2 } \\
\text { Mean } \pm \text { SD }\end{array}$ & $\begin{array}{c}\text { Total } \\
\text { Mean } \pm \text { SD }\end{array}$ \\
\hline$\triangle B M$ & $-0.37 \pm 0.71$ & $-0.01 \pm 0.82$ & $-0.20 \pm$ & $-0.26 \pm 0.64$ & $-0.23 \pm 0.69$ & $-0.25 \pm$. \\
$(\mathrm{kg} / \mathrm{wk})$ & & & 0.77 & & & $0.65^{* *}$ \\
WI (V/d) & $2.3 \pm 0.8^{*}$ & $2.6 \pm 0.7^{*}$ & $2.4 \pm 0.7^{*}$ & $2.2 \pm 0.6^{*}$ & $2.2 \pm 0.5^{*}$ & $2.2 \pm 0.6^{\circ}$ \\
WO (V/d) & $2.9 \pm 0.7$ & $3.2 \pm 0.7$ & $3.0 \pm 0.7$ & $2.7 \pm 0.6$ & $2.9 \pm 0.5$ & $2.8 \pm 0.6$ \\
\hline
\end{tabular}

${ }^{\mathrm{t}}$ Between period 1 and 2 was a time lapse of 12 weeks

"Significantly lower than water loss (paired t-tests; $\mathrm{P}<0.0001$ )

". Significantly different from zero (one sample $t$-test, $\mathrm{P}=0.03$ ) 
Table 7.3: The amount of underreporting, underrecording and undereating for two repeated measurements (period 1 and period $2^{t}$ ). (Values are means and standard deviations for 19 subjects in the exercise group and 15 subjects in the control group)

\begin{tabular}{l|ccc|ccc} 
& $\begin{array}{c}\text { Exercise } \\
\text { Mean } \pm \text { SD }\end{array}$ & $\begin{array}{c}\text { Period 1 } \\
\text { Control } \\
\text { Mean } \pm \text { SD }\end{array}$ & $\begin{array}{c}\text { Total } \\
\text { Mean } \pm \text { SD }\end{array}$ & $\begin{array}{c}\text { Exercise } \\
\text { Mean } \pm \text { SD }\end{array}$ & $\begin{array}{c}\text { Period 2 } \\
\text { Control } \\
\text { Mean } \pm \text { SD }\end{array}$ & $\begin{array}{c}\text { Total } \\
\text { Mean } \pm \text { SD }\end{array}$ \\
\hline $\begin{array}{l}\text { \%under- } \\
\text { reporting }\end{array}$ & $25.1 \pm 15.9$ & $16.2 \pm 18.8$ & $21.2 \pm 17.5$ & $29.7 \pm 16.4^{*}$ & $23.4 \pm 17.9$ & $26.9 \pm 17.1^{\circ}$ \\
$\begin{array}{l}\text { \%under- } \\
\text { recording } \\
\text { \%under- } \\
\text { eating }\end{array}$ & $23.0 \pm 12.9$ & $17.3 \pm 10.5$ & $20.5 \pm 12.1$ & $18.4 \pm$ & $22.5 \pm 14.6$ & $20.2 \pm 12.3$ \\
\hline
\end{tabular}

${ }^{t}$ Between period 1 and 2 was a time lapse of 12 weeks

-Significantly different from period $1(\mathrm{P}<0.05)$

- Significantly lower than \%underreporting (paired sign test $P=0.019$ )

The reported energy percentages fat carbohydrate and protein in period one were respectively, $36.1 \pm 4.5,43.2 \pm 6.8$ and $15.5 \pm 3.1 \%$ and were not different from the reported energy percentages fat, carbohydrate and protein in period two of respectively, $36.3 \pm 5.6,42.2 \pm 6.0$ and $15.9 \pm 3.0 \%$ (paired t-tests $\mathrm{P}>0.05$ ). Absolute intakes of protein and fat were not significantly different between period one and two. Only the carbohydrate intake was lower in period two compared to period one (paired t-test $\mathrm{P}=0.02$ ). In the first period the energy percentages fat, carbohydrate and protein were not related in simple regression analysis ( $P>0.05$, data not shown) to the total \% underreporting, thus there was no indication for selective underreporting of macronutrients. However, in the second period the energy percentage fat and the energy percentage protein were significantly related to the percentage underreporting (figure 7.3, simple regression analysis both $\mathrm{P}=0.02$, not influenced by exercise intervention). Table 7.4 shows the results of simple regression analysis of reported energy intakes at the different meals related to the \% underreporting for period one and two. The reported energy intakes at the different meals were all related to the \% underreporting, thus there was no selective underreporting of food intake at specific meals.

Table 7.4: Simple regression analysis of reported energy intakes at different meals $(y)$ and the percentage of underreporting $(x)$ in 34 subjects for two repeated measurements (period 1 and 2, 12 weeks later)

\begin{tabular}{lcccc}
\hline$y$ & \multicolumn{2}{c}{ Period one } & \multicolumn{2}{c}{ Period two } \\
\hline Breakfast & $\mathbf{r}$ & $\mathbf{P}$ & $\mathrm{r}$ & $\mathrm{P}$ \\
Moming snack & 0.38 & 0.0282 & 0.40 & 0.019 \\
Lunch & 0.33 & 0.0608 & 0.32 & 0.064 \\
Aftemoon snack & 0.52 & 0.0018 & 0.48 & 0.004 \\
Dinner & 0.65 & $<0.0001$ & 0.59 & 0.0002 \\
Evening snack & 0.53 & 0.0013 & 0.62 & $<0.0001$ \\
\hline
\end{tabular}




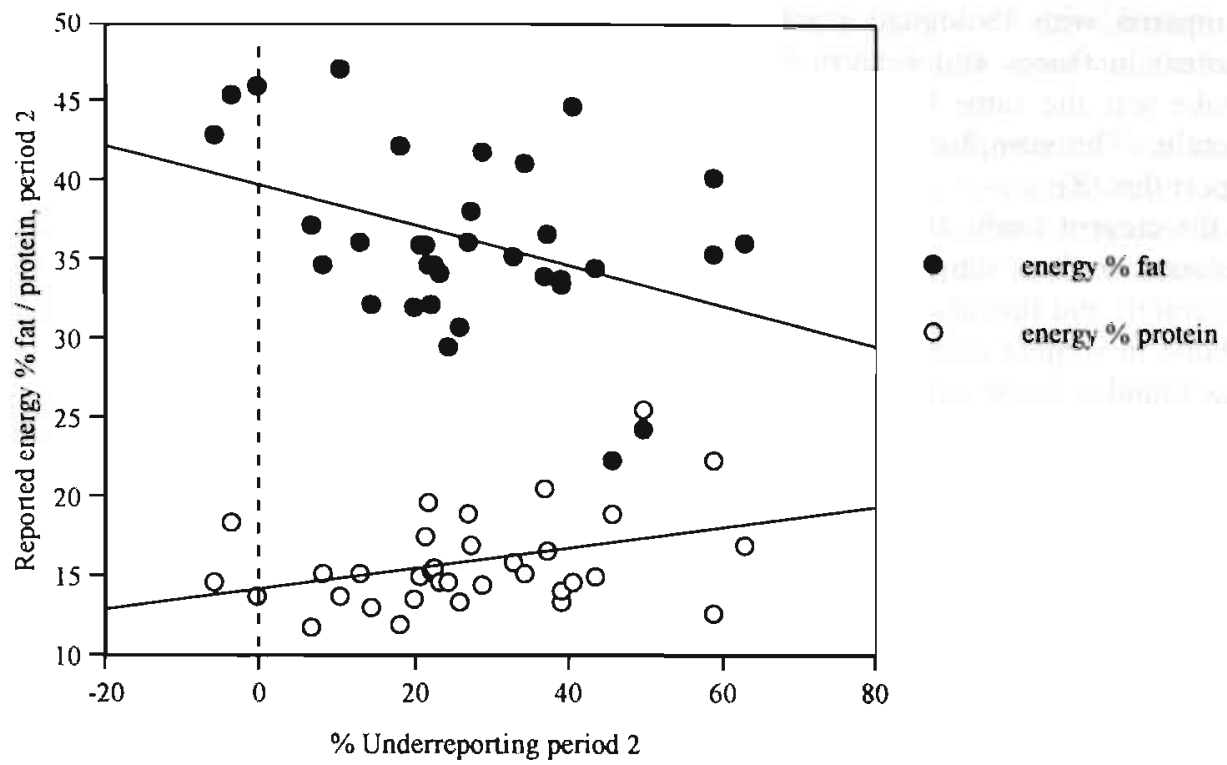

Figure 7.3. Reported energy \% fat and protein plotted against the \% underreporting for the second period with the calculated regression lines: energy \% fat $=-0.13 * \%$ underreporting $+40 \quad(r=-0.39$, $\mathrm{P}=0.02)$ and energy \% protein $=0.06 \% \%$ underreporting $+14(\mathrm{r}=0.37, \mathrm{P}=0.02)$.

\section{Discussion}

The results of the repeated measurement of food intake with a 12 week interval in a group of elderly men and women showed an increase of about $6 \%$ in the total amount of underreporting. The \% underrecording remained the same, but during the second period subjects ate less than habitual. Besides the increase in the \% underreporting in the second period, subjects also selectively underreported their fat intake and overreported their protein intake. Individual differences in reported energy intake were explained by differences in the amount of underreporting between period one and two. Thus, the assessment of food intake the second time caused a higher quantitative and a qualitative underreporting of food intake.

Whether subjects had an exercise intervention or not, did not seem to influence the food reporting here. This might be different if instead of an exercise intervention a nutrition intervention was performed as was done in a study of Kristal et al (10). They showed half of their subjects a videotape with information on the consequences of eating a high fat diet and the other half a placebo videotape. Subjects received preintervention and post-intervention assessment or only post-intervention assessment of their diet. The reported fat intake significantly decreased in the subjects who watched the intervention videotape compared to the control subjects. The effect of a nutrition intervention influenced the reporting of food intake, while the real food intake was not changed and thus one might say that the nutrition intervention failed (10). This effect was also reported by Johansson et al (8), where subjects had to change from a mixed 
diet to a lactovegetarian diet. The reported fibre intake at 3,6 and 12 months was compared with biological markers for fibre intake (i.e. total faecal weight, water content in faeces and excretion of short-chain fatty acids). The validity of the food intake was the same before the dietary shift and at 3 months and was lowest at 12 months. The compliance to the new diet was decreased although subjects did not report this (8).

In the current study, the degree of underreporting between the two periods was rather constant within subjects. Subjects who reported their food intake the first time accurately did this also the second time and vice versa. The \% underreporting was not related to subject characteristics such as body mass index or age (data not shown) as was found in some other studies $(9,16)$.

In the second period a selective underreporting of fat and an overreporting of protein intake was measured. A selective underreporting of fat was found before in obese men (7) and also in two other studies with older men and women $(11,14)$. We observed no selective omission of foods at specific meals as was found in a study with obese men who selectively underreported their food intake at lunch, dinner and during the evening (7). Subjects changed their diet during the second period by eating less (15\% undereating). Food recording for 7 days is often perceived as quite a burden and this might result in subjects eating less and differently $(5,7)$. A second time of food recording might increase this behaviour even more (16). The reason for selective underreporting of fat and overreporting of protein during the second period remains unclear. Subjects did not receive any information on nutrition or a healthy diet and the exercise did also not influence the results, thus the selective under- / overreporting is not the result of a specific intervention.

The mean body mass, total energy expenditure and energy intake of period one and two did not differ significantly between both periods. Individual changes in total reported food intake were due to changes in the amount of underreporting. Total reported food intake between both periods thus, remained the same. However, the food choice of subjects might have been different between both periods, because period one was in the autumn and period two in the winter. The energy $\%$ fat, carbohydrate and protein did not differ between both periods, but during the second period subjects selectively underreported fat and overreported their protein intake. A seasonal effect of food choice was probably present in the current study. The changed errors in the food reporting covered the changes in the habitual food intake between the two measurements. The effect of nutrition, exercise or other interventions on food intake might thus not be discovered. A biomarker for reported food intake must be included in studies of the effect of an intervention on food intake.

In the second period the sum of the undereating (15\%) and the underrecording (18\%) was higher than the total amount of underreporting $(27 \%)$, although the difference was not significant. For the calculation of the \% undereating the energy content of $1 \mathrm{~kg}$ body mass was assumed to be $30 \mathrm{MJ}$ ( $75 \%$ fat mass, $25 \%$ fat free mass with $73 \%$ water) $(6,17)$. The used mass ratio for storage or mobilisation of energy between fat and fat free mass might differ on the individual level and errors in the calculation of undereating are the result. Besides an error in the calculation of the amount of undereating, a small error in the calculation of underreporting might also be present. The amount of underreporting is calculated from energy expenditure as derived from basal metabolic rate and physical activity. The formula for the calculation of energy 
expenditure had a residual SD of $0.809 \mathrm{MJ} / \mathrm{d}$ and small errors in the estimation of energy expenditure might be present. However in a former study the combination of BMR and physical activity as assessed with a triaxial accelerometer was found to be a good validation method for reported energy intake (4).

The results presented here are for a group of elderly men and women and more research is needed to find out whether these results also apply for younger age groups. In summary, a second time of food reporting after 12 weeks caused a higher total underreporting due to subjects consuming less than habitual and a selective underreporting of fat and overreporting of protein intake.

\section{References}

1. Bandini, LG, Schoeller, DA, Cyr, HN, and Dietz. WH. Validity of reported energy intake in obese and nonobese adolescents. Am J Clin Nutr 52: 421-425, 1990.

2. Bouten, C, Verboeket-van de Venne, W, Westerterp, K, Verduin, M, and Janssen, J. Daily physical activity assessment: comparison between movement registration and doubly labeled water J Appl Physiol 81: 1019-1026, 1996.

3. Fjeld, CR, Brown, KH, and Schoeller, DA. Validation of the deuterium oxide method for measuring average daily milk intake in infants. Am J Clin Nutr 48: 67I-679, 1988

4. Goris, AHC, Meijer, EP, Kester, A, and Westerterp, KR. Use of a triaxial accelerometer to validate reported food intakes. Am J Clin Nutr In Press, 2001.

5. Goris, AHC, and Westerter, KR. Improved reporting of habitual food intake after confrontation with earlier results on food reporting. British Journal of Nutrition 83: 363-369, 2000.

6. Goris. AHC. and Westerterp. KR. Underreporting of habitual food explained by undereating in motivatud lean women. J Nutr 129: 878-882, 1999.

7. Goris, AHC. Westerterp-Plantenga, MS, and Westerterp, KR. Undereating and underrecording of habitual food intake in obese men; selective underreporting of fat intake. Am J Clin Nutr 71: 130$134,2000$.

8. Johansson. G. Callmer, E, and Gustafsson, J-A. Validity of repeated dietary measurements in a dietary intervention study. Eur J Clin Nutr 46: 717-728, 1992.

9. Johnson, RK, Goran, MI, and Poehlman, ET. Correlates of over- and underreporting of energy intake in healthy older men and women. Am J Clin Nutr 59: 1286-1290, 1994.

10. Kristal. AR Andrilla, HA, Koepsell, TD, Diehr, PH, and Cheadle, A. Dietary assessment instruments are susceptible to intervention-associated response set bias. J Am Diet Assoc 98: 4043. 1998

11. Schaefer, E, Augustin, J, Schaefer, M. Rasmussen, H, Ordovas, J, and Dallal, G. Lack of efficacy of a food-frequency questionnaire in assessing dietary macronutrient intakes in subjects consuming diets of known composition. Am J Clin Nutr 71: 746-751, 2000.

12. Schoeller, DA. How accurate is self-reported dietary energy intake? Nutr Rev 48:373-379, 1990

13. Schoffelen, PFM, Westerterp, KR, Saris, WHM and ten Hoor, F. A dual-respiration chamber system with automated calibration. J Appl Physiol 83: 2064-2072, 1997.

14. Tomoyasu, N, Toth, M, and Poehlman. E. Misreporting of total energy intake in older African Americans. Int J Obes 24: 20-26, 2000.

15. Weir, JB. New methods for calculating metabolic rate with special reference to protein metabolism. J Physiol 109: 1-9, 1949

16. Westerterp, K, Verboeket-van de Venne, W, Meijer, G, and ten Hoor, F. Self-reported intake as a measure for energy intake. A validation against doubly labelled water. Obes Eur 91: 17-22, 1991.

17. Westerterp, KR, Donkers, JH, Fredrix, EW, and Bockhoudt, P. Energy intake, physical activity and body weight: a simulation model. Br J Nutr 73: 337-347, 1995.

18. Westerterp, KR, Kayser, B, Brouns, F, Herry, JP, and Saris, WH. Energy expenditure climbing Mt. Everest. J Appl Physiol 73: 1815-1819. 1992. 
Chapter 7

19. Westerterp, KR, Robach, P, Wouters, L, and Richalet, JP. Water balance and acute mountain sickness before and after arrival at high altitude of 4,350 m. J Appl Physiol 80: 1968-1972, 1996. 
Chapter 8

Energy balance in depleted ambulatory patients with chronic obstructive pulmonary disease; the effect of physical activity and oral nutritional supplementation

Annelies HC Goris, Marja AP Vermeeren*, Annemie MWJ Schols*, Klaas R Westerterp

Department of Human Biology and *Department of Pulmonology, Maastricht University, The Netherlands 


\section{Abstract}

Patients with chronic obstructive pulmonary disease (COPD) often suffer from weight loss. The aim of this study was to get insight in the energy balance of depleted ambulatory COPD patients, in relation to the habitual level of physical activity and the consumption of nutritional supplements. Patients $(n=15$, body mass index 19.9 2.1 $\mathrm{kg} / \mathrm{m}^{2}$ ) were studied one and three months after discharge from the clinic and were at random assigned to a control or intervention group with regard to nutritional supplementation $(2.38 \mathrm{MJ} / \mathrm{d})$. Energy intake was measured with a 7 day food record. Energy expenditure was calculated from a simultaneous 7 day assessment of physical activity with a tri-axial accelerometer for movement registration in combination with measured basal metabolic rate. Body mass changes over the recording- and over a non-recording week were assessed to check for a change in diet while food recording. The water balance method was used to determine the food intake recording accuracy. There was no indication for a change in diet while food recording and the food intake was recorded accurately. At month one, the daily cumulative energy intake as fraction of energy expenditure was $20 \%$ higher in the intervention group than in the control group. The difference was mainly due to higher intakes in the afternoon and evening for the intervention group. The mean body mass change between month 1 and 3 was negatively related to the mean physical activity level $(r=-0.59, \mathrm{P}=0.05)$. In conclusion, nutritional supplementation had a positive effect on energy balance. Energy balance was negatively associated with the energy requirement for physical activity.

\section{Introduction}

Patients with chronic obstructive pulmonary disease (COPD) often suffer from weight loss, due to an inadequate dietary intake compared to, increased, energy expenditure (16). Nutritional depletion in COPD patients influences functional status and health related quality of life $(4,12,14,21)$. Insight in factors related to the energy balance of depleted COPD patients at home helps to optimise the implementation of nutritional supplements.

Nutrition therapy in a rehabilitation setting seems to improve the condition of depleted COPD patients, especially when it is combined with exercise or an anabolic stimulus $(4,15)$. The success of nutrition therapy in ambulatory depleted COPD patients varies and probably depends on the consumption of the supplements, as there is less control on the food intake of the patients than in a clinical situation $(5,10)$. Efthimou et al. observed in 7 depleted COPD outpatients a weight increase of about $10 \mathrm{~kg}$ after 3 months of supplementation with $2.5 \mathrm{MJ} /$ day, while in the control group no change of body mass was observed. They did not make a distinction between the energy intake with the supplements and with the habitual diet (5). In a study of Lewis et al., depleted COPD outpatients received about $3.0 \mathrm{MJ} /$ day extra for 8 weeks, while no significant increase in body mass was observed compared to a control group (10). The patients ate less of their habitual diet and the effect of the dietary supplementation was lost. Stratton et al., in a review of 84 trials on the use of oral nutritional supplements in the community, showed that information on consumption of nutritional supplements and 
of the habitual diet is often lacking or not reliable due to infrequent dietary assessment (17).

An increase in energy intake by supplementation does not necessarily imply a positive energy balance. The energy balance of ambulatory depleted COPD patients might also be a function of the energy requirement of the patients. Physical activity, as the main determinant of variation in energy requirement, probably plays a role as well.

The aim of this study was to get insight in the energy balance of ambulatory, depleted COPD patients in relation to the habitual level of physical activity and consumption of nutritional supplements. The measurement of the food intake is complicated through problems of misreporting or a change in diet while food recording $(7,8)$. Mostly, an underreporting of food intake is observed (13). However, in depleted patients intake might also be overreported. For example, Kayser-Jones et al, observed a higher food intake during the food recording period in depleted nursing home patients (9). The distinction of misreporting into misrecording, the failure to record accurately everything consumed, or a change in diet while food recording gives additional information for the interpretation of the nutritional status of depleted patients. Here, reported energy intake was compared with energy expenditure as estimated from measured basal metabolic rate and physical activity assessed with a tri-axial accelerometer (7). The water balance was used to determine recording accuracy, and body mass change over a non-recording interval and over the recording interval was measured for the assessment of a change in diet while food recording (8).

\section{Subjects and methods}

\section{Protocol}

Fifteen depleted COPD patients were studied one and three months after discharge from the university hospital in Maastricht or from the pulmonary rehabilitation centre in Hom, The Netherlands. At discharge the patients were at random assigned to the intervention group $\left(3 \times 125 \mathrm{ml}\right.$ Respifor $\left.{ }^{\star}, 2.38 \mathrm{MJ} / \mathrm{d}\right)$ or to the control group. Patients from the hospital and rehabilitation centre were equally distributed over the intervention group and control group. Food intake, energy expenditure and water loss were measured over a one week period. Energy balance was controlled by measurements of body mass, and body composition was measured at the start of the recording week. Six patients of the control group and six patients of the intervention group were also studied at three months after discharge.

\section{Suhjects}

Inclusion criteria were a body mass index $\leq 22 \mathrm{~kg} / \mathrm{m}^{2}$ or a body mass index $\leq 25$ $\mathrm{kg} / \mathrm{m}^{2}$ in combination with recent weight loss (>5\%). Exclusion criteria were gastrointestinal or endocrine diseases, malignancies or dementia. Patients were informed about the aim and procedures of the study and they gave written consent. The medical ethics committee of the university and the hospital approved the protocol. The characteristics of the subjects at discharge are described in table 8.1. Patients had a moderate to severe airflow obstruction in combination with normal blood gasses. 
Table 8.1: Characteristics (mean \pm SD) of patients with chronic obstructive pulmonary disease at discharge

\begin{tabular}{lccc}
\hline & $\begin{array}{c}\text { Intervention group } \\
(\mathrm{n}=8)\end{array}$ & $\begin{array}{c}\text { Control group } \\
(\mathrm{n}=7)\end{array}$ & $\begin{array}{c}\text { Total } \\
(\mathrm{n}=15)\end{array}$ \\
\hline Male / female & $4 / 4$ & $5 / 2$ & $9 / 6$ \\
Age $(\mathrm{yr})$ & $60 \pm 13$ & $61 \pm 11$ & $61 \pm 12$ \\
$\mathrm{BMI}\left(\mathrm{kg} / \mathrm{m}^{2}\right)$ & $19.8 \pm 2.4$ & $20.1 \pm 1.8$ & $19.9 \pm 2.1$ \\
$\mathrm{FEV}(\%$ predicted $)$ & $43.5 \pm 12.6$ & $42.7 \pm 21.4$ & $43.1 \pm 16.6$ \\
IVC $(\%$ predicted $)$ & $95.1 \pm 13.9$ & $90.6 \pm 11.6$ & $93.0 \pm 12.7$ \\
$\mathrm{PaO}_{2}(\mathrm{kPa})$ & $9.5 \pm 1.6$ & $9.4 \pm 1.2$ & $9.4 \pm 1.4$ \\
$\mathrm{PaCO}_{2}(\mathrm{kPa})$ & $5.4 \pm 0.9$ & $5.9 \pm 0.9$ & $5.6 \pm 0.9$ \\
\hline
\end{tabular}

BMI: body mass index, $\mathrm{FEV}_{1}$ : forced expiratory volume in 1 second, IVC: inspiratory vital capacity, $\mathrm{PaO}_{2}$ : arterial $\mathrm{O}_{2}$ tension, $\mathrm{PaCO}_{2}$; arterial $\mathrm{CO}_{2}$ tension.

\section{Body mass and bocty composition}

Measurements on body mass and body composition were performed at month 1 and month 3 after discharge. Body mass was measured three times, with 7 day intervals, 1 week before the start of the recording week, at the start and at the end of the recording week. Thus, possible weight changes due to food recording can be compared with normal body mass fluctuations. Patients were weighed in indoor clothing and without shoes, in the morning before any drink or beverage consumption and after voiding, on a digital balance accurate to $\pm 0.1 \mathrm{~kg}$ (Seca, Almere, The Netherlands). The balances used in the hospital and in the rehabilitation centre were calibrated.

Body composition was derived from total body water (TBW) as measured by deuterium dilution following the Maastricht protocol (19). The evening prior to the start of the recording week subjects drank a weighed dose of a deuterium dilution, $70 \mathrm{~g}$ water with an enrichment of 5 atom $\%$ excess ${ }^{2} \mathrm{H}$, after voiding (background sample). Deuterium enrichment was measured in urine from the second voiding of the following morning. Fat free mass was calculated from TBW with the hydration factor for FFM of 0.73 . The fat-free mass index $\left(\mathrm{FFMI}=\mathrm{kg} \mathrm{FFM} / \mathrm{m}^{2}\right.$ ) was calculated for comparison between individuals.

\section{Food and water intake}

A 7-day structured food record was used to measure total food and water intake. Each day of the food record was divided into 6 'meals': breakfast, morning snack, lunch, afternoon snack, dinner and evening snack. Subjects received instructions from a dietician on how to fill in the food record. The food records were converted into intakes of total energy, macronutrients and water with a computer program based on food tables (Becel Nutrition Program, Nederlandse Unilever Bedrijven B.V., Rotterdam, The Netherlands). Energy intake was calculated per meal. For the intervention group, the energy derived from supplements was calculated separately. The amount of metabolic water was calculated by multiplying energy expenditure by the percentages of energy from protein, fat, and carbohydrate from the 7 day food record. Oxidation of protein yields $0.41 \mathrm{ml}$ water $/ \mathrm{g}$, fat yields $1.07 \mathrm{ml}$ water $/ \mathrm{g}$ and carbohydrate yields $0.60 \mathrm{ml}$ water $/ \mathrm{g}(6)$. 


\section{Energy expenditure}

Energy expenditure was estimated from measured basal metabolic rate (BMR) and physical activity (PA) assessed with a tri-axial accelerometer for movement registration. BMR was measured at the start of the recording week after an overnight fast, while lying for 30 minutes in a supine position, with a ventilated hood system (Oxycon-B; Mijnhardt, Bunnik, The Netherlands).

PA was measured with a tri-axial accelerometer for movement registration (Tracmor) during the recording week. The Tracmor is a small device $(7 \times 2 \times 0.8 \mathrm{~cm}, 30 \mathrm{~g})$ which measures accelerations in the anteroposterior, mediolateral and vertical directions of the trunk. Subjects wore the Tracmor during waking hours in a belt at the back of the waist. The Tracmor has been validated against doubly labelled water which gave the following formula using Tracmor counts and BMR for the calculation of total energy expenditure $(\mathrm{EE}): \mathrm{EE}(\mathrm{MJ} / \mathrm{d})=-2.289+1.777 * \mathrm{BMR}(\mathrm{MJ} / \mathrm{d})+0.063 *$ counts/minute (regression analysis $\mathrm{r}^{2}=0.82, \mathrm{P}<0.0001 ; \mathrm{n}=26$ healthy elderly) (7). The physical activity level was calculated by expressing energy expenditure as a multiple of basal metabolic rate $(\mathrm{PAL}=\mathrm{EE} / \mathrm{BMR})$.

\section{Water loss}

Water loss was measured with the deuterium elimination method. Subjects collected urine samples, additional to the urine samples for the calculation of TBW, in the evening of day 1 at the start of the recording week, the evening of day 7 and the morning of day 8 . Water lcss was calculated from ${ }^{2} \mathrm{H}$ elimination with the equation of Fjeld et al (6), as described before (18).

\section{Statistics}

Mean and standard deviations were calculated. Non-parametric tests were used, as data was not normally distributed. Differences between groups were tested with the Mann Whitney test and differences between measurements within groups were tested with paired sign tests. Spearman rank correlations were calculated to describe relations between parameters.

The cumulative energy intake was calculated as a fraction of total energy expenditure to correct for differences in energy needs. For the intervention group the cumulative energy intake was calculated with and without the energy from the supplements.

For 12 subjects who had measurements at 1 and 3 months after discharge, body mass changes and mean physical activity levels of month 1 and 3 were calculated.

Significance was set on $\mathrm{P}<0.05$.

\section{Results}

At month 1 after discharge there were no significant differences in body composition between the intervention and control group (table 8.2). 
Table 8.2: Body mass index (BMI), fat-free mass index (FFMI), \% body fat (BF) of the interventioncontrol- and total group at 1 month after discharge.

\begin{tabular}{lccc}
\hline & $\begin{array}{c}\text { Intervention group } \\
(\mathrm{n}=8)\end{array}$ & $\begin{array}{c}\text { Control group } \\
(\mathrm{n}=7)\end{array}$ & $\begin{array}{c}\text { Total } \\
(\mathrm{n}=15)\end{array}$ \\
\hline BMI $\left(\mathrm{kg} / \mathrm{m}^{2}\right)$ & $19.8 \pm 2.3$ & $20.4 \pm 1.2$ & $20.1 \pm 1.8$ \\
FFMI $\left(\mathrm{kg} / \mathrm{m}^{2}\right)$ & $14.9 \pm 1.7$ & $14.8 \pm 0.8$ & $14.8 \pm 1.3$ \\
BF $(\%)$ & $25.1 \pm 5.8$ & $27.2 \pm 4.6$ & $26.1 \pm 5.2$ \\
\hline
\end{tabular}

The body mass change between discharge and month 1 was $0.15 \pm 0.98(-0.91-2.26) \mathrm{kg}$ and $0.88 \pm 2.07(-1.28-5.08) \mathrm{kg}$ for the intervention group and for the control group, respectively (Mann Whitney test, $\mathrm{P}=0.417$ ). Results on energy intake and expenditure at month 1 are presented in table 8.3. Energy intake was not significantly different from energy expenditure, neither for the intervention group, nor for the control group. There was no statistical significant difference in energy balance between the two groups (Mann Whitney test; $\mathrm{P}=0.355$ ). The intervention group had a positive energy balance of $0.51 \mathrm{MJ} / \mathrm{d}$ and the control group had a negative energy balance of -1.27 $\mathrm{MJ} / \mathrm{d}$.

Table 8.3: Energy intake (EI), basal metabolic rate (BMR), physical activity level (PAL) and energy expenditure (EE) of the intervention-, control- and total group at 1 month after discharge.

\begin{tabular}{lccccc} 
& \multicolumn{2}{c}{$\begin{array}{c}\text { Intervention group } \\
(\mathrm{n}=8)\end{array}$} & \multicolumn{2}{c}{$\begin{array}{c}\text { Control group } \\
(\mathrm{n}=7)\end{array}$} & $\begin{array}{c}\text { Total } \\
(\mathrm{n}=15)\end{array}$ \\
& Mean $\pm \mathrm{SD}$ & (range) & Mean $\pm \mathrm{SD}$ & $($ range) & \multicolumn{1}{c}{ Mean \pm SD } \\
\hline BMR (MJ/d) & $5.8 \pm 0.7$ & $(4.7-6.8)$ & $6.3 \pm 1.0$ & $(4.6-7.7)$ & $6.0 \pm 0.9$ \\
PAL & $1.55 \pm 0.06$ & $(1.46-1.64)$ & $1.57 \pm 0.07$ & $(1.48-1.66)$ & $1.56 \pm 0.06$ \\
EE (MJ/d) & $9.0 \pm 1.1$ & $(7.2-11.1)$ & $9.9 \pm 1.9$ & $(7.2-12.4)$ & $9.4 \pm 1.5$ \\
EI $(\mathrm{MJ} / \mathrm{d})$ & $9.5 \pm 2.0$ & $(6.9-12.7)$ & $8.6 \pm 2.7$ & $(4.9-12.6)$ & $9.1 \pm 2.3$ \\
\hline
\end{tabular}

For the total group, the mean body mass change over the recording week $(0.07 \pm 0.56$ $\mathrm{kg}$ ) was not different from zero (one-sample sign test, $\mathrm{P}=0.61$ ), nor different from the body mass change over the non-recording week $(0.05 \pm 0.58 \mathrm{~kg}$, paired sign test $\mathrm{P}>0.999$ ). Comparable results were found for both groups separately. Thus, there was no indication for a change in diet while food recording.

The total water intake, reported water intake plus metabolic water $(2.8 \pm 0.8 \mathrm{l} / \mathrm{d})$ was not significantly different from the measured water loss $(3.0 \pm 0.61 / \mathrm{d}, \mathrm{P}=0.3)$. Nor was there a difference between total water intake and water loss for the intervention group and the control group separately. Thus, there was no indication for under- or overrecording of food intake either, and total food intake was reported accurately. The intervention group consumed on average $95 \pm 13 \%$ of the prescribed nutritional supplements, resulting in a mean energy intake from the supplements of $2.2 \mathrm{MJ} / \mathrm{day}$. The supplements were mostly consumed in between meals and amounted to $25 \pm 5$ (1833) $\%$ of total energy intake. Figure 8.la shows the cumulative energy intake, expressed as a fraction of daily energy expenditure. For the intervention group, the difference in cumulative energy intake from the control group, with and without energy from the supplements, is plotted in figures $8.1 \mathrm{~b}$ and $8 . \mathrm{lc}$. In the morning there was no difference in energy intake between both groups. A difference in energy intake between the intervention and control group, although not statistically significant, was only visible from the afternoon until the end of the day. At the end of the day, the energy intake of the intervention group was on average $20 \%$ higher than the energy 
intake of the control group. Most patients in the intervention group compensated part of the intake from the supplements with a reduction of the intake from their habitual diet.
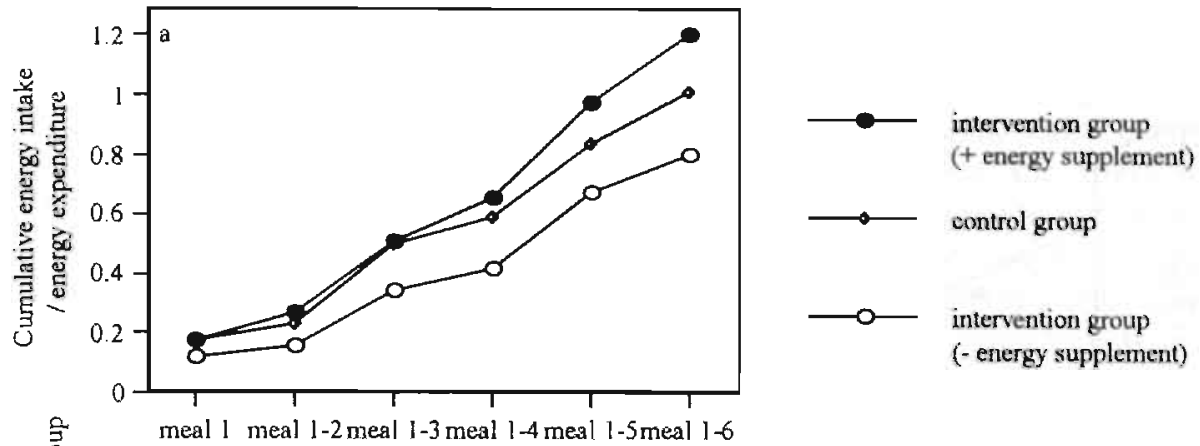

- intervention group (- energy supplement)
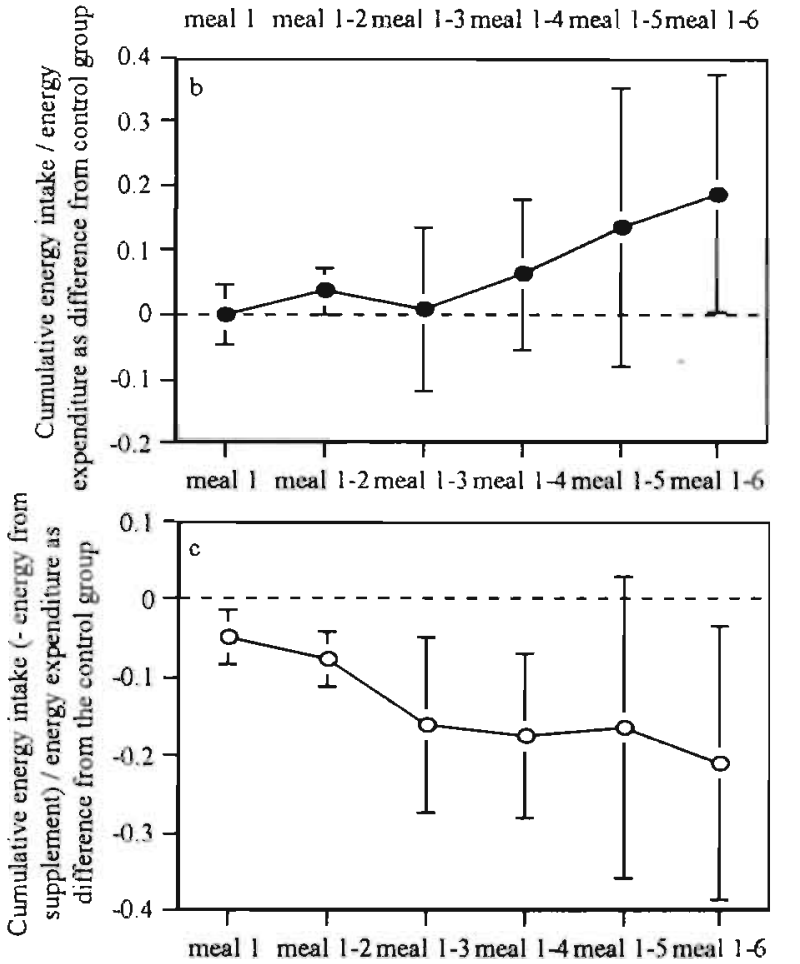

Figure 8.1 above: Cumulative energy intake as fraction of daily energy expenditure for the control group $(n=7)$ and for the intervention group with or without energy from nutritional supplements $(n=8)$; middle: Cumulative energy intake as fraction of energy expenditure plotted as difference from the control group; below: Cumulative energy intake minus energy from the supplements as fraction of encrgy expenditure plotted as difference from the control group. (meal 1, breakfast; meal 2, morningsnack; meal 3, lunch; meal 4, afternoon-snack; meal 5, dinner; and meal 6, evening-snack). 
The mean body mass change from month one to month three was $0.56 \pm 1.11 \mathrm{~kg}$ and $0.21 \pm 1.93 \mathrm{~kg}$ for patients in the intervention group $(\mathrm{n}=6)$ and in the control group $(\mathrm{n}=6)$, respectively (Mann Whitney test, $\mathrm{P}=0.75$ ). The body mass change was negatively correlated with the mean physical activity level (Figure 8.2; Spearman rank correlation $\mathrm{r}=-0.59, \mathrm{P}<0.05$ ). Patients with a physical activity level higher than about 1.55 , probably had an insufficient energy intake for their relative high energy expenditure and lost weight over the two-month interval. The physical activity level was not related to the body composition of the patients.

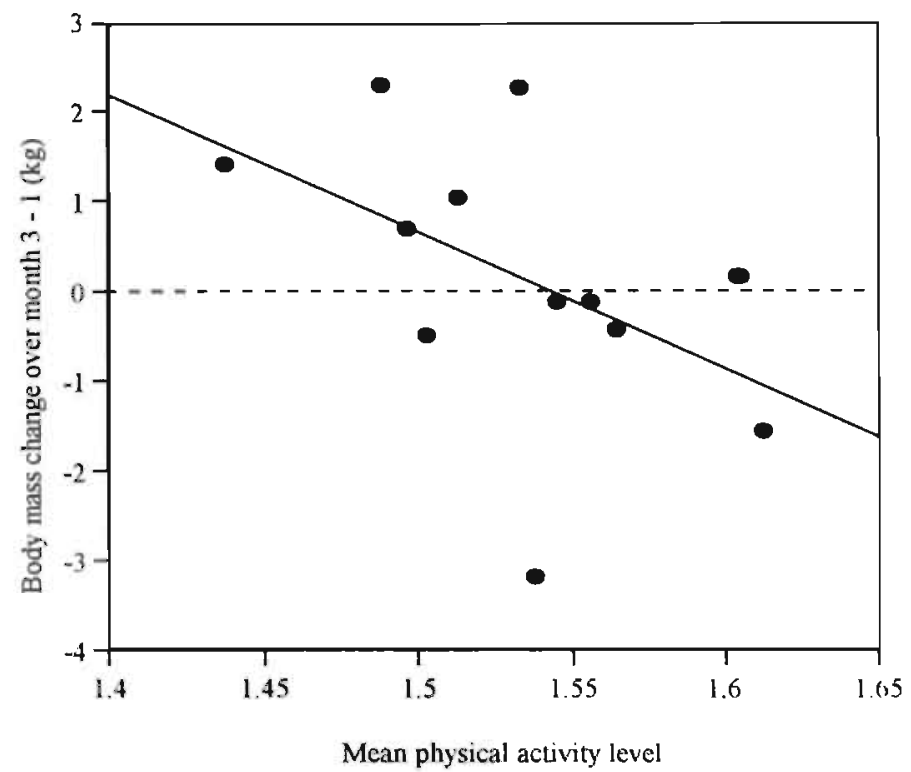

Figure 8.2: Body mass change from month one to month three plotted against the mean physical activity level $(\mathrm{n}=12 ; \mathrm{r}=-0.59, \mathrm{P}<0.05)$.

\section{Discussion}

In the first month after discharge. patients from both, the intervention and control group, gained weight. This was probably the result of an increased appetite and food intake of the patients when they were just back at home. The social context has a powerful influence on the food intake (3). One month after discharge, differences in energy balance between the intervention and control group became visible. The positive energy balance in the intervention group resulted in a weight gain from month 1 to month 3. However, the difference in weight gain over the two-month interval between both groups was not significant, probably due to the small number of subjects. The mean difference in relative weight change over the two-month interval between the intervention and control group was about $2 \%$. Stratton et al found, in their review, a mean difference in percentage weight change between supplemented and unsupplemented outpatients with COPD, of $4.7 \pm 2.7 \%$. The supplementation period in 
the different studies ranged from 1 to 4 months (17). Some studies reported significant functional improvements, like muscle strength and duration of exercise, in relation to weight gain (17).

The positive energy balance in the intervention group was especially due to a higher energy intake from meals in the afternoon and in the evening. During the morning no differences in energy intake as function of energy expenditure were fouhd between the intervention and control group. In the morning humans generally consume smaller meals than during the remainder of the day $(2,20)$, which might be even more pronounced in COPD patients who often suffer from dyspnea in the morning. In this study the patients of the intervention group were not able to consume extra energy during the morning, despite the consumption of supplements. From the afternoon onwards, the energy intake of the intervention group increased compared to the control group. In a study on circadian rhythms of food intake, De Castro suggested that humans obtain less satiety from a given amount of food later in the day than earlier on, which might be functional in anticipation of the overnight fast (2). Supplementation with extra energy might thus be more successful if it takes place in the afternoon and evening. The patients of the intervention group consumed the supplements mostly in between the meals in the morning, in the afternoon and in the evening as was recommended by the dietician.

A compensation of energy intake from the habitual diet for the energy from the supplement was found in most subjects of the intervention group. The consumption of supplements during the morning resulted in a lower energy intake at lunch in the intervention group, compared to the control group. Total compensation was on average about $20 \%$, which is comparable with other studies (17). Even in a clinical situation. with a high control on supplement and food intake, some compensation of habitual food intake was found (4).

The physical activity level of about 1.55 in this group of outpatients with COPD, was lower than measured in COPD patients in a rehabilitation centre (1) and lower than measured in a group of healthy elderly men and women (11). In the rehabilitation centre patients followed a daily program including physical exercises, which resulted in a higher physical activity level. Additionally, the physical activity level of the COPD patients in the rehabilitation centre, was calculated from energy expenditure measured with the doubly labelled water method and basal metabolic rate measured with the ventilated hood. Thus, the activity related energy expenditure included also energy needed for the decreased mechanical efficiency in COPD patients (1). Here, physical activity was measured with a triaxial accelerometer for movement registration and an eventually lower mechanical efficiency was not taken into account.

At home physical exercise is probably limited in COPD patients. However, a lower physical activity level is not per se negative. COPD patients with a lower physical activity level were able to eat sufficient for their energy needs and remained in energy balance or even gained weight (figure 8.2). A high physical activity level must be accompanied with a higher energy intake to maintain at least energy balance. This was probably difficult for the COPD patients with a high physical activity level, because they lost weight. In a controlled setting, a rehabilitation centre, patients with a high physical activity level were still able to maintain their body weight or even gained 
weight (4). More research is needed, to be able to give advises about physical activity and food intake to depleted outpatients with COPD.

The food intake was reported accurately and the patients did not change their diet while food recording. The patients were motivated to report their food intake accurately and had probably sufficient time to record everything, because they were mostly at home. Results on reported food intake could therefore be used to compare the energy balance between the intervention and control group.

In summary, COPD patients reported their food intake accurately, which made it possible to compare the reported food intake between the intervention and control group. At one month after discharge from the clinic COPD patients from the intervention group had a positive energy balance compared to the COPD patients of the control group. The positive energy balance in the supplemented patients was mainly achieved from the energy intake in the afternoon and evening. The weight gain from month 1 to month 3 was negatively associated with the energy requirement for physical activity. These preliminary results suggests, that knowledge about the individual physical activity level is necessary for the estimation of the energy need of the patient and to give an appropriate advise about the food intake and the use of supplements. However, more research is needed to find out which combination of supplementation and physical activity results in the highest weight gain and functional improvement in depleted COPD patients at home.

\section{References}

1. Baarends, E, Schols, A, Pannemans, D, Westerterp, K, and Wouters, E. Total free living energy expenditure in severe chronic obstructive pulmonary disease. Am J Respir Crit Care Med 155: 549-554, 1997.

2. Castro, JM de. Circadian rhytms of the spontaneous meal pattern, macronutrient intake, and mood of humans. Physiol \& Behav 40: 437-446, 1987.

3. Castro, JM de. Weekly rhythms of spontaneous nutrient intake and meal pattern of humans. Physiology \& behavior 50: 729-738, 1991.

4. Creutzberg, EC. Anabolic management in patients with COPD. Maastricht, 2000.

5. Efthimou, J, Fleming, J, Gomes. C, and Spiro, SG. The effect of supplementary oral nutrition in poorly nourished patients with chronic obtructive pulmonary disease. Am Rev Respir Dis 137: 1075-1082, 1988.

6. Fjeld $\mathrm{CR}$, Brown, $\mathrm{KH}$, and Schoeller, DA. Validation of the deuterium oxide method for measuring average daily milk intake in infants. Am J Clin Nutr 48: 671-679, 1988.

7. Goris, AHC, Meijer, EP, Kester, A, and Westerterp, KR. Use of a triaxial accelerometer to validate reported food intakes. Am J Clin Nutr In Press, 2001.

8. Goris, AHC, and Westerterp, KR. Underreporting of habitual food explained by undereating in motivated lean women. J Nutr 129: 878-882, 1999.

9. Kayser-Jones, J, Schell, ES, Porter, C, Barbaccia, JC, Steinbach, C, Bird, WF, Redford, M, and Pengilly, K. A prospective study of the use of liquid oral dietary supplements in nursing homes. $J$ Am Geriatr Soc 46: 1378-1386, 1998.

10. Lewis, MI, Belman, MJ, and Dorr-Uyemura, L. Nutritional supplementation in ambulatory patients with chronic obstructive pulmonary disease. Am Rev Respir Dis 135: 1062-1068, 1987.

11. Meijer, EP, Goris, AHC, Wouters, L, and Westerterp, KR. Physical inactivity as a determinant of the physical activity level in the elderly. Int J Obes 24: S181, 2000. 
12. Mostert, R, Goris, A, Weling-Scheepers, C, Wouters, EFM, and Schols, AMWJ. Tissue depletion and health related quality of life in patients with chronic obstructive pulmonary disease. Resp Med 9: 859-867, 2000.

13. Schoeller, DA. How accurate is self-reported dietary energy intake? Nutr Rev 48: $373-379,1990$.

14. Schols, AMWJ, Slangen, J, Volovics, L, and Wouters, EFM. Weight loss is a reversible factor in the prognosis of chronic obstructive pulmonary disease. Am J Resp Crit Care Med 157: 17911797, 1998.

15. Schols, AMWJ, Soeters, PB, Mostert, R, Pluymers, RJ, and Wouters, EFM. Physiologic effects of nutritional support and anabolic steroids in patients with chronic obstructive pulmonary disease. Am J Respir Crit Care Med 152: 1268-1274, 1995.

16. Schols, AMWJ, Soeters, PB, Mostert, R, Saris, WHM, and Wouters, EFM. Energy balance in chronic obstructive pulmonary disease. Am Rev Respir Dis 143: 1248-1252, 1991.

17. Stratton, RJ, and Elia, M. A critical, systematic analysis of the use of oral nutritional supplements in the community. Clin Nutr 18: S29-S84, 1999.

18. Westerterp, KR, Kayser, B, Brouns, F, Herry, JP, and Saris, WH. Energy expenditure climbing Mt. Everest. J Appl Physiol 73: 1815-1819, 1992.

19. Westerterp, KR, Wouters, L, and Marken Lichtenbelt van, W. The Maastricht protocol for the measurement of body composition and energy expenditure with labeled water. Obcs Res 3 suppl 1: 49-57, 1995.

20. Westerterp-Plantenga, MS, Pasman, WJ, Yedema, MJW, and Wijckmans-Duijsens, NEG. Energy intake adaptation of food intake to extreme energy densities of food by obese and non-obese women. Eur J Clin Nutr 50: 401-407, 1996.

21. Wilson, DO, Rogers, RM, Wright, EC, and Anthonisen, NR. Body weight in chronic obstructive pulmonary disease. Am Rev Respir Dis 139: 1435-1438, 1989. 
Chapter 9

General discussion 


\section{Misreporting of food intake}

Misreporting of food intake, mostly underreporting, is observed in many populations ranging from children to the elderly (8) and the outcome of the studies presented in this thesis is in accordance with this. Figure 9.1 shows the magnitude of misreporting and the proportions of misrecording and a change in dietary intake in the diverse groups of subjects studied. Both the obese men and the dieticians ate less while recording food intake, but probably for different reasons. The dieticians ate less because weighing and recording was perceived as a great burden, which might also count for the obese men. However, the obese men used the recording period also as an opportunity to start dieting. The recording error observed in the obese men and in the elderly men and women was probably due to under estimation of food portion sizes and to not-recording of all foods consumed. Only the depleted COPD patients reported their food intake accurately and they did not change their diet while recording food intake.

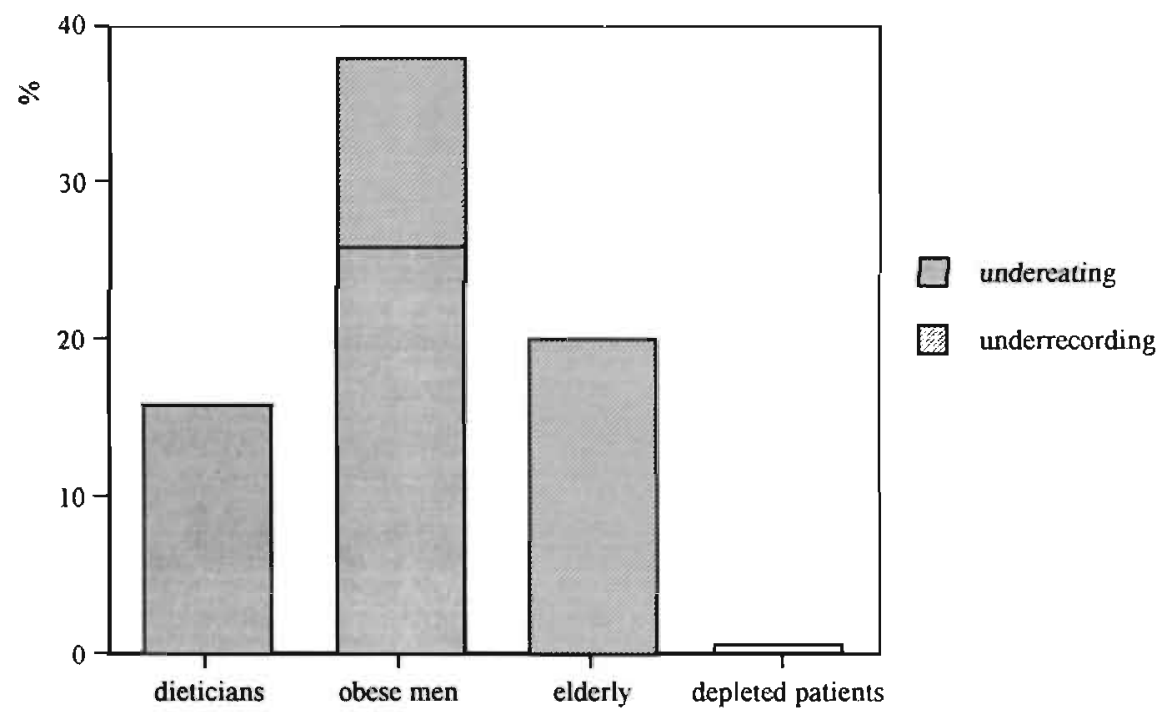

Figure 9.1 Percentage misreporting, divided into misrecording and a change in diet, in lean women $(n=24$, chapter 2$)$, obese men $(n=30$, chapter 4$)$, elderly men and women $(n=24$, chapter 6$)$ and depleted patients ( $n=15$, chapter 8 ). Data are presented as measured energy expenditure minus recorded energy intake divided by measured energy expenditure times $100(\%)$.

\section{Selective misreporting of food intake}

Direct indications for selective underreporting of fat intake were found in the obese men (chapter 4 ) and in the elderly men and women when reporting their food intake a second time (chapter 6). The reported percentage of energy from fat was a function of the amount of underreporting. The obese men reported the foods consumed at lunch, dinner and in the evening less accurately than the foods consumed in the morning (chapter 4)

If subjects are used to consume foods with a high energy density (especially obese subjects (47)) and they eat less while food intake recording, a selective underreporting of fat would be the result. A selective underreporting of fat might also be the result 
when subjects report the foods they are supposed to eat. Studies of Fricker et al. and Heymsfield et al. $(15,24)$ both showed that subjects who underreported their food intake, i.e. reported energy intake was lower than basal metabolic rate, tended to present a favourable impression of themselves. They reported a low fat, low sugar intake and low extra-prandial consumption. Becker et al. compared patterns of nutrient and food intakes in men classified according to their ratio of energy intake over basal metabolic rate. A low ratio was characterised by denial of consumption, by underreporting the quantity consumed and by underreporting eating occasions (5).

A high reported energy and fat intake seems to be associated with a low social desirability score $(19,43)$. The bias of social desirability is higher in women than in men (19). In men the bias of social approval is more evident (20).

\section{Change in reporting behoviour with repeated measurements}

Repeated measurement of food intake increased the magnitude of underreporting and induced a selective underreporting of fat and overreporting of protein in elderly men and women (chapter 7). Thus, the statement that the bias in reported food intake may not be important if subjects are studied more than once, and therefore act as their own controls (8), is not always correct. The observed effects of interventions in food intake are probably not only due to the intervention, but also to changes in food intake reporting.

\section{Explanations for under-/ over reporting}

The division of misreporting in misrecording and a change in the diet (chapters 2, 3, 4, 6,7 and 8) gives insight into the issue of misreporting (figure 9.1). Other studies tried to find the reasons for misreporting of food intake using questionnaires. For example, Macdiarmid and Blundell asked the subjects in their study if they underreported their food intake and the reasons for it (33). Half of the subjects admitted changing their diet during the recording period, either deliberately and knowingly or due to the difficult circumstances. Subjects felt embarrassed or guilty recording some foods consumed or found it a real burden to record everything (33). This last point was also mentioned in chapter 2 , the study with the dieticians who had to weigh and record everything consumed. The women changed their diet by eating less than habitually, but this was probably done unconsciously according to their answers on a questionnaire about their experience with the food intake reporting. The change in the diet was also reflected by the change in body mass over the recording period. The depleted COPD patients reported their food intake accurately and had no change in their diet while recording food intake. This was, besides a high motivation to report accurately, probably also because they had enough time to report everything for seven days as they were mostly at home. Mela et al. did a study on self-reported diet-recording behaviour. Subjects with a body mass index $>25 \mathrm{~kg} / \mathrm{m}^{2}$ did not respond differently from subjects with a body mass index $<25 \mathrm{~kg} / \mathrm{m}^{2}$. The average score for honest and complete reporting was about 7 on a $10-\mathrm{cm}$ likelihood scale. Cognitively restrained eaters (i.e. with a tendency to control food intake consciously in order to prevent weight gain or to promote weight loss) reported higher scores on a likelihood scale for eating differently and less than usual during the food recording period than unrestrained eaters did (34). High dietary restraint scores were found to be associated with a higher magnitude of underreporting 
in women and subjects with a low score on 'general hunger' were likely to eat less while recording food intake $(4,30)$.

The transition from a low level to a higher level of energy expenditure might also induce underreporting of food intake. Subjects might not yet be accustomed to their higher food intake and thus still report a lower food intake $(1,14)$.

People are likely to report intakes that are similar to the expectations for the population. Obese subjects report an intake similar to the non-obese, athletes report an intake similar to less active subjects and subjects on a diet report an intake similar to the prescribed diet (chapter $8,(23,38)$ ). Additionally, the recording of food intake by obese subjects might also be perceived as an opportunity to diet for these subjects (38). Another problem with dietary assessment might be the estimation of food portion sizes if a non-weighed dietary record is used. Some studies suggest a growing trend to larger portions, especially in fast food restaurants $(18,25)$. The portion size that is considered as normal by the obese is objectively considered as large (47). If the portion sizes of foods are still calculated as 'normal' portion sizes by the dietician, an underreporting of food intake would be the result.

The literacy level of subjects might affect the reporting accuracy as the reading of food labels and the writing of the foods consumed are more difficult $(10,27)$.

Generally, misreporting of food intake is observed in all types of subjects (8) and is due to embarrassment about foods consumed (33), social desirability (43), a change in diet or because food intake recording is perceived as a burden (chapter 2, (33)).

\section{Implicutions of misroporting}

Both obese and lean subjects are known to misreport, especially underreport, their food intake. Obese subjects probably misreport their food intake to a greater extent and, as the number of obese people is growing (40) the error in reported food intake of populations might be expected to increase (38). The implications of misreporting will count to a certain extent for all populations and if the food intake is not validated by means of an independent marker, one might draw erroneous conclusions.

An example of this is a study by Heini et al. entitled: "Divergent trends in obesity and fat intake patterns: the American paradox". In the adult population the prevalence of overweight has increased since 1976 with $31 \%$ and at the same time reported energy intake and \% energy from fat decreased. This might be due to a lower physical activity and a higher consumption of low-energy foods, but underreporting has also increased since 1976 (21). Combining these results with the results of studies showing selective underreporting of fat intake (chapter $4,(22,44)$ ) the reported decrease in energy and fat intake in the US seems to be doubtful. National health campaigns aimed at lowering fat intakes might not be so successful as it is concluded from the results of national food consumption measurements showing a decline in reported fat intakes over several years. Figure 9.2 shows reported percentages of energy from fat of national food consumption studies in the Netherlands and in the U.S.A. and the percentage of energy from fat reported by obese men, corrected and uncorrected for underreporting (chapter 4). Lissner et al. showed with the use of a theoretical example that the relation between fat intake and obesity can be overestimated or hidden as a consequence of selective underreporting (31). Thus, the relation between fat intake and obesity is still not clear. Errors in the assessment of food intake might disturb the outcome of nutrition intervention studies, or prevent to reveal relations between nutrition and parameters of 
health or disease (38). Greenwald et al. demonstrated that dietary assessment methods may not be able to detect a possible dietary fat-breast cancer association because of measurement error biases (17).

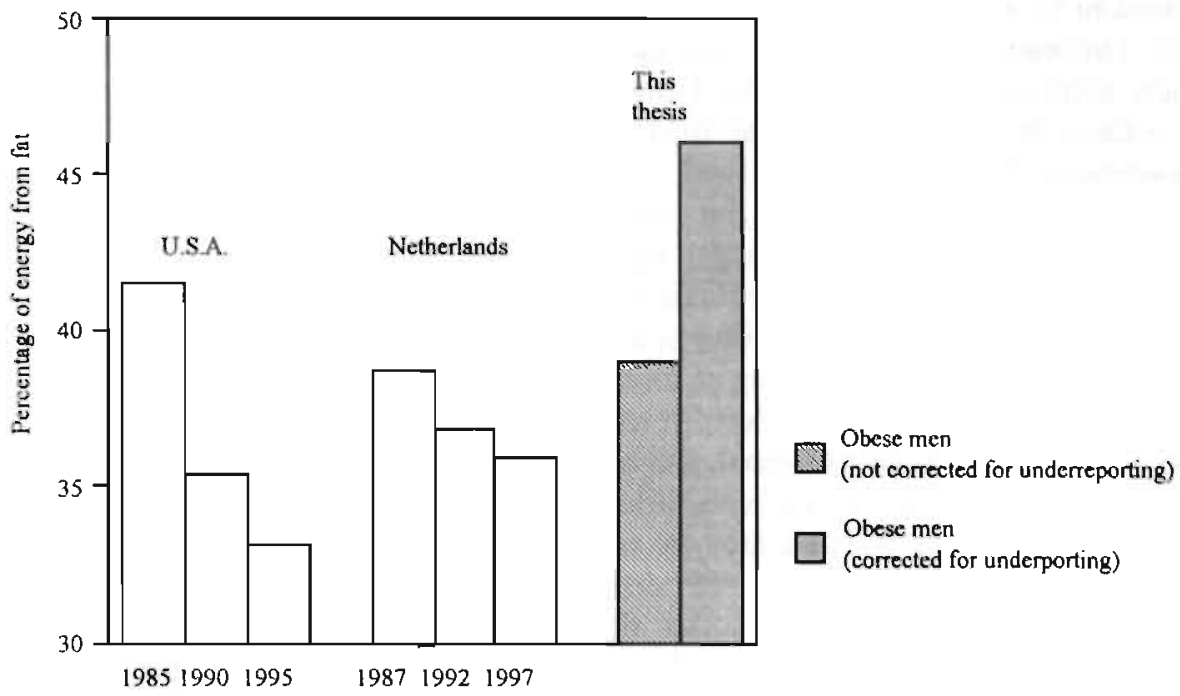

Figure 9.2: Percentages of energy from fat as measured in national food consumption studies in the U.S.A. in 1985, 1990 and 1995 (29) and in The Netherlands in 1987, 1992 and 1997 (11) and in obese men, uncorrected and corrected for underreporting (chapter 4).

An overreporting of food intake of nutritional depleted patients might overestimate the health situation of these patients. An accurate measurement of food intake of depleted patients is necessary for clinical treatment (42).

Consequences of errors in the reported food intake of free living populations are hidden, or result in under/overestimated relations between nutrition and health/disease parameters. This might finally result in, for example, errors in recommended daily allowance of nutrients or in errors in treatment of free living depleted patients.

\section{Validation of dietary assessment}

The described problem of misreporting and the implications for nutrition research makes it clear that dietary assessment cannot be executed without a validation. 'The main issue of this thesis was to find different methods for validation of assessment of habitual daily food intake in humans, taking the sources of possible misreporting into account. The validation methods showed a characterisation of misreporting of food intake as 1) misrecording: failure to record accurately in a food diary everything that is consumed and 2) as a change in the diet during measurement of food intake. Both quantitative and qualitative misreporting of food intake was determined, which provided insight into the pitfalls associated with the assessment of habitual daily food intake. 


\section{Dietary assessment}

For validation of quantitative and qualitative assessment of habitual daily food intake in adults the validation of the 7-day weighed food intake record was chosen as a dietary assessment method. It was evaluated in a group of dieticians (chapter 2) and it was found to be an accurate dietary assessment method in these motivated free living humans. The main reason for this was that no errors were made in portion sizes of foods and there was no misrecording. However, weighing all foods interfered with the eating behaviour; subjects ate about $16 \%$ less than habitual. Thus, this study showed that assessment of habitual daily food intake using 7-day weighed food records is perfectly well possible, when the subjects record their consumptions in a professionally accurate way. The pitfall of undereating that occurred the first time of food intake recording in these subjects disappeared when they had been made aware of it. A questionnaire the dieticians filled in after the recording period revealed that they regarded the weighing and recording of food intake for 7 days as too much interference with their daily lives. They considered it as impossible to require this as a method of measurement when non-professional subjects would be involved. Therefore, in the other studies (chapter 4 to 8), subjects did not have to weigh everything they ate and drank in order to make it possible (for the subjects) to report habitual food intake for 7 days. A dietician checked the estimated portion sizes.

A food intake recording period shorter than 7 days is not advisable because the measurement of energy expenditure on the individual level requires at least 7 days. If subjects would report a lower food intake at the end of the 7-day recording period because of getting tired of the procedure of writing down everything they eat, the reporting accuracy will be improved if a 3 day dietary record is used (43). However, a decline in reported energy intake at the end of the 7-day food recording period was never observed in the studies discussed in this thesis. With respect to other food intake recording methods, for the assessment of food intake on the group level 3 days of food recording has reported to be sufficient (3).

The dietary history is also possible to measure habitual food intake, however a subject bias and an observer bias are known to be present $(6,8)$. Still, studies which used the dietary history method also observed misreporting of food intake $(37,45)$. Therefore, a dietary assessment method with less burden for the subject is not automatically a more valid method.

\section{Validation methods}

The biomarkers 1) deuterium to measure water loss, 2) energy balance to measure a change in the diet, 3) the triaxial accelerometer to measure physical activity and 4) postabsorptive respiratory quotient to measure the carbohydrate / fat intake were validated in the studies described in this thesis.

The triaxial accelerometer to measure physical activity was validated itself using the doubly labelled water method (9). It could be used to estimate total energy expenditure, which serves as a reference for total energy intake. Thus, the combination of measured or estimated basal metabolic rate and physical activity assessed with a triaxial accelerometer was shown to be a good validation method for reported food intake (chapter 6). This validation method is applicable for many types of studies as it 
is easy and cheap and therefore it is a good alternative for the expensive doubly labelled water method.

For the validation of food intake in individuals one has to keep in mind that subjects do not have to be in energy balance over periods shorter than 1 month $(3,13)$. Measurements of body mass changes over the recording period and over a nonrecording period are necessary to find out whether subjects ate more or less during the recording period. An energy equivalent of $30 \mathrm{MJ} / \mathrm{kg}$ body mass (46) was used to convert body mass change into energy. As shown in chapter 4 and 6 (studies which used doubly labelled water), this gives a good estimation of the energy content of one $\mathrm{kg}$ body mass on the group level. On the individual level the energy equivalent of one $\mathrm{kg}$ body mass might differ between persons (46). The current methods for the assessment of body composition are not sensitive enough to measure changes in fat and fat free mass over a period of 7 days. For example, the precision of fat-change estimates is $1.02 \mathrm{~kg}$ with the three compartment model, where fat- and fat free mass is estimated by combining measurements of body weight, body volume and total body water (36). Obviously, the energy content of the body mass change has to be estimated and then the assessment of a change in diet on the individual level is less sensitive than on the group level.

The water-balance method for the determination of misrecording, i.e. the failure to record accurately in a food diary everything that is consumed, was proven to be an accurate measure of food intake recording on group level. The studies described in chapter 4 and 6 showed that the sum of undereating and underrecording as assessed with the water balance method was equal to the total amount of underreporting as measured with the doubly labelled water method.

Water loss can accurately be measured (coefficient of variation is $7 \%(39)$ ) and can be compared with total water intake. The total water intake is the reported water intake plus the metabolic water as estimated from protein, carbohydrate and fat intakes. The amount of metabolic water might be underestimated if it is calculated from the reported macronutrient intake. Metabolic water can better be calculated from measured macronutrient oxidation by multiplying energy expenditure with the reported fraction of energy from protein, fat, and carbohydrate.

Furthermore, the assumptions made on respiratory and cutaneous water loss and fractionation in the calculation of water loss might cause small errors in the calculation of the water balance and correction is eventually necessary (39). The water balance method is more sensitive on the group level than on the individual level.

The postabsorptive respiratory quotient was not indicative for the ratio of carbohydrate to fat intake. Thus, a validation method for the carbohydrate and fat intake is not yet available.

\section{Recommendations}

\section{This thesis}

The 7-day food intake record together with measured or estimated basal metabolic rate and physical activity assessed with a triaxial accelerometer was found to be a good 
combination for a validated assessment of habitual food intake. Misreporters can be identified and can either be stimulated to improve their reporting a second time or the data of the misreporters can be excluded. Measurements of the water balance and of body mass changes give insight in the reporting behaviour of subjects, which can be used as key information for motivated subjects to improve their reporting. This strategy of improvement was successful in dieticians (chapter 3 ), but whether this is also the case in other populations remains to be studied. An example of a study that used reporting accuracy as an inclusion criterion is a study of Westerterp-Plantenga et al. All subjects were informed about this inclusion criterion and from the 78 subjects, obese and non-obese women, 8 subjects had to be excluded because they underreported their food intake with more than $10 \%$ (47).

A reported energy intake within the $95 \%$ confidence limits of measured energy expenditure gives no guarantee for correctly reported macronutrient intake. However, a selective underrecording of, for example fat has then to be accompanied by an overrecording of carbohydrate and or protein intake. A correction for energy intake is not a possibility to solve the problem of misreporting of food intake, because the intake of macronutrients might be either over- or underestimated if selective misreporting is present.

Recommendations or solutions for the valid assessment of food intake in humans might differ for nutrition intervention studies and epidemiological studies. A number of more or less successful solutions for the valid assessment of food intake are described below. Often, more research is still needed to find out whether these methods are useful.

\section{Observer}

An observer in the habitual surrounding of the subject who records the food intake of the subject is a possibility to get an accurate measurement of the food intake (32). However, the observer must be unbiased regarding the food intake of the subject otherwise the recording accuracy will decrease. For example, a study of Simmons et al. (41) found an overestimation of the food intake of nursing home residents of $22 \%$ when recorded by the nursing home staff compared to a method where all foods consumed were photographed and compared to direct observation by the research staff. Besides, the observer must also stay the whole recording period in the surrounding of the subject.

\section{Control/ confrontation}

The confrontation of motivated subjects with their food intake recording behaviour, i.e. a change in diet and/or misrecording, increased the reporting accuracy of the dieticians (chapter 3). Instructions on recording the food intake, on not to change habitual activity-, eating- and behaviour patterns during the food recording period were not sufficient to avoid underreporting of food intake the first time of food reporting in this group dieticians (chapter 3). A training on estimating food portion sizes with the use of food models, photographs and an instruction video could also not prevent subjects from underreporting their food intake (26).

In a study of Muhlheim et al. (35) subjects were told that their reported food intake would be verified with the doubly labelled water method. It was hypothesised that the belief that the reported food intake was validated would cause subjects to report their 
food intake more accurately. The experimental group, who were told that their food intake recording was verified, reported a higher energy intake than the control group but still underreported their food intake (35). Subjects recorded their food intake for two weeks, which is a long period and the authors suggested that the doubly labelled water method as a verification method for food intake recording was perhaps for subjects not convincing enough. Maybe if subjects knew that a good food intake reporting is rewarded with for example inclusion in the study or a present, then they would be stimulated to report more accurately.

\section{Multimedia dietary record}

The recording of food intake is often perceived as a real burden. Thus, solutions to make recording easier might increase the reporting accuracy. The Portable Electronic Tape Recorded Automatic (PETRA) system is one example that is aimed to make the recording of food intake easier. The weight and the spoken description of each food item are recorded onto a cassette tape. Subjects are not able to recover the information transcribed to the system and cannot make changes anymore. However, Bingham et al. who validated the protein intake by recording food intake with the PETRA system, using urinary nitrogen loss as a reference, found in a group of 160 women still $20 \%$ unvalid food intake records (7).

Kaczkoweki et al. validated a four-day multimedia diet record, consisting of a tape recorder and camera, with doubly labelled water (28). They expected that the multimedia diet record would reduce the subjects' burden and increase the reporting accuracy. However, this multimedia record could not prevent the subjects from underreporting their food intake with $24 \%$ (28).

Neither in the study with the PETRA system, not in the study with the multimedia diet record a distinction between misrecording and a change in the diet was made. This distinction would be useful to judge both methods as these methods still rely on the subjects' competence and willingness to record all they eat. If the main problem of misreporting is a change in the diet and the use of the multimedia record is not practical in a restaurant and at work, then a small pocket camera could be a tool for subjects to report their habitual intake. Misrecording of food intake, because of subjects being ashamed about foods consumed or giving social desirable answers, is probably not reduced or avoided with a multimedia diet record or the PETRA system. However, the magnitude of misrecording due to errors in the estimation of food portion sizes is likely to be reduced with these methods.

\section{Food selection}

Information on food preferences of subjects might give an idea of the habitual food consumption. The so-called macronutrient self-selection paradigm was used to detect the range of fat consumption in a study of Geiselman et al. (16). Subjects could choose from large portions of foods varying in macronutrient content from high fat and high sugar, high fat and complex carbohydrate, high fat and low carbohydrate and high protein to the low fat variants of these combinations. The repeatability of the percentage energy from fat was within $1.6 \%$ and a range of 3 to $50 \%$ energy from fat could be detected in a group of 9 men (16). This is comparable with the within subject coefficient of variation of $10 \%$ and the between subject coefficient of variation of $40 \%$ 
for energy and macronutrient intake that Arvaniti et al found using a buffet-type meal (2).

The success of a macronutrient self-selection paradigm for assessing habitual food intake as described above, is partly depending on the range and the macronutrient specificity of the foods the subjects can select from. More research is needed to find out whether food-selection can give a qualitative indication of habitual food intake.

\section{Conclusions}

1. Validation by the water-balance method can serve as an indicator for misrecording of food intake, i.e. the failure to record accurately in a food intake diary everything that is consumed.

2. The measurement of body mass changes over a recording period and a nonrecording period provides information about a possible change in the diet due to food recording.

3. Information on misrecording and a change in the diet can be used as key information to inform subjects about their way of food reporting. With this information dieticians were able to improve their food intake reporting a second time.

4. In obese men, underreporting of habitual food intake was mainly due to a change in diet.

5. Obese men selectively underreported their fat intake.

6. The postabsorptive respiratory quotient (RQ) is not indicative for the carbohydrate fat ratio of the diet. The energy balance over the days prior to the measurement of the postabsorptive RQ was the most important factor influencing the postabsorptive RQ.

7. The combination of basal metabolic rate, measured or estimated, and physical activity assessed with a triaxial accelerometer is a good and cheap validation method for reported food intake.

8. Repeated measurement of food intake increases the reporting error and induces also selective misreporting, as observed in the elderly.

9. The energy balance of depleted ambulatory patients with chronic obstructive pulmonary disease was negatively associated with the energy requirement for physical activity.

10. Supplementation with extra energy in ambulatory depleted patients with chronic obstructive pulmonary disease is probably most successful if it takes place in the afternoon and evening.

\section{References}

1. Ambler, C, Eliakim, A, Brasel, JA, Lee, W-NP, Burke, G, and Cooper, CM. Fitness and the effect of exercise training on the dietary intake of healthy adolescents. Int J Obes 22: 354-362. 1998

2. Arvaniti, K, Richard, D, and Tremblay, A. Reproducibility of energy and macronutrient intake and related substrate oxidation rates in a buffet-type meal. Br J Nutr 83: 489-495. 2000. 
3. Basiotis, PP, Welsh, SO, Cronin, FJ, Kelsay, JL, and Mertz, W. Number of days of food intake records required to estimate individual and group nutrient intakes with defined confidence. J Nutr 117: 1638-1641, 1987

4. Bathalon, G, Tucker, K, Hays, N, Vinken, A, Greenberg, A, McCrory, M, and Roberts, S. Psychological measures of eating behavior and the accuracy of 3 common dietary assessment methods in healthy postmenopausal women. Am J Clin Nutr 71: 739-745, 2000.

5. Becker, W, Foley, S, Shelley, E, and Gibney, M. Energy under-reporting in Swedish and Irish dietary surveys: implications for food-based dietary guidelines. Br J Nutr 81: S127-S131, 1999.

6. Bingham, SA. The dietary assessment of individuals; methods, accuracy, new techniques and recommendations. Nutr Abst and Rev 57: 705-742, 1987.

7. Bingham, SA. Dietary assessments in the European prospective study of diet and cancer (EPIC). Eur J Cancer Prev 6: 118-124, 1997.

8. Black, AE, Prentice, AM, Goldberg, GR, Jebb, SA, Bingham, SA, Livingstone, MB, and Coward, WA. Measurements of total energy expenditure provide insights into the validity of dietary measurements of energy intake. J Am Diet Assoc 93: 572-579, 1993.

9. Bouten. C, Verboeket-van de Venne, W, Westerterp, K, Verduin, M, and Janssen, J. Daily physical activity assessment: comparison between movement registration and doubly labeled water. J Appl Physiol 81: 1019-1026, 1996.

10. Braam, LAJLM, Ocke, MC, Bueno-de-Mesquita, B, and Seidell, JC. Determinants of obesityrelated underreporting of energy intake. Am J Epid 147: 1081-1086, 1998.

11. Breedveld, BC, and Hulshof, KFAM. Hoe goed voedt de gemiddelde Nederlander zich? Voeding 1: $11-15,1998$.

12. Drewnowski, A, and Hann, C. Food preferences and reported frequencies of food consumption as predictors of current diet in young women. Am J Clin Nutr 70: 28-36, 1999.

13. Edholm, OG, Fletcher, JG, Widdowson, EM, and McCance, RA. The energy expenditure and food intake of individual men. $B_{r} J$ Nutr 9: 286-300, 1955.

14. Etten, LMLA, Westerterp, KR, Verstappen, FTJ, Boon, BJB, and Saris, WHM Effect of an 18wk weight-training program on energy expenditure and physical activity. J Appl Physiol 82: 298304, 1997.

15. Fricker, J, Baelde, D, Igoin-Apfelbaum, L, Huet, JM, and Apfelbaum, M. Underreporting of food intake in obese "small eaters". Appetite 19: 273-283, 1992

16. Geiselman, PJ, Anderson, AM, Dowdy, ML, West, DB, Redmann, SM, and Smith, SR. Reliability and validity of a macronutrient self-selection paradigm and a food frequency questionnaire. Psych \& Beh 63: 919-928, 1998.

17. Greeawald, P, Sherwood, K, and Mcdonald, SS. Fat, caloric intake, and obesity: lifestyle risk factors for breast cancer. J Am Diet Assoc 97: S24-S30, 1997.

18. Hamack, LJ, Jeffery, RW, and Boutelle, KN. Temporal trends in energy intake in the United States: an ecologic perspective. Am J Clin Nutr 71: 1478-1484, 2000.

19. Hebert, JR, Clemow, L, Pbert, L, Ockene, IS, and Ockene, JK. Social desirability bias in dittary self-report may compromise the validity of dietary intake measures. Int J Epidem 24: 389-398, 1995.

20. Hebert, JR, Ma, Y, Clemow, L, Ockene, IS, Saperia, G, Stanek, EJ. Merriam, PA, and Ockcne, JK. Gender differences in social desirability and social approval bias in dietary sclf-report. Am J Epidem 146: 1046-1055, 1997.

21. Heini, AF, and Weinsier, RL. Divergent trends in obesity and fat intake patterns: the Anucrican paradox. Am J Med 102: 259-264, 1997.

22. Heitmann, B, Lissner, L, and Osler, M. Do we eat less fat, or just report so? Int J Obes 24: 435442,2000 .

23. Heitmann, BL. The influence of fatness, weight change, slimming history and other lifestyle variables on diet reporting in Danish men and women aged 35-65 years. Int J Obes 17: 329-336, 1993

24. Heymsfield. SB, Darby, PC, Muhlheim, LS, Gallagher, D, and Wolper, C. The calorie: myth, measurement, and reality. Am J Clin Nutr 62: 1034S-104 IS, 1995

25. Hill, JO, and Peters, JC. Evironmental contributions to the obesity epidemic. Science 280: 1371$1373,1998$. 
26. Howat, PM, Mohan, R, Champagne, C, Monlezun, C, Wozniak, P, and Bray, GA. Validity and reliability of reported dietary intake data. J Am Diet Assoc 94: 169-173, 1994.

27. Johnson, RK, Soultanakis, RP, and Matthews, DE. Literacy and body fatness are associated with underreporting of energy intake in US low-income women using the multiple-pass 24 -hour recall: a doubly labeled water study. J Am Diet Assoc 98: 1136-1140, 1998.

28. Kaczkoweki, CH, Jones, PJH, Feng, J, and Bayley, HS. Four-day multimedia diet records underestimate energy needs in middle-aged and elderly women as determined by doubly-labeled water. J Nutr 10: 802-805, 2000.

29. Kennedy, ET, Bowman, SA, and Powell, R. Dietary-fat intake in the US population. J Am Coll Nutr 18: 207-212, 1999.

30. Lafay, L, Basdevant, A, Charles, MA, Vray, M, Balkau, B, Borys, JM, Eschwege, E, and Romon, $M$. Determinants and nature of dietary underreporting in a free-living population: the Fleurbaix Laventie Vill Sante (FLVS) study. Int J Obes 21: 567-573, 1997

31. Lissner, L, Heitmann, BL, and Lindroos, AK. Measuring intake in free-living human subjects: a question of bias. Proc Nutr Soc 57: 333-339, 1998.

32. Livingstone, MBE. Assessment of food intakes: are we measuring what people eat? $\mathrm{Br} \mathrm{J}$ Biomed Sci 52: 58-67, 1995.

33. Macdiarmid, JI, and Blundell, JE. Dietary under-reporting: what people say about recording their food intake. Eur J Clin Nutr 51: 199-200, 1997.

34. Mela, DJ, and Aaron, JI. Honest but invalid: What subjects say about recording their food intake. J Am Diet Assoc 97: 791-793, 1997.

35. Muhlheim, LS, Allison, DB, Heshka, S, and Heymsfield, SB. Do unsuccessful dieters intentionally underreport food intake? Int J Eat Disord 24: 259-266, 1998.

36. Murgatroyd, $\mathrm{P}$, and Coward, $\mathrm{W}$. An improved method for estimating changes in whole-body fat and protein mass in man. Br J Nutr 62: $311-314,1989$.

37. Rothenberg, E, Bosaeus, I, Lernfelt, B, Landahl, S, and Steen, B. Energy intake and expenditure. validation of a diet history by heart rate monitoring, activity diary and doubly labeled water. Eur $\mathrm{J}$ Clin Nutr 52: 832-838, 1998.

38. Schoeller, DA. How accurate is self-reported dietary energy intake? Nutr Rev 48: 373-379, 1990 .

39. Schoeller, DA, and Santen, Ev. Measurement of energy expenditure in humans by doubly labeled water method. J. Appl. Physiol. 53: 955-959, 1982.

40. Seidell, JC. Dietary fat and obesity: an epidemiologic perspective. Am J Clin Nutr 67: 546S-550S, 1998.

41. Simmons, SF, and Reuben, D. Nutritional intake monitoring for nursing home residents: a comparison of staff documentation, direct observation, and photography models. J Am Geriatr Soc 48: 209-213, 2000.

42. Stallings, V, Zemel, B, Davies, J, Cronk, C, and Chamey, E. Energy expenditure of children and adolescents with severe disabilities: a cerebral palsy model. Am J Clin Nutr 64: 627-634, 1996.

43. Taren, D, Tobar, M, Hill, A, Howell, W, Shisslak, C, Bell, I, and Ritenbaugh, C. The association of energy intake bias with psychological scores of women. Eur J Clin Nutr 53: 570-578, 1999.

44. Tomoyasu, N, Toth, M, and Poehlman, E. Misreporting of total energy intake in older African Americans. Int J Obes 24: 20-26, 2000.

45. Visser, M, Groot, Ld, Deurenberg, P, and van Staveren, W. Validation of dietary history method in a group of elderly women using measurements of total energy expenditure. Br J Nutr 74: 775-785, 1995.

46. Westerterp, KR, Donkers, JH, Fredrix, EW, and Boekhoudt, P. Energy intake, physical activity and body weight: a simulation model. $\mathrm{Br} J$ Nutr 73: 337-347, 1995.

47. Westerterp-Plantenga, MS, Pasman, WJ, Yedema, MJW, and Wijckmans-Duijsens, NEG. Energy intake adaptation of food intake to extreme energy densities of food by obese and non-obese women. Eur J Clin Nutr 50: 401-407, 1996. 


\section{Summary}

Errors in the assessment of food intake might disturb the outcome of nutrition intervention studies, or inhibit to reveal relations between nutrition and parameters of health or disease. Thus, the assessment of habitual food intake of free living humans cannot be executed without valid biomarkers. The validation methods described in this thesis either served as an indicator for misreporting individuals or were used as feedback for subjects, which improved their reporting accuracy.

The main issue of the thesis was to find methods for the validation of the assessment of habitual daily food intake in humans. The seven-day food record was used as dietary assessment method, as it measures recent habitual food intake, and the outcome of the record was compared with several biomarkers.

Misreporting of habitual food intake can be divided into misrecording, the failure to record accurately everything consumed, and a change in diet while food recording. Distinguishing misrecording from a change in diet provides insight in the reporting behaviour of subjects and this was also used as a tool to give feedback to the subjects.

Next to misreporting of energy intake, subjects might also selectively misreport their macronutrient intake.

Finally, problems associated with repeated measurements of food intake reporting were studied in different circumstances.

Misrecording was identified using the water balance method. A reported water intake below measured water loss indicates an underrecording of water intake, and vice versa. The recording of water intake was assumed to be representative for total food intake recording. A change in diet was identified by comparing body mass changes over the recording period with body mass changes over a non-recording period. The distinction of misreporting into misrecording and a change in diet was first studied in a group of dieticians, as they are professionally familiar with food reporting.

Misreporting was also determined using the comparison with energy expenditure as measured with the doubly labelled water method, and with energy expenditure as calculated from basal metabolic rate and physical activity. The combination of basal metabolic rate, measured or estimated, and physical activity assessed with a tri-axial accelerometer, as a measure for total reported energy intake was validated in a group of elderly men and women, against the doubly labelled water method.

Furthermore, the magnitude of misreporting, as determined by the doubly labelled water method, was related to the reported macronutrient intake, in order to identify possible selective misreporting in obese men.

To determine an indication for macronutrient intake, postabsorptive oxidation of carbohydrate and fat (RQ, respiratory quotient) was measured in lean and obese men and women.

Finally, problems associated with repeated measurements of food intake were studied in elderly men and women, in dieticians who got feedback on the accuracy of their first time of food intake reporting and in a group of depleted outpatients with chronic obstructive pulmonary disease (COPD). This group of depleted patients were ad random assigned to an intervention group who received extra energy supplements, or to a control group who received no supplements. 
The results of the study with the distinction of misrecording from a change in diet, showed an undereating of $16 \%$ and no misrecording in the dieticians. After confrontation with these results, the dieticians were able to report their food correctly; no change in the diet occurred anymore and their recording accuracy was even higher. From the study on the combination of basal metabolic rate, measured or estimated, and physical activity as assessed with a tri-axial accelerometer, it was proven that this was valid against doubly labelled water. This appeared to be an easy marker for the reported energy intake.

Assessment of selectivity in underreporting showed that obese men underreported their food intake with 37 percent of energy, which could be divided into $26 \%$ undereating and $12 \%$ underrecording. They selectively underreported their fat intake; subjects with a high amount of underreporting reported a lower fat intake than subjects with a lower amount of underreporting.

The results of the study with lean and obese men and women on postabsorptive RQ measurements showed that this was not a reliable indicator for habitual FQ, even when corrected for energy balance and body composition.

Finally, repeated measurement of food intake appeared to induce an increase in underreporting of food intake from $21 \%$ (first period) to $27 \%$ (second period) and a selective underreporting of fat intake and overreporting of protein intake.

The depleted outpatients with COPD reported their food intake accurately and the preliminary results showed a positive energy balance for the patients of the intervention group. The positive energy balance was mainly achieved from the energy intake in the afternoon and evening.

The amount of misreporting ranged from 0 to -37 percent of energy in the described studies and the use of the biomarkers studied made it possible to distinguish a change in the diet from misrecording. Next to quantitative misreporting, also qualitative misreporting was observed. Qualitative misreporting implies that possible correction factors based upon energy intake estimation for misreporting are useless because then the macronutrient intake would still be under or overestimated. No valid biomarker for the macronutrient reporting is available yet.

The studies executed on validation of food intake reporting showed qualitative and quantitative incorrect food intake recording, as well as a change in behaviour while recording food intake, leading to a change in the diet, resulting in a change from the habitual diet. The solutions for quantitatively incorrect reporting that these studies provide are: 1) giving feedback on the reporting behaviour; this has been shown to lead to correct food intake reporting in highly, i.e. professionally, motivated individuals; 2) the possibility to select correctly reporting individuals in a relatively easy way, i.e. determining their total energy intake from their total energy expenditure using basal metabolic rate and a measurement for energy spent on physical activity, i.e. with a tri-axial accelerometer.

For qualitatively incorrect reporting the studies unfortunately did not find any indication for a solution. 


\section{Samenvatting}

Fouten in meting van de voedselinname kunnen de uitkomsten van voedingsinterventie onderzoek verstoren, of kunnen mogelijke relaties tussen voeding en parameters van gezondheid en ziekte verhullen. Het is duidelijk dat de meting van de dagelijkse voedselinname van mensen niet zonder valide biologische merkers kan worden uitgevoerd. Het doel van dit proefschrift was om verschillende validatie methoden te vinden voor de meting van de dagelijkse voedselinname van mensen. Als meetmethode voor de voedselinname is een zevendaags voedingsdagboek gebruikt, omdat het de dagelijkse voedselinname meet op basis van de recente consumptie. De uitkomst hiervan werd vergeleken met verschillende biologische merkers.

De beschreven validatie methoden in dit proefschrift werden gebruikt voor identificatie van individuen die hun voeding niet goed rapporteerden of werden gebruikt als feedback voor proefpersonen, zodat de rapportage nauwkeurigheid kon worden verbeterd.

Onjuiste rapportage van de voedselinname kan het gevolg zijn van het onjuist opschrijven van de voeding en van een verandering van de voedselinname tijdens de voedselrapportage. Het onderscheid tussen het onjuist opschrijven en een verandering in de voedselinname geeft inzicht in het rapportage-gedrag van proefpersonen. Dit inzicht werd ook gebruikt om feedback aan de proefpersonen te geven.

Naast onjuiste rapportage van de energie-inname kunnen proefpersonen selectief de macronutrienten-inname onjuist rapporteren.

Tenslotte werden eventuele problemen, geassocieerd met herhaald opschrijven van de voeding, bestudeerd in verschillende omstandigheden.

Fouten in het opschrijven van de voeding werden geïdentificeerd met behulp van de water balans methode. Een gerapporteerde water inname lager dan gemeten water verlies betekent een onder rapportage van de water inname en vice versa. Het opschrijven van de water inname werd representatief geacht voor het opschrijven van de totale voedsel inname. Een veranderd eetpatroon werd geïdentificeerd door het vergelijken van de verandering van het lichaamsgewicht over de opschrijfperiode met de gewichtsverandering over een niet-opschrijfperiode. Het onderscheid binnen het onjuist opschrijven en een veranderde voedselinname werd eerst onderzocht in ecn groep diëtisten, omdat zij professioneel bekend zijn met het rapporteren van de voedselinname.

Onjuiste rapportage werd ook gekwantificeerd door de energie inname te vergelijken met het energie gebruik zoals gemeten is met tweevoudig gemerkt water en met het energie gebruik berekend op basis van het rustmetabolisme en het energiegebruik voor lichamelijke activiteit. De combinatie van rustmetabolisme, gemeten of geschat, en lichamelijk activiteit gemeten met een drie-dimensionale versnellingsopnemer, als referentie voor de totaal gerapporteerde energie inname werd gevalideerd in een groep oudere mannen en vrouwen met behulp van tweevoudig gemerkt water.

Daarnaast werd onjuiste rapportage, zoals vastgesteld met de tweevoudig gemerkt water methode, gerelateerd aan de gerapporteerde macronutrienten inname, om mogelijke selectieve onjuiste rapportage te herkennen. Dit laatste onderzoek werd gedaan bij obese mannen. 
Voor de bepaling van een indicator voor de macronutrient inname, werd de postabsorptieve oxidatie van koolhydraat en vet gemeten bij mannen en vrouwen met en zonder overgewicht.

Tenslotte werden problemen die samenhangen met herhaalde metingen van de voedselinname bestudeerd bij oudere mannen en vrouwen, bij diëtisten die feedback hadden gekregen over de nauwkeurigheid van een eerste keer voedsel rapporteren en bij ondervoede patiënten met chronisch obstructief longlijden in de thuissituatie. De groep ondervoede patiënten werd at random onderverdeeld in een interventie groep die extra energie supplementen kreeg en in een controle groep die geen supplementen kreeg.

De resultaten van het onderzoek naar het onderscheid tussen fouten in het opschrijven en een verandering in de voedselinname, lieten in de groep diëtisten een gemiddelde verlaging van $16 \%$ van de voedselinname zien tijdens de opschrijfperiode, maar wat er was gegeten was juist genoteerd. Na confrontatie met deze resultaten rapporteerden de diëtisten de voedselinname correct; er was geen veranderde voedselinname meer tijdens de opschrijfperiode en de voedselinname werd nog nauwkeuriger opgeschreven.

De studie naar berekening van het energiegebruik op basis van een combinatie van rustmetabolisme, gemeten of geschat, en lichamelijke activiteit zoals gemeten met een drie-dimensionale versnellingsopnemer, liet zien dat dit een valide methode was in vergelijking met tweevoudig gemerkt water. Het bleek een goed alternatief voor de validatie van de gerapporteerde energie inname te zijn.

De meting van selectieve onderrapportage liet zien dat obese mannen hun voedselinname onderrapporteerden met $37 \%$ wat kon worden onderverdeeld in $26 \%$ minder eten tijdens het noteren van de voeding en $12 \%$ minder opschrijven. Deze mannen onderrapporteerden selectief hun vet-inname; degenen met een sterke onderrapportage rapporteerden een lagere vet-inname, uitgedrukt als percentage van de energieinname, dan degene die de voedselinname beter rapporteerden.

Uit de resultaten van de studie met mannen en vrouwen met en zonder overgewicht en de metingen van de postabsorptieve oxidatie van koolhydraat en vet bleek dat dit geen betrouwbare indicator is voor de samenstelling van de gebruikelijke voeding, zelfs niet wanneer werd gecorrigeerd voor de energiebalans en de lichaamssamenstelling.

Tenslotte bleek dat bij herhaalde metingen van de voedselinname, de totale onderrapportage toenam van $21 \%$ (eerste periode) tot $27 \%$ (tweede periode) en dat herhaalde meting een selectieve onderrapportage van de vet-inname en overrapportage van de eiwit-inname induceerde.

De ondervoede patiënten met chronisch obstructief longlijden rapporteerden hun voedselinname nauwkeurig en de eerste resultaten lieten een positieve energie balans zien voor de patiënten van de interventie groep. De positieve energie balans kwam voomamelijk door de energie inname in de middag en avond.

De mate van onjuiste rapportage varieerde van 0 tot $37 \%$ van het energie gebruik in de beschreven onderzoeken. Het gebruik van de gevalideerde biologische merkers maakte het mogelijk een veranderde voedselinname tijdens de voedselrapportage te onderscheiden van fouten in het opschrijven van de voedselinname. Naast een kwantitatief onjuiste rapportage werd ook een kwalitatief onjuiste rapportage gemeten. Een kwalitatief onjuiste rapportage betekent dat mogelijke correctie factoren 
gebaseerd op de energie-inname schatting voor onjuiste rapportages geen zin hebben, omdat de macronutrienten-inname dan nog steeds onder- of overschat wordt. Er is nog geen valide biologische merker voor de gehele macronutrient inname rapportage gevonden.

De uitgevoerde studies met betrekking tot de validatie van de voedselinname rapportage lieten een kwalitatief en een kwantitatief onjuiste rapportage zien, evenals een gedragsverandering tijdens de voedselinname rapportage die leidde tot een veranderde voedselinname. De oplossingen voor kwantitatief onjuiste rapportage zoals beschreven in deze studies zijn: 1) feedback geven over het rapportage gedrag; dit leidde tot een nauwkeurige voedselinname rapportage bij professioneel gemotiveerde personen; 2) de mogelijkheid tot - op een relatief makkelijke manier - selecteren van individuen die nauwkeurig rapporteren. Het laatste is mogelijk door vergelijking van de voedselinname met het energie gebruik, berekend op basis van het rustmetabolisme en het gemeten energiegebruik voor lichamelijke activiteit, met een drie-dimensionale versnellingsopnemer.

Voor kwalitatief onjuiste rapportage is helaas geen oplossing gevonden in deze studies. 



\section{Dankwoord}

Vier jaar van onderzoek heeft geresulteerd in dit proefschrift. Een proefschrift waar ik niet alleen aan heb gewerkt en daarom wil ik hier een aantal mensen bedanken.

Als eerste wil ik Klaas Westerterp bedanken voor het initiëren van dit onderzoeksproject, het begeleiden van de onderzoeken en voor het kritisch lezen van alle manuscripten. Ik heb de afgelopen jaren veel geleerd over het energiemetabolisme van de mens en het uitvoeren van onderzoeken; veel dank hiervoor.

Soms was het handig als een derde persoon (Margriet Westerterp) de geschreven manuscripten ook nog eens doomam. Margriet, bedankt voor al het leeswerk, je opmerkingen bij de geschreven stukken en de discussies over de voedselinname van mensen.

Een goede medewerking van proefpersonen is bij het uitvoeren van onderzoeken erg belangrijk. Daarom, diëtisten uit de regio zuid-Limburg, collega's, studenten, de proefpersonen met overgewicht of ondergewicht en de groep 55-plussers hartelijk dank voor jullie deelname aan de onderzoeken.

De collega's van het 'leptine project', Margriet Westerterp, Chris Hukshorn en Tanja Hermans, wil ik bedanken voor de mogelijkheid en de medewerking die zij mij gaven, om in hun studie de voedselinname van mannen met overgewicht te kunnen valideren met tweevoudig gemerkt water.

De afdeling diëtetiek van Groene Kruis Heuvelland wil ik bedanken voor de prettige samenwerking tijdens de studie naar het meten van de voedselinname en substraatoxidatie.

Erwin Meijer, vier jaar lang was je mijn collega en kamergenoot; bedankt voor de goede samenwerking tijdens de vele practica die we hebben gegeven en de samen uitgevoerde 55+ studie. Ook bedankt voor de goede sfeer op kamer 3.242 en dat je mijn paranimf wilt zijn.

Het onderzoek naar de energiebalans bij ondervoede COPD patiënten in de thuissituatie was niet mogelijk geweest zonder de medewerking van Annemie Schols, Marja Vermeeren en Clarie Weling. Het onderzoek is nog niet helemaal afgerond, maar ik wil jullie hierbij alvast bedanken voor de samenwerking.

Loek Wouters en Paul Schoffelen wil ik bedanken voor de technische ondersteuning bij de calonimetrie metingen, voor de Macintosh ondersteuning en voor de vele deuteriumbepalingen (Loek).

De collega's van de capaciteitsgroep Humane Biologie wil ik bedanken voor de goede werksfeer waarin ik vier jaar lang heb mogen werken.

Mijn dank gaat ook uit naar de leden van de beoordelingscommissie: Prof. dr. ir. P. van den Brandt, Prof. dr. A. Astrup, Prof. dr. ir. W. Saris, Prof. dr. ir. J. Seidell, Prof. dr. E. Wouters.

Drie jaar lang ben ik elke dag op en neer met de trein van Eindhoven naar Maastricht gegaan. De aanwezigheid van treincollega's (o.a. Susan Vermunt) maakte de reis 
aangenamer, zeker als de trein weer eens vertragingen had. Toch ben ik blij dat de dagelijkse treinreizen erop zitten; ik ga weer op de fiets naar mijn werk!

Familie en vrienden wil ik bedanken, omdat ze er zijn en mijn thuisfront vormen. Pita, bedankt voor de tekeningen op de omslag van dit boekje. Margriet bedankt dat je mijn paranimf wilt zijn.

Ronald, bedankt voor je rol als kritisch publiek bij mijn 'oefen-presentaties', je rol als proefpersoon, maar vooral bedankt dat je er voor mij was en zal zijn. 


\section{Curriculum vitae}

Annelies Goris werd geboren op 25 januari 1972 te Brummen (Gelderland). In 1990 haalde zij haar VWO diploma aan het Baudartius College in Zutphen. Dat zelfde jaar begon ze aan de studie Voeding \& Diëtetiek aan de Hogeschool Nijmegen. Van januari tm juli 1994 verbleef zij in Zimbabwe waar ze een afstudeeronderzoek verrichte naar voedselpatronen van zelfvoorzienende plattelandshuishoudens in verschillende landbouwregio's. In 1994 studeerde ze af en begon ze aan de studie Biologische gezondheidskunde aan de faculteit Gezondheidswetenschappen van de Universiteit Maastricht. Ze haalde haar doctoraal in maart 1997 na een afstudeerstage aan de vakgroep pulmonologie (faculteit Geneeskunde, Universiteit Maastricht) onder leiding van Dr. A. Schols. In diezelfde maand starte ze als assistent in opleiding bij de capaciteitsgroep Humane Biologie aan de Universiteit van Maastricht onder leiding van Dr. K. Westerterp. Tijdens de promotieperiode ontving ze de 'Foppe ten Hoor prijs 1999' voor haar presentatie bij de najaarsretraite van de werkgemeenschap van N.W.O.-voeding. Vanaf november 2000 is ze werkzaam bij Philips Research, Personal Care Institute, te Eindhoven. 



\section{Publications}

\section{Full papers}

Goris, AHC, Westerterp, KR. Underreporting of habitual food intake is explained by undereating in highly motivated lean women. (1999) J Nutr 129:878-882.

Mil, EGAH van, Goris, AHC. Westerterp, KR. Debate Physical activity and the prevention of childhood obesity - Europe versus the United States. (1999) Int J Obes 23:Supplement 3:S41-S44.

Goris, AHC, Westerterp-Plantenga, MS, Westerterp, KR. Undereating and underrecording of habitual food intake in obese men: selective underreporting of fat intake. (2000) Am J Clin Nutr. 71:130-134.

Goris, AHC, Westerterp, KR. Underreporting of habitual food intake can it be improved? (2000) Br J Nutr. 83:363-369.

Goris, AHC, Westerterp, KR. Postabsorptive respiratory quotient and food quotient an analysis in lean and obese men and women. (2000) Eur J Clin Nutr. 54:546-550.

Mostert, R, Goris, AHC, Weling-Scheepers, CAPM, Wouters, EFM, Schols, AMWJ. Tissue depletion and health related quality of life in patients with chronic obstructive pulmonary disease. (2000) Respir. Med. 9:859-867

Goris, AHC, Westerterp, KR. The assessment of food intake in humans. Review. (2000) Recent Res Devel Nutrition 3:27-41.

Goris, AHC, Meijer, EP, Kester, A., Westerterp, KR. Use of a triaxial accelerometer to validate reported food intakes. (2001) Am. J Clin Nutr. In Press.

Goris, AHC, Meijer, EP, Westerterp, KR. Repeated measurement of habitual food intake increases underreporting and induces selective underreporting. (200I) $\mathrm{Br} \mathrm{J}$ Nutr. ln Press.

\section{Abstracts}

Goris, AHC, Schols, AMWJ, Weling-Scheepers, CAPM, Wouters, EFM. Tissue depletion in relation to physical function and quality of life in patients with severe chronic obstructive pulmonary disease. (1997) Clin Nutr 16:S39.

Goris, AHC, Westerterp, KR. Underreporting of habitual food intake, underrecording or undereating? (1998) Eur J Clin Nutr. 52:S18.

Goris, AHC, Westerterp, KR. Underreporting of habitual food intake can it be improved? (1998) Int J Obes. 22:Supplement 3:S42.

Goris, AHC, Westerterp, KR. Physical activity as a measure to identify underreporters of food intake. (1999) Int J Obes 23:Supplement 3:S82.

Goris, AHC, Westerterp-Plantenga, MS, Westerterp, KR. Underreporting of food intake in obese men is explained by undereating and underrecording, and characterized by a selective underreporting of fat intake. (1999) Int J Obes 23:Supplement 5:S90 
Goris, AHC, Wouters, L, Westerterp, KR. The water-balance technique as a measure for compliance with food recording. (2000) Int J Obes. 24:Supplement 1:S182.

Goris, AHC, Meijer, EP, Kester, A, Westerterp, KR. The use of a triaxial accelerometer for the individual validity of reported food intake. (2000) Int J Obes. 24:Supplement 1:S65.

Meijer, EP, Goris, AHC, Wouters, L, Westerterp, KR. Mean physical activity level in the elderly is inversely related to time spent on low activity intensity. (2000) Int J Obes. 24:Supplement 1:S181. 


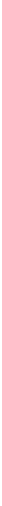